\title{
World Meteorological Organization
}

7 bis avenue de la Paix

Case postale 2300

$\mathrm{CH}-1211$ Geneva 2

Switzerland

\section{United Nations Environment Programme \\ Ozone Secretariat}

P.O. Box 30552

Nairobi, 00100

Kenya

\section{US Department of Commerce}

National Oceanic and Atmospheric Administration

$14^{\text {th }}$ Street and Constitution Avenue NW

Herbert C. Hoover Building, Room 5128

Washington, D. C. 20230

\section{National Aeronautics and Space Administration \\ Earth Science Division}

NASA Headquarters

300 E. Street SW

Washington, D.C. 20546-0001

\section{European Commission}

Directorate-General for Research

B-1049 Bruxelles

Belgium

Published online January 2019

ISBN: 978-1-7329317-1-8

This report is available on the internet at the following locations:

http://ozone.unep.org/science/assessment/sap

https://www.esrl.noaa.gov/csd/assessments/ozone/2018/

This document should be cited as:

WMO (World Meteorological Organization), Scientific Assessment of Ozone Depletion: 2018, Global Ozone Research and Monitoring Project-Report No. 58, 588 pp., Geneva, Switzerland, 2018.

Example Chapter Citation:

Engel, A. and M. Rigby (Lead Authors), J.B. Burkholder, R.P. Fernandez,

L. Froidevaux, B.D. Hall, R. Hossaini, T. Saito, M.K. Vollmer, and B. Yao,

Update on Ozone-Depleting Substances (ODSs) and Other Gases of

Interest to the Montreal Protocol, Chapter 1 in Scientific Assessment of

Ozone Depletion: 2018, Global Ozone Research and Monitoring

Project-Report No. 58, World Meteorological Organization, Geneva, Switzerland, 2018. 
World Meteorological Organization

Global Ozone Research and Monitoring Project-Report No. 58

\section{SCIENTIFIC AsSessment OF Ozone Depletion: 2018}

World Meteorological Organization

United Nations Environment Programme National Oceanic and Atmospheric Administration National Aeronautics and Space Administration European Commission 


\title{
Scientific Assessment of Ozone Depletion: 2018
}

\author{
Assessment Co-chairs \\ David W. Fahey \\ Paul A. Newman \\ John A. Pyle \\ Bonfils Safari \\ Scientific Steering Committee \\ David W. Fahey \\ Paul A. Newman \\ John A. Pyle \\ Bonfils Safari \\ Martyn P. Chipperfield \\ David J. Karoly \\ Doug Kinnison \\ Malcolm K. Ko \\ Michelle Santee \\ Assessment Coordinator \\ Sarah J. Doherty \\ Chapter Lead Authors \\ Chapter 1: Update on Ozone-Depleting Substances (ODSs) and \\ Other Gases of Interest to the Montreal Protocol \\ Andreas Engel and Matthew Rigby \\ Chapter 2: Hydrofluorocarbons (HFCs) \\ Stephen A. Montzka and Guus J.M. Velders \\ Chapter 3: Update on Global Ozone: Past, Present, and Future \\ Peter Braesicke and Jessica Neu \\ Chapter 4: Polar Stratospheric Ozone: Past, Present, and Future \\ Ulrike Langematz and Matthew B. Tully \\ Chapter 5: Stratospheric Ozone Changes and Climate \\ Alexey Yu. Karpechko and Amanda C. Maycock \\ Chapter 6: Scenarios and Information for Policymakers \\ Lucy J. Carpenter and John S. Daniel \\ Twenty Questions and Answers About the Ozone Layer: 2018 Update \\ Ross J. Salawitch \\ Appendix A: Summary of Abundances, Lifetimes, ODPs, REs, GWPs, and GTPs \\ James B. Burkholder

\section{Report Design and Production} \\ Debra A. Dailey-Fisher and Ann M. Reiser




\section{Scientific Assessment of Ozone Depletion: 2018}

\section{CONTENTS}

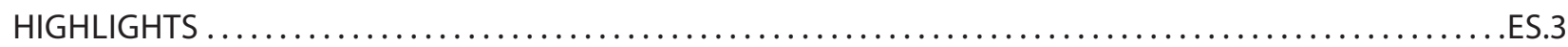

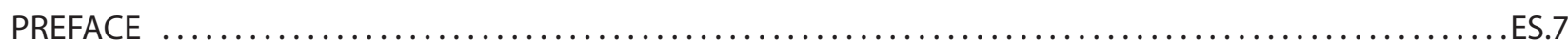

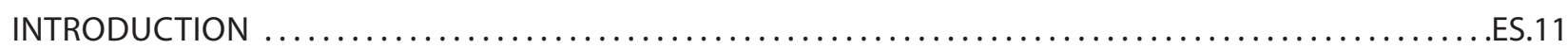

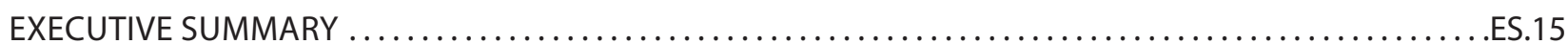

Chapter 1: UPDATE ON OZONE-DEPLETING SUBSTANCES (ODSs) AND

OTHER GASES OF INTEREST TO THE MONTREAL PROTOCOL Lead Authors: Andreas Engel and Matthew Rigby

Scientific Summary.

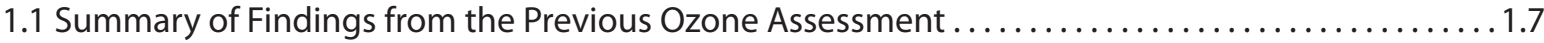

1.2 Updated Abundances, Trends, Lifetimes, and Emissions of

Longer-lived Halogenated Source Gases . . . . . . . . . . . . . . . . . . . . . . . . . . . . . . 1.7

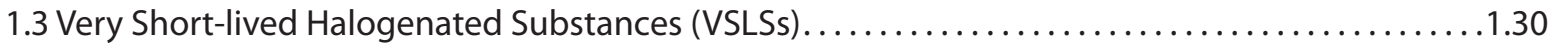

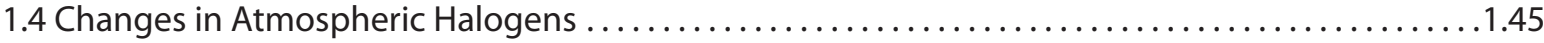

1.5 Changes in Other Trace Gases that Influence Ozone and Climate ........................61

References ................................................................66

Chapter 2: HYDROFLUOROCARBONS (HFCs)

Lead Authors: Stephen A. Montzka and Guus J.M. Velders

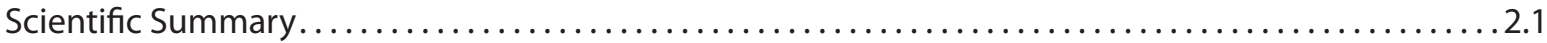

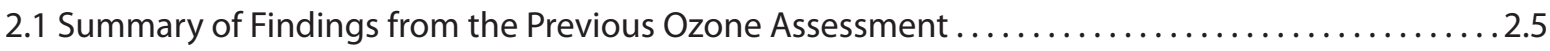

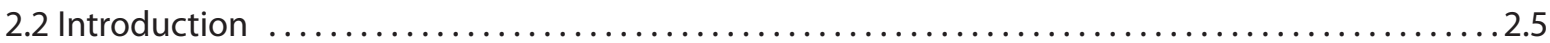

2.3 Atmospheric Observations and Derived Emission Estimates ........................ 2.7

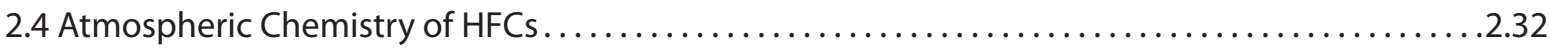

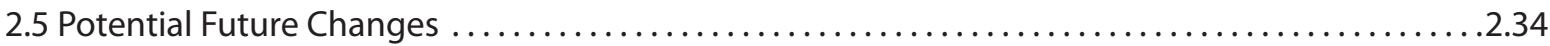

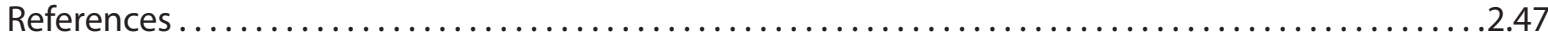

Chapter 3: UPDATE ON GLOBAL OZONE: PAST, PRESENT, AND FUTURE Lead Authors: Peter Braesicke and Jessica Neu

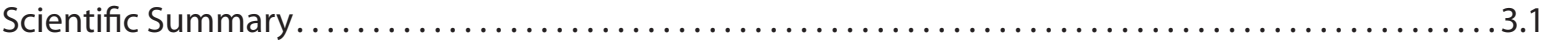

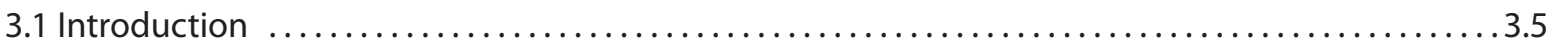

3.2 Natural Ozone Variations and Trend Detection ................................... 3

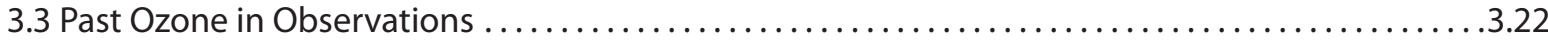

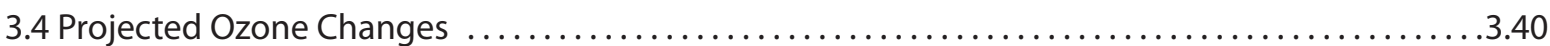

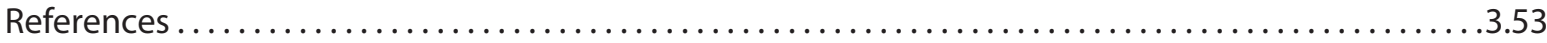

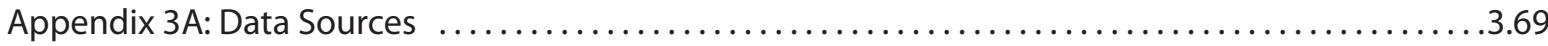

Chapter 4: POLAR STRATOSPHERIC OZONE: PAST, PRESENT, AND FUTURE Lead Authors: Ulrike Langematz and Matthew B. Tully

Scientific Summary....................................................... 4

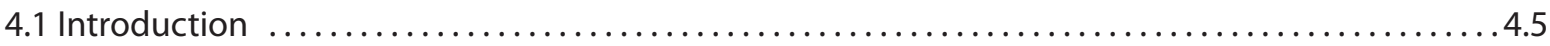

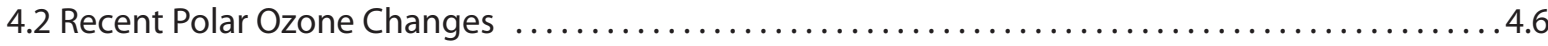


4.3 Understanding of Polar Ozone Processes ..................................... 45

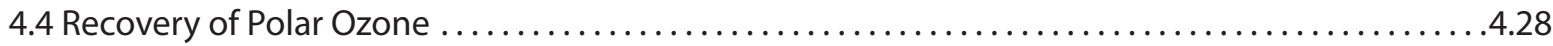

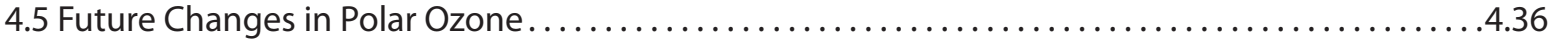

References .................................................................. 49

Chapter 5: STRATOSPHERIC OZONE CHANGES AND CLIMATE

Lead Authors: Alexey Yu. Karpechko and Amanda C. Maycock

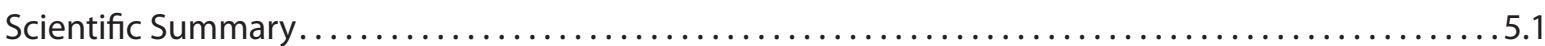

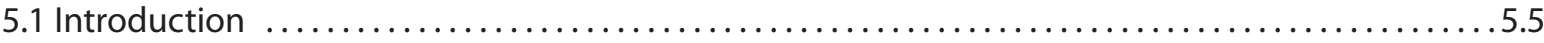

5.2 Observed Changes in Atmospheric Constituents and External Forcings that Relate to Climate ...5.6

5.3 Observed and Simulated Changes in Stratospheric Climate . . . . . . . . . . . . . . . . . . . . . 5.12

5.4 Effects of Changes in Stratospheric Ozone on the Troposphere and Surface................5.29

5.5 Climate Impacts of the Montreal Protocol. ...................................... 5.48

References ................................................................. 5.50

Chapter 6: SCENARIOS AND INFORMATION FOR POLICYMAKERS

Lead Authors: Lucy J. Carpenter and John S. Daniel

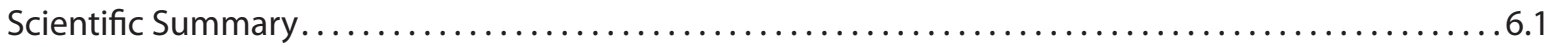

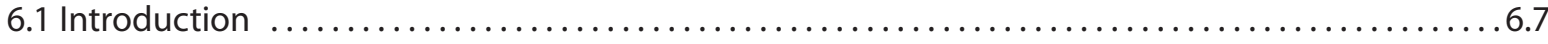

6.2 Issues of Potential Importance to Stratospheric Ozone and Climate. .................... 6.9

6.3 Metrics for Changes in Ozone and Climate..................................... 6.21

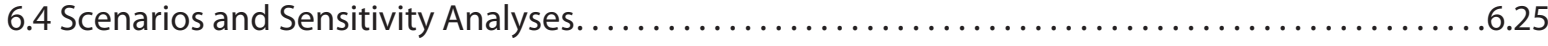

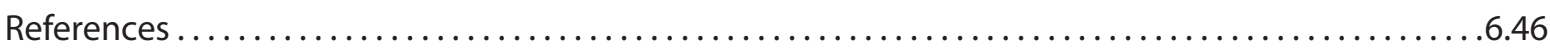

Appendix 6A: Current State of Knowledge on Stratospheric Sulfate Geoengineering. ............6.57

Appendix 6B: Comparison of Past and Future Ozone Projections of the

GSFC 2-D Model with GEOSCCM 3-D Simulations...................................6.61

Appendix 6C: Evaluation of Alternative Scenarios Using New EESC Formalism . . . . . . . . . . . 6.69

Appendix A: SUMMARY OF ABUNDANCES, LIFETIMES, ODPs, REs, GWPs, GTPs $\ldots \ldots \ldots \ldots \ldots \ldots \ldots \ldots . \ldots .1$

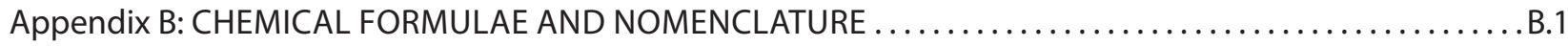

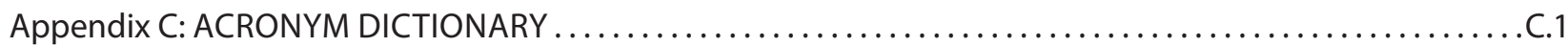

Appendix D: LIST OF AUTHORS, CONTRIBUTORS, AND REVIEWERS $\ldots \ldots \ldots \ldots \ldots \ldots \ldots \ldots \ldots \ldots \ldots \ldots \ldots .1$ 
Cover photo: Plenary discussion during the 28th Meeting of the Parties to the Montreal Protocol in Kigali, Rwanda. The historic Kigali Amendment was adopted on 15 October 2016 limiting future production and consumption of hydrofluorocarbons. Photo: Courtesy of IISD/ENB | Kiara Worth at http://enb.iisd.org/ozone/resumedoewg38-mop28/11oct.html 


\section{CONTENTS}

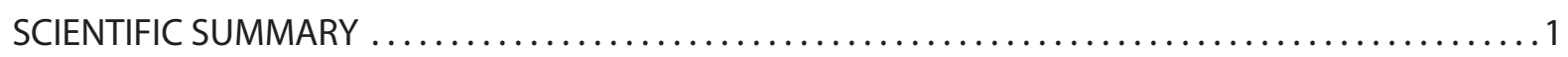

2.1 SUMMARY OF FINDINGS FROM PREVIOUS ASSESSMENTS $\ldots \ldots \ldots \ldots \ldots \ldots \ldots \ldots \ldots \ldots$

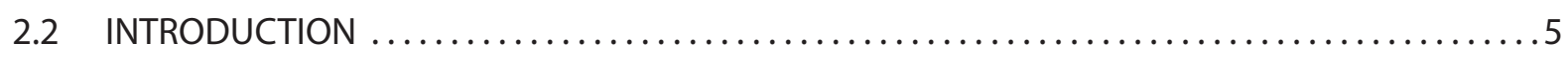

2.3 ATMOSPHERIC OBSERVATIONS AND DERIVED EMISSION ESTIMATES . ................

2.3.1 Global HFC Concentration Changes and

Estimated Emissions on Regional to Global Scales ................... 7

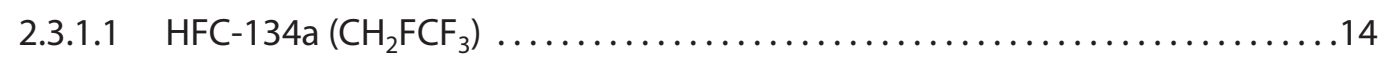

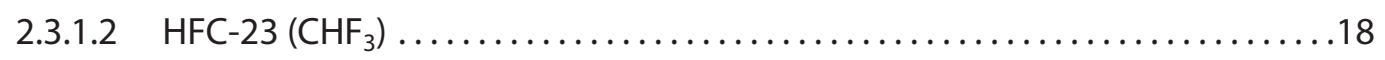

2.3.1.3 HFC-32 $\left(\mathrm{CH}_{2} \mathrm{~F}_{2}\right), \mathrm{HFC}-125\left(\mathrm{CHF}_{2} \mathrm{CF}_{3}\right), \mathrm{HFC}-143 \mathrm{a}\left(\mathrm{CH}_{3} \mathrm{CF}_{3}\right) \ldots \ldots \ldots \ldots \ldots .22$

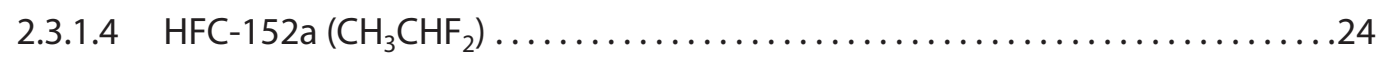

2.3.1.5 HFC-245fa $\left(\mathrm{CHF}_{2} \mathrm{CH}_{2} \mathrm{CF}_{3}\right), \mathrm{HFC}-365 \mathrm{mfc}\left(\mathrm{CH}_{3} \mathrm{CF}_{2} \mathrm{CH}_{2} \mathrm{CF}_{3}\right)$, HFC-227ea

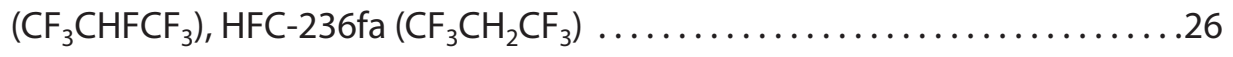

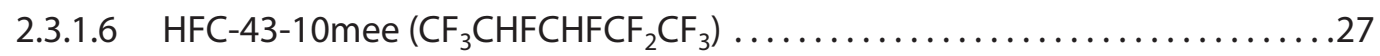

2.3.2 Summed Radiative Forcing and $\mathrm{CO}_{2}$-eq Emissions Attributable to HFCs . . . ... 27

2.3.3 Comparison of Recent Observed Changes Versus Projections Made in the Past . 28

2.3.4 Aggregate Sums of HFC Emissions Reported to the UNFCCC and Contributions from Non-Reporting Countries ...................... 29

2.3.5 Next Generation Substitutes .................................... 30

2.3.5.1 HFC-1234yf $\left(\mathrm{CF}_{3} \mathrm{CF}=\mathrm{CH}_{2}\right)$ and $\mathrm{HFC}-1234 \mathrm{ze}(E)\left((E)-\mathrm{CF}_{3} \mathrm{CH}=\mathrm{CHF}\right) \ldots \ldots \ldots . . .30$

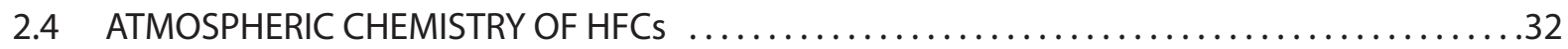

2.4.1 New Developments on Loss Rates and Lifetimes .................... 32

2.4.2 Updates on TFA Formation and Tropospheric Ozone Formation ............ 33

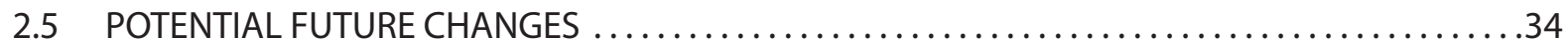

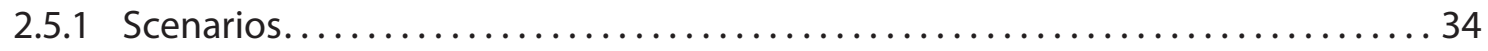

2.5.1.1 HFC Scenarios Without Consideration of Controls: "Baseline" Scenarios . . . .34

2.5.1.2 Effect of National and Regional HFC Control Measures on Future Projections ............................ 38

2.5.1.3 Projected Impact of the Kigali Amendment......................38

2.5.1.4 Climate Impacts of HFCs .................................40

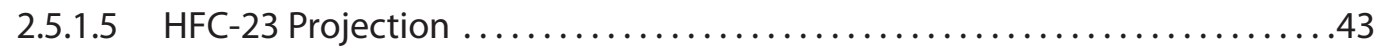

2.5.2 HFC Alternatives........................................ 43

2.5.2.1 Alternatives: HFOs, Hydrocarbons, $\mathrm{CO}_{2}, \mathrm{NH}_{3}$, Not-in-Kind Alternatives . . ...43 
Chapter 2 |HFCs

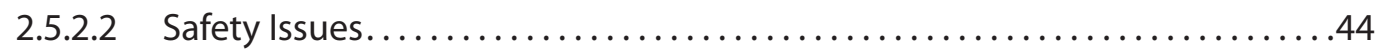

2.5.2.3 Energy Efficiency vis-à-vis GWP..........................44

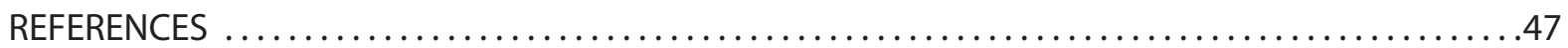




\section{ChAPTER 2}

\section{HYDROFLUOROCARBONS (HFCs)}

\section{SCIENTIFIC SUMMARY}

The Montreal Protocol is an international agreement designed to heal the ozone layer. It outlines schedules for the phase-out of ozone-depleting substances (ODSs) such as chlorofluorocarbons (CFCs), hydrochlorofluorocarbons (HCFCs), chlorinated solvents, halons, and methyl bromide. As a result of this phase-out, alternative chemicals and procedures were developed by industry for use in many applications including refrigeration, air-conditioning, foam-blowing, electronics, medicine, agriculture, and fire protection. Hydrofluorocarbons (HFCs) were used as ODS alternatives in many of these applications because they were suitable substitutes and they do not contain ozone-depleting chlorine or bromine; in addition, most HFCs have smaller climate impacts per molecule than the most widely used ODSs they replaced. Long-lived HFCs, CFCs, and HCFCs, however, are all potent greenhouse gases, and concerns were raised that uncontrolled future use of HFCs would lead to substantial climate warming.

As a result of these concerns, HFCs were included as one group of greenhouse gases for which emissions controls were adopted by the 1997 Kyoto Protocol under the 1992 United Nations Framework Convention on Climate Change (UNFCCC). Consequently, developed countries (those listed in Annex I to this Convention, or "Annex I" Parties) supply annual emission estimates of HFCs to the UNFCCC.

Since the Kyoto Protocol only specified limits on the sum of all controlled greenhouse gases, emissions of HFCs were not explicitly controlled. However, following the Kyoto Protocol, some countries enacted additional controls specifically limiting HFC use based on their global warming potentials (GWPs). Ultimately the Kigali Amendment to the Montreal Protocol was agreed upon in 2016, and this Amendment supplies schedules for limiting the production and consumption of specific HFCs. Although the radiative forcing supplied by HFCs is currently small, this Amendment was designed to ensure that the radiative forcing from HFCs will not grow uncontrollably in the future. The Kigali Amendment will come into force at the start of 2019. HFC concentrations are currently monitored through atmospheric measurements. All HFCs with large abundances are monitored, as are most with small abundances.

Most HFCs that are emitted to the atmosphere are intentionally produced for use in a variety of applications that were once dependent on ODSs. An exception is HFC-23, which is emitted to the atmosphere primarily as a by-product of HCFC-22 production. HFC-23 is also unique in that it has a substantially longer atmospheric lifetime and higher GWP than nearly all other HFCs. As a result, the Kigali Amendment includes different control schedules for HFC-23 production than for other HFCs. To date, HFC-23 emissions have been partially abated in developed countries through regulations or voluntary measures and in developing countries with assistance from the UNFCCC's Clean Development Mechanism (CDM).

- Atmospheric mole fractions of most currently measured HFCs are increasing in the global atmosphere at accelerating rates, consistent with expectations based on the ongoing transition away from use of ozone-depleting substances.

- HFC-134a remained the most abundant HFC in the atmosphere, reaching a global mean surface mole fraction of nearly $90 \mathrm{ppt}$ in 2016. Its rate of increase averaged $5.6 \pm 0.2 \mathrm{ppt} \mathrm{yr}^{-1}\left(7.3 \pm 0.2 \% \mathrm{yr}^{-1}\right)$ during 2012-2016, which is about $0.6 \mathrm{ppt} \mathrm{yr}^{-1}$ faster than the mean increase for 2008-2012.

- The next four most abundant HFCs in 2016 were HFC-23, HFC-125, HFC-143a, and HFC-32. Their global mean surface mole fractions in 2016 were 28.9 ppt, 20.4 ppt, 19.2 ppt, and 11.9 ppt, respec-

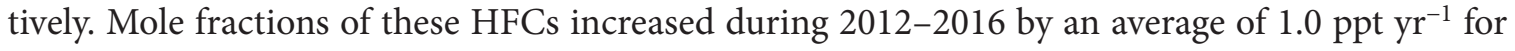




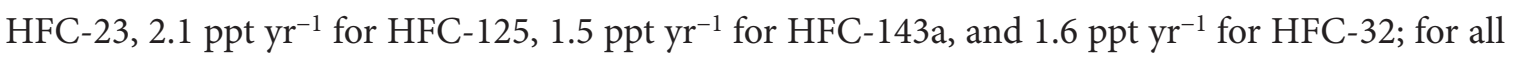
of these gases, these rates are faster than the average growth rates reported for 2008-2012 in the last Assessment.

- Global mole fractions of most HFCs increased through 2016 at rates similar to those projected in the baseline scenario of the last Assessment, despite the fact that this scenario was created nearly a decade ago. The HFCs for which mole fractions are increasing substantially less rapidly than originally projected include HFC-152a, HFC-365mfc, and HFC-245fa.

- Radiative forcing from measured HFCs continues to increase; it currently amounts to $1 \%$ of the total forcing from all long-lived greenhouse gases. The radiative forcing arising from measured atmospheric mole fractions of HFCs totaled $0.030 \mathrm{~W} \mathrm{~m}^{-2}$ in 2016 , up by $36 \%$ from $0.022 \mathrm{~W} \mathrm{~m}^{-2}$ in 2012; HFC-134a accounted for $47 \%$ of this forcing in 2016, while the next largest contributors were HFC-23 (17\%), HFC-125 (15\%) and HFC-143a (10\%). Total HFC radiative forcing in 2016 accounted for $~ 10 \%$ of the $0.33 \mathrm{~W} \mathrm{~m}^{-2}$ supplied by ODSs (see Chapter 1), and $1.0 \%$ of the $3 \mathrm{~W} \mathrm{~m}^{-2}$ supplied by all long-lived GHGs combined, including $\mathrm{CO}_{2}, \mathrm{CH}_{4}, \mathrm{~N}_{2} \mathrm{O}$, ODSs and HFCs.

- Global emissions of nearly all measured HFCs continue to increase; they currently amount to 1.5\% of total emissions from all long-lived greenhouse gases $\left(\mathrm{CO}_{2}, \mathrm{CH}_{4}, \mathrm{~N}_{2} \mathrm{O}\right.$, and long-lived halocarbons) in $\mathrm{CO}_{2}$ equivalent emissions. As derived from atmospheric observations, total emissions of HFCs increased by $23 \%$ from 2012 to 2016 and summed to 0.88 ( \pm 0.07 ) $\mathrm{GtCO}_{2}$-eq $\mathrm{yr}^{-1}$ in 2016; this increase outpaced decreases in $\mathrm{CO}_{2}$-eq emissions from CFCs and HCFCs. These $\mathrm{CO}_{2}$-eq $\mathrm{HFC}$ emissions stem primarily from four gases: HFC-134a (34\% of total), HFC-125 (24\% of total), HFC-23 (18\% of total), and HFC$143 \mathrm{a}$ ( $16 \%$ of total). $\mathrm{HFC} \mathrm{CO}_{2}$-eq emissions were comparable to those of CFCs $\left(0.8 \pm 0.3 \mathrm{GtCO}_{2}\right.$-eq $\left.\mathrm{yr}^{-1}\right)$ and $\mathrm{HCFCs}\left(0.76 \pm 0.11 \mathrm{GtCO}_{2}\right.$-eq $\left.\mathrm{yr}^{-1}\right)$ in 2016 .

- HFC emissions estimated from the combination of inventory reporting and atmospheric observations indicate that the HFC emissions originate from both developed and developing countries. Large differences are observed between global total emissions derived from atmospheric observations and the totals reported to the UNFCCC. These differences arise primarily because only developed (Annex I) countries are obligated to report HFC emissions to the UNFCCC. When summed, these reported HFC emissions account for less than half of the global total inferred from observations (as $\mathrm{CO}_{2}$-eq emissions).

- Annual global emissions of HFC-23 derived from atmospheric measurements have varied substantially in recent years. This variability is mostly consistent with expectations based on reported HCFC-22 production and reported and estimated HFC-23 emissions. This long-lived HFC is emitted to the atmosphere primarily as a by-product of HCFC-22 production. HFC-23 emissions, after reaching a low of $\sim 10 \mathrm{Gg} \mathrm{yr}^{-1}$ $\left(0.13 \mathrm{GtCO}_{2}\right.$-eq $\left.\mathrm{yr}^{-1}\right)$ 2009-2010, owing in part to destruction in developing countries facilitated under the UNFCCC's Clean Development Mechanism (CDM), increased and subsequently peaked at $\sim 14 \mathrm{Gg}$ $\mathrm{yr}^{-1}\left(0.18 \mathrm{GtCO}_{2}\right.$-eq $\left.\mathrm{yr}^{-1}\right)$ in 2013-2014. The mean global emission rate over 2013-2014 is slightly higher than that derived for 2005-2006, when CDM-facilitated destruction had yet to be fully implemented. Global emissions estimated from observations for 2015 and 2016 dropped below the 2013-2014 peak; emissions in 2016 were $12.3 \pm 0.7 \mathrm{Gg} \mathrm{yr}^{-1}\left(0.16 \mathrm{GtCO}_{2}\right.$-eq yr$\left.{ }^{-1}\right)$, or approximately $2 \mathrm{Gg} \mathrm{yr}^{-1}$ below those in 2014. New controls put in place under the Kigali Amendment mandate HFC-23 by-product destruction, to the extent practicable, beginning in 2020. These controls are expected to limit future emissions and thus slow or reverse atmospheric concentration increases of this potent greenhouse gas.

- Some next-generation substitute chemicals with very low GWPs (unsaturated HCFCs and unsaturated HFCs, also known as hydrofluoroolefins, or HFOs) have now been detected in ambient air, consistent with the transition to these compounds being underway. Unsaturated HFCs and HCFCs are replacement compounds for some long-lived HCFCs and HFCs. Because unsaturated HFCs have short atmospheric 
lifetimes (days) and GWPs typically less than 1 they are not included as controlled substances in the Kigali Amendment to the Montreal Protocol. Very low mole fractions (typically below $1 \mathrm{ppt}$ ) of two unsaturated HFCs (HFC-1234yf and HFC-1234ze(E)) have been measured at a continental background European site.

- Global adherence to the HFC phasedown schedule of the 2016 Kigali Amendment to the Montreal Protocol would substantially reduce future projected global HFC emissions. Emissions are projected to peak before 2040 and decline to less than $1 \mathrm{GtCO}_{2}$-eq $\mathrm{yr}^{-1}$ by 2100 . Only marginal increases are projected for $\mathrm{CO}_{2}$-eq emissions of the low-GWP alternatives despite substantial projected increases in their emission mass. The estimated avoided HFC emissions as a result of this Amendment is $2.8-4.1 \mathrm{GtCO}_{2}$-eq yr emissions by 2050 and $5.6-8.7 \mathrm{GtCO}_{2}$-eq $\mathrm{yr}^{-1}$ by 2100 . For comparison, total $\mathrm{CH}_{4}$ emissions in 2100 are projected to be 7.0 and $25 \mathrm{GtCO}_{2}$-eq $\mathrm{yr}^{-1}$ in the RCP-6.0 and RCP-8.5 scenarios, respectively, and total $\mathrm{N}_{2} \mathrm{O}$ emissions in 2100 are projected to be 5.0 and $7.0 \mathrm{GtCO}_{2}-\mathrm{eq} \mathrm{yr}^{-1}$ in these same scenarios.

- The 2016 Kigali Amendment to the Montreal Protocol, assuming global compliance, is expected to reduce future radiative forcing due to HFCs by about $50 \%$ in 2050 compared to the forcing from HFCs in the baseline scenario. Currently (in 2016), HFCs account for a forcing of $0.025 \mathrm{~W} \mathrm{~m}^{-2}$ not including 0.005 from HFC-23; forcing from these HFCs was projected to increase up to $0.25 \mathrm{~W} \mathrm{~m}^{-2}$ by 2050 (excluding a contribution from HFC-23) with projected increased use and emissions in the absence of controls. With the adoption of the Kigali Amendment, a phasedown schedule has been agreed for HFC production and consumption in developed and developing countries under the Montreal Protocol. With global adherence to this Amendment in combination with national and regional regulations that were already in place in, e.g., Europe, the USA, and Japan, along with additional recent controls in other countries, future radiative forcing from HFCs is projected to reach $0.13 \mathrm{~W} \mathrm{~m}^{-2}$ by 2050 (excluding HFC-23), or about half the forcing projected in the absence of these controls.

- The Kigali Amendment and national and regional regulations are projected to reduce global average warming in 2100 due to $\mathrm{HFCs}$ from $0.3-0.5^{\circ} \mathrm{C}$ in a baseline scenario to less than $0.1^{\circ} \mathrm{C}$. If the global production of HFCs were to cease in 2020, the surface temperature contribution of HFC emissions would stay below $0.02^{\circ} \mathrm{C}$ for the whole 21 st century. The magnitude of the avoided temperature increase due to the provisions of the Kigali Amendment is substantial in the context of the 2015 UNFCCC Paris Agreement, which aims to limit global temperature rise to well below $2.0^{\circ} \mathrm{C}$ above pre-industrial levels and to pursue further efforts to limit the temperature increase to $1.5^{\circ} \mathrm{C}$.

- Improvements in energy efficiency in refrigeration and air-conditioning equipment during the transition to low-GWP alternative refrigerants can potentially double the climate benefits of the HFC phasedown of the Kigali Amendment. The conversion from equipment using HFC refrigerants with high GWPs to refrigerants with lower GWPs, which will most likely result from the Kigali Amendment, provides an opportunity to consider other technological improvements that offer additional climate benefits. The total climate impact related to refrigerant use and associated emissions is not only associated with the radiative properties and lifetime of the refrigerant, but also with $\mathrm{CO}_{2}$ emissions resulting from the energy used by the equipment over its entire life cycle. The use of a refrigerant with a lower GWP than the currently-used HFCs (i.e., following the Kigali Amendment) offers the opportunity to redesign equipment and improve its energy efficiency. For example, a 30\% improvement in the energy efficiency of the global stock of mini-split air conditioners (the most widely used air conditioning systems today) in 2030 would provide a climate benefit comparable to replacing the mix of current HFC refrigerants commonly used in this application (which have GWPs averaging about 2,000) with a mix of alternatives that have GWPs of less than about 5 to about 700. An energy efficiency improvement of $30 \%$ is estimated to be technically and economically feasible and cost-effective in many economies. 
- Some HFCs degrade in the environment to produce trifluoroacetic acid (TFA), a persistent toxic chemical. The environmental effects of this source of TFA are currently small and are expected to remain negligible over the next decades. Atmospheric degradation of HFC-1234yf, a replacement compound for some long-lived HCFCs and HFCs, produces TFA. Potential impacts beyond a few decades of this TFA source could require future evaluation due to the environmental persistence of TFA and uncertainty in future emissions of HFC-1234yf and other HFCs that produce TFA upon degradation.

- Improvements in the understanding of reaction rates have been incorporated into revised lifetime estimates for saturated and unsaturated HFCs. Most of these changes are small, although lifetimes of HFC$245 \mathrm{cb}\left(\mathrm{CF}_{3} \mathrm{CF}_{2} \mathrm{CH}_{3}\right)$, octafluorocyclopentene (cyclo- $\left.\mathrm{CF}=\mathrm{C}_{4} \mathrm{~F}_{7^{-}}\right)$, (E)-HFC-1214yc $\left((E)-\mathrm{CF}_{3} \mathrm{CH}=\mathrm{CHCF}_{3}\right)$, and $(E)-\mathrm{HFC}-1438 \mathrm{mzz}\left((E)-\mathrm{CF}_{3} \mathrm{CH}=\mathrm{CHC}_{2} \mathrm{~F}_{5}\right)$ were noticeably changed because the relevant reaction rate information has become available for the first time. Lifetimes for a few HFCs considered here remain estimates based on either analogy with similar compounds or structure-activity relationships. 


\section{ChAPTER 2}

\section{HydrofLUOROCARBONS (HFCs)}

\subsection{SUMMARY OF FINDINGS FROM PREVIOUS ASSESSMENTS}

Information pertaining to HFCs was included in Chapter 1 and Chapter 5 of the 2014 Assessment report. That Assessment reported that tropospheric mole fractions of HFCs continued to increase, adding to the warming of Earth's climate. The radiative forcing supplied by HFCs in 2012, the last year assessed in that report, was small compared to that from CFCs and HCFCs, but projections suggested the potential for significant increases in HFC-associated warming in the future. Furthermore, the documented climate benefits achieved by the Montreal Protocol through reductions in the production and emission of CFCs and HCFCs might be substantially offset if emissions of the substitute HFCs were allowed to continue unabated. The sum of HFC emissions in 2012 had reached $0.72 \pm 0.05 \mathrm{GtCO}_{2}$-equivalent $\mathrm{yr}^{-1}$ (for $\mathrm{CO}_{2}$-eq considering a 100-yr time horizon) after having increased by nearly $7 \% \mathrm{yr}^{-1}$ from 2008 to 2012 . This total was similar to the magnitude of emissions from CFCs $(0.9$ $\left.\pm 0.3 \mathrm{GtCO}_{2} \mathrm{yr}^{-1}\right)$ and HCFCs $\left(0.78 \pm 0.10 \mathrm{GtCO}_{2}\right.$-eq $\mathrm{yr}^{-1}$ ) for 2012. This total included a global emission of approximately $0.16 \pm 0.01 \mathrm{GtCO}_{2}$-eq $\mathrm{yr}^{-1}$ from the potent greenhouse gas $\mathrm{HFC}-23\left(\mathrm{CHF}_{3}\right)$, which is emitted primarily as a by-product during the production of HCFC-22 and not as a result of use in industrial applications and products. Although global emissions of this HFC had decreased from 2005 to 2009, they increased after 2009 and by 2012 were $\sim 40 \%$ above the minimum recorded for 2009.

\subsection{INTRODUCTION}

Hydrofluorocarbons have been used in refrigeration, air conditioning, thermal insulating foam, and miscellaneous applications since the 1990s, replacing the CFCs and HCFCs that were traditionally used in these applications. The first widespread HFC use was of HFC-134a beginning in the early 1990s, as a substitute for CFC-12 in mobile air conditioning (Montzka et al., 1996; Oram et al., 1996; Andersen et al., 2013). Within a decade most mobile air conditioners used this HFC
(Papasavva et al., 2009), and this remains true today. With the global CFC phase-out in 2010 and the ongoing HCFC phase-out, the use of HFCs has increased substantially, not only for various refrigeration and air conditioning applications, but also as foam blowing agents, as medical aerosols, and to a lesser extent as cleaning, etching, and fire-fighting agents. As was true for ODSs, emissions of HFCs follow production and consumption with a delay of months to decades, depending on the type of application in which the HFCs are used.

HFCs do not contain ozone-depleting chlorine or bromine, but are potent greenhouse gases (Harris and Wuebbles et al., 2014). To ensure that radiative forcing from the substitute HFCs does not offset climate gains provided by the Montreal Protocol phase-out of CFCs and HCFCs, Parties to the Montreal Protocol agreed to an Amendment in Kigali, Rwanda in October 2016, to include some HFCs as controlled substances and to phase down their production and consumption (GWPweighted) in coming decades (UNEP, 2016a; for a list of controlled HFCs, see footnote to Table 2-1 [or HFCs with asterisks in Table 2-2]). The Kigali Amendment will enter into force on January 1, 2019, since more than 20 Parties have ratified, accepted, or approved this Amendment. Limiting climate change is not the primary goal of the 1985 Vienna Convention for the Protection of the Ozone layer, but climate change considerations are addressed in this Convention. Limiting climate change was also a contributing factor to the 2007 Adjustment of the Montreal Protocol for an accelerated HCFC phase-out (UNEP, 2007).

Since 1997, HFCs have been included in the Kyoto Protocol to the United Nations Framework Convention on Climate Change as one group among many greenhouse gases for which emissions overall should be reduced by up to $8 \%$ in the period $2008-2012$ by some developed countries relative to baseline levels (mostly the year 1990). HFC emissions were not directly controlled by the Kyoto Protocol, however, since controls applied to the sum of all greenhouse gases. 
Table 2-1. Base level and phasedown schedule for production and consumption of controlled HFCs ${ }^{1}$, expressed as $\mathrm{CO}_{2}$-eq, under the Kigali Amendment to the Montreal Protocol (UNEP, 2016a).

\begin{tabular}{|c|c|c|c|}
\hline & \multicolumn{2}{|c|}{ Developing Countries* } & \multirow{2}{*}{$\frac{\text { Developed Countries* }^{*}}{\text { Non-A5 Countries }^{4}}$} \\
\hline & A5 Group 1 Countries $^{2}$ & A5 Group 2 Countries $^{3}$ & \\
\hline Base level: & $\begin{array}{l}\text { Average HFCs } 2020-2022 \\
\text { plus } 65 \% \text { of HCFC base level }\end{array}$ & $\begin{array}{l}\text { Average HFCs } 2024-2026 \\
\text { plus } 65 \% \text { of HCFC base level }\end{array}$ & $\begin{array}{l}\text { Average HFCs } 2011-2013 \\
\text { plus } 15 \% \text { of HCFC base level }\end{array}$ \\
\hline Freeze: & 2024 & 2028 & - \\
\hline 1st step: & 2029: $10 \%$ reduction & 2032: 10\% reduction & 2019: 10\% reduction \\
\hline 2nd step: & 2035: 30\% reduction & 2037: 20\% reduction & 2024: $40 \%$ reduction \\
\hline 3rd step: & 2040: 50\% reduction & 2042: 30\% reduction & 2029: 70\% reduction \\
\hline 4th step: & & & 2034: $80 \%$ reduction \\
\hline Plateau: & 2045: 80\% reduction & 2047: 85\% reduction & 2036: 85\% reduction \\
\hline \multicolumn{4}{|c|}{$\begin{array}{l}\text { In the UNFCCC, developing countries are referred to as "non-Annex I" countries, and developed countries are referred to as } \\
\text { "Annex I countries." }\end{array}$} \\
\hline \multicolumn{4}{|c|}{$\begin{array}{l}\text { HFCs controlled by the Kigali Amendment include: HFC-23, HFC-134, HFC-134a, HFC-143, HFC-245fa, HFC-365mfc, HFC-227ea, } \\
\text { HFC-236cb, HFC-236ea, HFC-236fa, HFC-245ca, HFC- } 43-10 \text { mee, HFC-32, HFC-125, HFC-143a, HFC- } 41 \text {, HFC-152, HFC-152a. This } \\
\text { Amendment also specifies that emissions of HFC-23 generated during production of HCFCs or HFCs be destroyed to the extent } \\
\text { practicable beginning January } 2020 \text {. }\end{array}$} \\
\hline \multicolumn{4}{|c|}{ Group 1: Article 5 (developing) countries not part of Group 2. Article 5 of the Montreal Protocol. } \\
\hline \multicolumn{4}{|c|}{$\begin{array}{l}\text { Group 2: Article } 5 \text { (developing) countries: Bahrain, India, the Islamic Republic of Iran, Iraq, Kuwait, Oman, Pakistan, Qatar, Saudi } \\
\text { Arabia and the United Arab Emirates. }\end{array}$} \\
\hline \multicolumn{4}{|c|}{ Non-A5 countries, also referred to as A2 countries (developed). Article $2 \mathrm{~J}$ of the Montreal Protocol. } \\
\hline \multicolumn{4}{|c|}{$\begin{array}{l}\text { For Belarus, Russian Federation, Kazakhstan, Tajikistan, Uzbekistan } 25 \% \text { HCFC component of base level and different initial two } \\
\text { steps (1) } 5 \% \text { reduction in } 2020 \text { and (2) 35\% reduction in 2025. Article } 2 J \text { of the Montreal Protocol. }\end{array}$} \\
\hline
\end{tabular}

Note: Non-Article 5 (developed) and UNFCCC Annex I (developed) countries include all EU-28 countries, Australia, Belarus, Canada, Iceland, Japan, Liechtenstein, Monaco, New Zealand, Norway, the Russian Federation, Switzerland, Ukraine, and the USA. Further, non-Article 5 countries are Andorra, Azerbaijan, the Holy See, Israel, Kazakhstan, San Marino, Tajikistan, and Uzbekistan. Turkey is solely an Annex I country.

In previous Assessments, observed concentrations, derived emissions, and atmospheric effects of HFCs were discussed together with those of ozone-depleting substances. In this Assessment, issues related to HFCs are covered in this separate chapter, with the main foci being updating observations of HFC atmospheric mole fractions and understanding what they imply for emissions on global to regional scales; determining if the observed mole fraction changes are consistent with expectations and emission magnitudes reported to UNFCCC and elsewhere; quantifying the associated climate- and environmental-related effects arising from HFC emissions and associated atmospheric changes; and considering how these influences might change in the future, especially in light of controls on HFC production and consumption specified in the Kigali Amendment to the Montreal Protocol.
With respect to climate influences, increases in radiative forcing resulting from recent increases in HFC atmospheric mole fractions are documented in this chapter. For HFCs with lifetimes longer than 1 year (e.g., those that are well mixed in the lower atmosphere), radiative forcing is linearly proportional to global mean surface mole fractions and the efficiency of the particular HFC in trapping outgoing terrestrial radiation (i.e., its radiative efficiency; see Table A-1). Total emission rates are also derived from these global-scale observations with consideration of lifetime-determined loss rates (Table 2-2) in an inverse budget analysis performed with box models (see Box 1-1). Emission magnitudes are considered here on a mass basis and with mass emissions weighted by 100yr GWPs to enable an assessment of integrated radiative forcing supplied by an HFC emission relative to an equivalent $\mathrm{CO}_{2}$ emission over a 100 -year time horizon 
( $\mathrm{CO}_{2}$-eq emissions, Figure 2-1; Table 2-2). GWPs associated with a 20 -year time horizon are also tabulated, but they are not considered further in this chapter.

Determining if atmospheric concentrations of ODSs or HFCs are changing as expected has always been an important remit for authors of this Assessment. For HFCs, this task is facilitated by the reporting by developed countries (Annex I Parties) to the UNFCCC of national emission magnitudes derived from country-specific analyses of production, imports, sales, exports, and use. For HFC-23, emission estimates for developing countries derived from information collected by the Montreal Protocol's Multilateral Fund ${ }^{1}$ are also considered. In this chapter, these inventory-based HFC emission totals are compared to national and global totals derived from atmospheric data on both a compound-specific and aggregate basis. Factors contributing to differences between UNFCCC-reported and observation-derived emissions for individual HFCs are discussed; they include inaccuracies in methods for deriving emissions from atmospheric mole fraction measurements, inaccuracies in emissions reporting by Annex I (developed) countries, reporting emissions as aggregated mixes of HFCs or HFCs and perfluorocarbons (PFCs), and the potential for significant emissions from non-Annex I (developing) countries not obligated to report their HFC emissions to the UNFCCC $^{2}$. Recent inverse analyses of atmospheric measurements made in the USA and Europe provide a means to assess UNFCCC inventory reporting from these regions. Similar observations from other regions are also considered and add to our understanding of emission magnitudes from countries not required to report emissions to the UNFCCC.

In Chapter 6 of this Assessment, as in related chapters in previous Assessments, scenarios are constructed for ODS concentrations in the future as part of the

\footnotetext{
1 The Multilateral Fund (MLF) for the implementation of the Montreal Protocol was established in 1991 to assist developing countries (Article 5 countries) to meet their Montreal Protocol commitments. Financial contributions to the MLF come from developed countries (non-Article 5 countries).

2 UNFCCC Parties listed in Annex I (as amended in 1998) include all the developed countries in the Organization for Economic Cooperation and Development, it also includes Economies in Transition, which are characterized as national economies in the process of changing from a planned economic system to a market economy. By default, other countries are referred to as non-Annex I countries.
}

Assessment itself, since such scenarios are usually not available in the literature. Also consistent with previous Assessments, new HFC scenarios have not been constructed here or in Chapter 6. Instead, projections of HFC use and emission magnitudes are taken from the literature and are discussed in this chapter. These scenarios were created based on data available at the time they were created, and they have not been updated to consider the most recent observational data. As a result, discrepancies between projected and observed HFC concentrations and emissions are apparent in years after the scenarios were created.

Discussions in this chapter extend those presented in specific chapters of the most recent Intergovernmental Panel on Climate Change (IPCC) assessment report (Hartmann, Tank, and Rusticucci et al., 2013; Myhre and Shindell et al., 2013) by updating observed mixing ratios and associated radiative forcings through 2016. Laboratory kinetic data published since that time are considered in providing updated lifetime estimates. Furthermore, the scenarios discussed here are based on more recent analyses, whereas those in the IPCC report are from the Representative Concentration Pathways (RCPs) scenarios (Meinshausen et al., 2011).

\subsection{ATMOSPHERIC OBSERVATIONS AND DERIVED EMISSION ESTIMATES}

\subsubsection{Global HFC Concentration Changes and Estimated Emissions on Regional to Global Scales}

Atmospheric abundances of HFCs are regularly measured throughout the global atmosphere by a few surface-based measurement networks at remote sites, by aircraft, and by satellite-borne instruments (Figure 2-2 and Table 2-3). These results imply substantial emissions of HFCs on a global scale, when independently-determined atmospheric removal rates (or lifetimes) are considered (Figure 2-1; Table 2-2). Emission rates are also derived on regional spatial scales using trace-gas measurements in non-remote regions (see Box 1-1). These results can provide estimates of region-specific HFC emissions that are independent of inventory-based approaches used in reporting to UNFCCC. Regional emission rates are typically derived from data analysis methods such as inter-species correlation and inverse modeling. Regional emission estimates typically have larger relative uncertainties 
Table 2-2. Trace gas lifetimes for selected halocarbons: partially fluorinated alkanes, partially fluorinated olefins, and perfluorinated olefins.

\begin{tabular}{|c|c|c|c|c|c|c|c|}
\hline \multirow{2}{*}{$\begin{array}{c}\text { Industrial } \\
\text { Designation } \\
\text { of Chemical } \\
\text { Name }\end{array}$} & \multirow[t]{2}{*}{$\begin{array}{l}\text { Chemical } \\
\text { Formula }\end{array}$} & \multirow{2}{*}{$\begin{array}{c}\text { Total } \\
\text { Lifetime, }^{\mathrm{a}} \\
\text { WMO-2014 } \\
\text { (years, unless } \\
\text { otherwise } \\
\text { indicated) }\end{array}$} & \multirow{2}{*}{$\begin{array}{c}\text { Total } \\
\text { Lifetime,, } \\
\text { this } \\
\text { Assessment } \\
\text { (years, unless } \\
\text { otherwise } \\
\text { indicated) }\end{array}$} & \multirow{2}{*}{$\begin{array}{l}\text { Radiative } \\
\text { Efficiency } \\
\left(\mathrm{W} \mathrm{m}^{-2}\right. \\
\left.\mathrm{ppb}^{-1}\right)\end{array}$} & \multicolumn{2}{|c|}{$\begin{array}{c}\text { GWP at Given } \\
\text { Time Horizon, } \\
\text { this } \\
\text { Assessment }\end{array}$} & \multirow[t]{2}{*}{ Notes } \\
\hline & & & & & $20-y r$ & $100-y r$ & \\
\hline \multicolumn{8}{|c|}{ Hydrofluorocarbons } \\
\hline HFC- $23 * *$ & $\mathrm{CHF}_{3}$ & 228 & 228 & 0.18 & 11,085 & 12,690 & 1 \\
\hline $\mathrm{HFC}-32 * *$ & $\mathrm{CH}_{2} \mathrm{~F}_{2}$ & 5.4 & 5.4 & 0.11 & 2,530 & 705 & 1 \\
\hline HFC- $41 * *$ & $\mathrm{CH}_{3} \mathrm{~F}$ & 2.8 & 2.8 & 0.02 & 430 & 116 & 1 \\
\hline $\mathrm{HFC}-125 * *$ & $\mathrm{CHF}_{2} \mathrm{CF}_{3}$ & 31 & 30 & 0.23 & 6,280 & 3,450 & 1 \\
\hline HFC- $134 * *$ & $\mathrm{CHF}_{2} \mathrm{CHF}_{2}$ & 9.7 & 10 & 0.19 & 3,625 & 1,135 & 1 \\
\hline HFC-134a ** & $\mathrm{CH}_{2} \mathrm{FCF}_{3}$ & 14 & 14 & 0.16 & 3,810 & 1,360 & 1 \\
\hline HFC- $143 * *$ & $\mathrm{CH}_{2} \mathrm{FCHF}_{2}$ & 3.5 & 3.6 & 0.13 & 1,250 & 340 & 1 \\
\hline HFC-143a ** & $\mathrm{CH}_{3} \mathrm{CF}_{3}$ & 51 & 51 & 0.16 & 7,050 & 5,080 & 1 \\
\hline HFC- $152 * *$ & $\mathrm{CH}_{2} \mathrm{FCH}_{2} \mathrm{~F}$ & $\begin{array}{c}146 \text { days } \\
(114-335 \\
\text { days })\end{array}$ & 172 days & 0.04 & 64 & 17 & $1, b$ \\
\hline HFC-152a ** & $\mathrm{CH}_{3} \mathrm{CHF}_{2}$ & 1.6 & 1.6 & 0.10 & 545 & 148 & 1 \\
\hline HFC-161 & $\mathrm{CH}_{3} \mathrm{CH}_{2} \mathrm{~F}$ & $\begin{array}{c}66 \text { days } \\
\text { (51-154 days) }\end{array}$ & 80 days & 0.02 & 20 & 6 & $1, b$ \\
\hline HFC-227ca & $\mathrm{CF}_{3} \mathrm{CF}_{2} \mathrm{CHF}_{2}$ & 28.2 & 30 & 0.27 & 5,260 & 2,865 & 2 \\
\hline HFC-227ea $* *$ & $\mathrm{CF}_{3} \mathrm{CHFCF}_{3}$ & 36 & 36 & 0.26 & 5,250 & 3,140 & 1 \\
\hline HFC-236cb ** & $\mathrm{CH}_{2} \mathrm{FCF}_{2} \mathrm{CF}_{3}$ & $\sim 13$ & 13.4 & 0.23 & 3,540 & 1,235 & 1 \\
\hline HFC-236ea $* *$ & $\mathrm{CHF}_{2} \mathrm{CHFCF}_{3}$ & 11.0 & 11.4 & 0.30 & 4,190 & 1,370 & 1 \\
\hline HFC-236fa ** & $\mathrm{CF}_{3} \mathrm{CH}_{2} \mathrm{CF}_{3}$ & 222 & 213 & 0.24 & 6,785 & 7,680 & 1 \\
\hline HFC-245ca ${ }^{* *}$ & $\mathrm{CH}_{2} \mathrm{FCF}_{2} \mathrm{CHF}_{2}$ & 6.5 & 6.6 & 0.24 & 2,530 & 720 & 1 \\
\hline HFC-245cb & $\mathrm{CF}_{3} \mathrm{CF}_{2} \mathrm{CH}_{3}$ & 47.1 & 39.9 & 0.24 & 6,340 & 4,000 & 1 \\
\hline HFC-245ea & $\mathrm{CHF}_{2} \mathrm{CHFCHF}_{2}$ & 3.2 & 3.3 & 0.16 & 880 & 240 & 1 \\
\hline HFC-245eb & $\mathrm{CH}_{2} \mathrm{FCHFCF}_{3}$ & 3.2 & 3.2 & 0.20 & 1,070 & 290 & 1 \\
\hline HFC-245fa ** & $\mathrm{CHF}_{2} \mathrm{CH}_{2} \mathrm{CF}_{3}$ & 7.9 & 7.9 & 0.24 & 2,980 & 880 & 1 \\
\hline HFC-263fb & $\mathrm{CH}_{3} \mathrm{CH}_{2} \mathrm{CF}_{3}$ & 1.1 & 1.1 & 0.10 & 250 & 68 & 1 \\
\hline HFC-272ca & $\mathrm{CH}_{3} \mathrm{CF}_{2} \mathrm{CH}_{3}$ & 2.6 & $\sim 9$ & 0.07 & 1,580 & 480 & 3 \\
\hline HFC-281 ea & $\mathrm{CH}_{3} \mathrm{CHFCH}_{3}$ & $\begin{array}{c}23 \text { days } \\
\text { (19-46 days) }\end{array}$ & 27 days & - & - & - & $1, b$ \\
\hline HFC-329p & $\mathrm{CHF}_{2} \mathrm{CF}_{2} \mathrm{CF}_{2} \mathrm{CF}_{3}$ & $\sim 30$ & 32 & 0.31 & 4,720 & 2,630 & 4 \\
\hline HFC-338pcc & $\mathrm{CHF}_{2} \mathrm{CF}_{2} \mathrm{CF}_{2} \mathrm{CHF}_{2}$ & 12.9 & 13.5 & - & - & - & 1 \\
\hline HFC-356mcf & $\mathrm{CH}_{2} \mathrm{FCH}_{2} \mathrm{CF}_{2} \mathrm{CF}_{3}$ & 1.2 & 1.2 & - & - & - & 1 \\
\hline
\end{tabular}




\begin{tabular}{|c|c|c|c|c|c|c|c|}
\hline HFC-356mff & $\mathrm{CF}_{3} \mathrm{CH}_{2} \mathrm{CH}_{2} \mathrm{CF}_{3}$ & 8.3 & 8.5 & - & - & - & 1 \\
\hline HFC-365mfc ** & $\mathrm{CH}_{3} \mathrm{CF}_{2} \mathrm{CH}_{2} \mathrm{CF}_{3}$ & 8.7 & 8.9 & 0.22 & 2,660 & 810 & 1 \\
\hline HFC-43-10mee $* *$ & $\begin{array}{l}\mathrm{CF}_{3} \mathrm{CHFCHF}- \\
\mathrm{CF}_{2} \mathrm{CF}_{3}\end{array}$ & 16.1 & 17.0 & 0.359 & 3,770 & 1,470 & 1,19 \\
\hline HFC-458mfcf & $\mathrm{CF}_{3} \mathrm{CH}_{2} \mathrm{CF}_{2} \mathrm{CH}_{2} \mathrm{CF}_{3}$ & 22.9 & 23.8 & - & - & - & 1 \\
\hline HFC-55-10mcff & $\begin{array}{l}\mathrm{CF}_{3} \mathrm{CF}_{2} \mathrm{CH}_{2} \mathrm{CH}_{2}^{-} \\
\mathrm{CF}_{2} \mathrm{CF}_{3}\end{array}$ & 7.5 & 7.7 & - & - & - & 1 \\
\hline HFC-52-13p & $\begin{array}{l}\mathrm{CHF}_{2} \mathrm{CF}_{2} \mathrm{CF}_{2^{-}} \\
\mathrm{CF}_{2} \mathrm{CF}_{2} \mathrm{CF}_{3}\end{array}$ & 32.7 & 35.2 & - & - & - & 5 \\
\hline HFC-72-17p & $\mathrm{CHF}_{2}\left(\mathrm{CF}_{2}\right)_{6} \mathrm{CF}_{3}$ & & 23.8 & - & - & - & 6 \\
\hline \multicolumn{8}{|c|}{ Fluorinated Olefinic HFCs - indicated here as HFOs } \\
\hline HFO-1123 & $\mathrm{CHF}=\mathrm{CF}_{2}$ & - & 1.5 days & 0.0019 & $<1$ & $<1$ & $1,7, b$ \\
\hline HFO-1132a & $\mathrm{CH}_{2}=\mathrm{CF}_{2}$ & $\begin{array}{c}4.0 \text { days } \\
(3.0-5.7 \text { days })\end{array}$ & 4.6 days & 0.004 & $<1$ & $<1$ & $1, b$ \\
\hline HFO-1141 & $\mathrm{CH}_{2}=\mathrm{CHF}$ & $\begin{array}{c}2.1 \text { days } \\
\text { (1.4-3.1 days) }\end{array}$ & 2.5 days & 0.002 & $<1$ & $<1$ & $1, b$ \\
\hline HFO-1234ye(E) & $(E)-\mathrm{CHF}=\mathrm{CFCHF}_{2}$ & $<5$ days & $<5$ days & - & - & - & $8, b$ \\
\hline HFO-1234ye(Z) & $(\mathrm{Z})-\mathrm{CHF}=\mathrm{CFCHF}{ }_{2}$ & $<5$ days & $<5$ days & - & - & - & $8, b$ \\
\hline HFO-1225ye(E) & $(E)-\mathrm{CF}_{3} \mathrm{CF}=\mathrm{CHF}$ & $\begin{array}{c}4.9 \text { days } \\
\text { (3.7-6.9 days) }\end{array}$ & 5.7 days & 0.01 & $<1$ & $<1$ & $1, b$ \\
\hline HFO-1225ye(Z) & $(\mathrm{Z})-\mathrm{CF}_{3} \mathrm{CF}=\mathrm{CHF}$ & $\begin{array}{c}8.5 \text { days } \\
\text { (6.2-12 days) }\end{array}$ & 10 days & 0.02 & $<1$ & $<1$ & $1, b$ \\
\hline HFO-1234ze(E) & (E) $-\mathrm{CF}_{3} \mathrm{CH}=\mathrm{CHF}$ & $\begin{array}{c}16.4 \text { days } \\
\text { (12.8-24 days) }\end{array}$ & 19 days & 0.04 & 4 & $<1$ & $1, b$ \\
\hline HFO-1234ze(Z) & (Z) $-\mathrm{CF}_{3} \mathrm{CH}=\mathrm{CHF}$ & 10.0 days & 10 days & 0.02 & 1 & $<1$ & $9, b$ \\
\hline HFO-1234yf & $\mathrm{CF}_{3} \mathrm{CF}=\mathrm{CH}_{2}$ & $\begin{array}{c}10.5 \text { days } \\
\text { (8.4-16 days) }\end{array}$ & 12 days & 0.02 & 1 & $<1$ & 1 \\
\hline HFO-1261zf & $\mathrm{CH}_{2} \mathrm{FCH}=\mathrm{CH}_{2}$ & $\begin{array}{c}0.7 \text { days } \\
(0.5-1.0 \text { days })\end{array}$ & 0.8 days & - & - & - & $1, b$ \\
\hline HFO-1234yс & $\mathrm{CF}_{2}=\mathrm{CFCH}_{2} \mathrm{~F}$ & $\sim 2$ days & $\sim 2$ days & - & - & - & $8, b$ \\
\hline HFO-1225zc & $\mathrm{CF}_{2}=\mathrm{CHCF}_{3}$ & $\sim 2$ days & $\sim 2$ days & - & - & - & $8, b$ \\
\hline HFO-1234zc & $\mathrm{CF}_{2}=\mathrm{CHCHF}_{2}$ & $<5$ days & $<5$ days & - & - & - & $8, b$ \\
\hline HFO-1336mzz(E) & (E) $-\mathrm{CF}_{3} \mathrm{CH}=\mathrm{CHCF}_{3}$ & (16-30 days) & 122 days & 0.13 & 60 & 16 & $10, \mathrm{~b}$ \\
\hline HFO-1336mzz(Z) & (Z) $-\mathrm{CF}_{3} \mathrm{CH}=\mathrm{CHCF}_{3}$ & (16-32 days) & 27 days & 0.07 & 6 & 2 & $1, b$ \\
\hline HFO-1243zf & $\mathrm{CHCF}_{3}=\mathrm{CH}_{2}$ & $\begin{array}{c}7.6 \text { days } \\
\text { (5.5-11 days) }\end{array}$ & 9 days & 0.01 & $<1$ & $<1$ & $1, b$ \\
\hline HFO-1345fz & $\mathrm{CHC}_{2} \mathrm{~F}_{5}=\mathrm{CH}_{2}$ & $\begin{array}{c}7.9 \text { days } \\
(5.8-11.4 \\
\text { days })\end{array}$ & 9 days & 0.01 & $<1$ & $<1$ & $1, b$ \\
\hline HFO-1438mzz(E) & $\begin{array}{l}(E)-\mathrm{CF}_{3} \mathrm{CH}= \\
\mathrm{CHCF}_{2} \mathrm{CF}_{3}\end{array}$ & (16-30 days) & $\sim 122$ days & - & - & - & $11, \mathrm{~b}$ \\
\hline HFO-1447fz & $\begin{array}{l}\mathrm{CH}_{2}= \\
\mathrm{CHCF}_{2} \mathrm{CF}_{2} \mathrm{CF}_{3}\end{array}$ & (6-10 days) & 9 days & - & - & - & $12, \mathrm{~b}$ \\
\hline
\end{tabular}




\begin{tabular}{|c|c|c|c|c|c|c|c|}
\hline $\begin{array}{l}\text { HFO-1549fz } \\
1 \mathrm{H}, 1 \mathrm{H}, 2 \mathrm{H}- \\
\text { Perfluorohexene }\end{array}$ & $\mathrm{CHC}_{4} \mathrm{~F}_{9}=\mathrm{CH}_{2}$ & 7.6 days & 9 days & 0.03 & $<1$ & $<1$ & $13, b$ \\
\hline $\begin{array}{l}\text { HFO-174-13fz } \\
1 \mathrm{H}, 1 \mathrm{H}, 2 \mathrm{H}- \\
\text { Perfluoro-1- } \\
\text { octene }\end{array}$ & $\mathrm{CHC}_{6} \mathrm{~F}_{13}=\mathrm{CH}_{2}$ & 7.6 days & 9 days & 0.03 & $<1$ & $<1$ & $13, \mathrm{~b}$ \\
\hline $\begin{array}{l}\text { HFO-194-17fz } \\
1 \mathrm{H}, 1 \mathrm{H}, 2 \mathrm{H}- \\
\text { Heptadecafluoro- } \\
\text { 1-decene }\end{array}$ & $\mathrm{CHC}_{8} \mathrm{~F}_{17}=\mathrm{CH}_{2}$ & 7.6 days & 9 days & 0.03 & $<1$ & $<1$ & $13, b$ \\
\hline HFO-1438ezy(E) & $\begin{array}{l}(\mathrm{E})-\left(\mathrm{CF}_{3}\right)_{2} \mathrm{CFCH}= \\
\mathrm{CHF}\end{array}$ & & 43 days & 0.34 & 42 & 11 & $14, b$ \\
\hline \multicolumn{8}{|c|}{ Perfluorinated Olefins } \\
\hline PFC-1114 & $\mathrm{CF}_{2}=\mathrm{CF}_{2}$ & $\begin{array}{c}1.1 \text { days } \\
\text { (0.7- } 1.6 \text { days) }\end{array}$ & 1.2 days & 0.002 & $<1$ & $<1$ & $1, b$ \\
\hline PFC-1216 & $\mathrm{CF}_{3} \mathrm{CF}=\mathrm{CF}_{2}$ & $\begin{array}{c}4.9 \text { days } \\
\text { (3.3-7.1 days) }\end{array}$ & 5.5 days & 0.01 & $<1$ & $<1$ & $1, b$ \\
\hline $\begin{array}{l}\text { Perfluoro } \\
\text { buta-1,3-diene }\end{array}$ & $\mathrm{CF}_{2}=\mathrm{CFCF}=\mathrm{CF}_{2}$ & $\begin{array}{c}1.1 \text { days } \\
(0.8-1.6 \text { days })\end{array}$ & 1.1 days & 0.003 & $<1$ & $<1$ & $1, b$ \\
\hline $\begin{array}{l}\text { Perfluoro } \\
\text { but-1-ene }\end{array}$ & $\mathrm{CF}_{3} \mathrm{CF}_{2} \mathrm{CF}=\mathrm{CF}_{2}$ & 6 days & 6 days & 0.02 & $<1$ & $<1$ & $15, b$ \\
\hline $\begin{array}{l}\text { Perfluorobut- } \\
\text { 2-ene (isomer } \\
\text { blend: } 71 \%(E) \\
\text { and } 29 \%(Z) \text { ) }\end{array}$ & $\mathrm{CF}_{3} \mathrm{CF}=\mathrm{CFCF}_{3}$ & & & & 4.8 & 1.3 & 16 \\
\hline $\begin{array}{l}\text { (E)-Perfluro } \\
\text {-2-butene }\end{array}$ & (E) $-\mathrm{CF}_{3} \mathrm{CF}=\mathrm{CFCF}_{3}$ & - & 22 days & 0.05 & 3.6 & 1.0 & $1, b$ \\
\hline $\begin{array}{l}\text { (Z)-Perfluro } \\
\text {-2-butene }\end{array}$ & $(Z)-\mathrm{CF}_{3} \mathrm{CF}=\mathrm{CFCF}_{3}$ & - & 35 days & 0.07 & 7.8 & 2.1 & $1, b$ \\
\hline $\begin{array}{l}\text { Perfluoro } \\
\text { (2-methyl-2- } \\
\text { pentene) }\end{array}$ & $\left(\mathrm{CF}_{3}\right)_{2} \mathrm{C}=\mathrm{CFCF}_{2} \mathrm{CF}_{3}$ & - & 192 days & - & - & - & $1, b$ \\
\hline \multicolumn{8}{|c|}{ Fluorinated Cycloolefins } \\
\hline $\begin{array}{l}\text { 3,3,4,4-Tetrafluro- } \\
\text { cyclobut-1-ene } \\
\text { 1H,2H-Tetrafluro } \\
\text { cyclobutene }\end{array}$ & $\begin{array}{l}\text { cyclo- } \mathrm{CH}= \\
\mathrm{CHCF}_{2} \mathrm{CF}_{2^{-}}\end{array}$ & & 84 days & 0.09 & 37 & 10 & $17, b$ \\
\hline $\begin{array}{l}\text { 2,3,3,4,4- } \\
\text { Pentafluoro } \\
\text { cyclobut-1-ene } \\
\text { 1H-Pentafluoro- } \\
\text { cyclobutene }\end{array}$ & $\begin{array}{l}\text { cyclo- } \mathrm{CH}= \\
\mathrm{CFCF}_{2} \mathrm{CF}_{2^{-}}\end{array}$ & & 270 days & 0.19 & 214 & 58 & 17 \\
\hline $\begin{array}{l}\text { Hexafluorocy- } \\
\text { clobutene }\end{array}$ & $\begin{array}{l}\text { cyclo- } \mathrm{CF}= \\
\mathrm{CFCF}_{2} \mathrm{CF}_{2^{-}}\end{array}$ & & 1.2 & 0.25 & 420 & 110 & 17 \\
\hline
\end{tabular}




\begin{tabular}{|l|l|l|l|l|l|l|}
\hline $\begin{array}{l}\text { Octafluorocyclo- } \\
\text { pentene }\end{array}$ & $\begin{array}{l}\text { cyclo- } \mathrm{CF}= \\
\mathrm{CFCF}_{2} \mathrm{CF}_{2} \mathrm{CF}_{2^{-}}\end{array}$ & 31 days & 1.05 & 0.27 & 300 & 82 \\
\hline
\end{tabular}

Table Heading Footnotes:

Although the designation HFC is applicable to both saturated and unsaturated chemicals, it is used to refer only to partially fluorinated alkanes in this table. Partially fluorinated unsaturated compounds, hydrofluoroolefins, are designated as HFO in this table for easier identification.

** Those HFCs listed as controlled substances in Annex F of the Kigali Amendment to the Montreal Protocol. Additional reporting requirements were adopted at the $29^{\text {th }}$ Meeting of the Parties of the Montreal Protocol (Decision XXIX/12) on consideration of HFCs not listed as controlled substances. This decision requested that production and consumption of HFCs with GWPs higher than the smallest GWP listed in Annex F also be reported to the Ozone Secretariat for informational purposes.

a Total lifetime, $\tau_{\mathrm{HFC}}$, reported in the 2014 Assessment (indicated as “WMO-2014"; Carpenter and Reimann et al., 2014).

b Lifetimes for VSLSs (values given in days) are calculated relative to the methyl chloroform (MCF) partial lifetime due to reaction with $\mathrm{OH}$ with the same procedure that is used for long-lived gases. Local lifetimes for VSLSs will depend on the season and location of the emission. Nevertheless, the characteristic values are within the range of likely lifetimes for an emission between the equator and midlatitudes. More detailed modeling is required to derive VSLS lifetimes associated with emission from a specific region and season. A representative range of local lifetimes taken from the 2014 Assessment (Carpenter and Reimann et al., 2014) (Tables 1-5 and 1-11) is given in parentheses where available.

c Italicized values indicate estimated lifetimes when no experimental data on $\mathrm{OH}$ reactivity is available.

d Radiative efficiency values are taken from recommendations given in Hodnebrog et al. (2013) based on a literature review of experimental data and a reanalysis of this information, unless another source is specified in notes to the table.

\section{Lifetime Footnotes:}

$1 \mathrm{OH}$ reaction rate constant was taken from JPL Publication 15-10 (Burkholder et al., 2015b).

$2 \mathrm{OH}$ reactivity assumed the same as $\mathrm{CHF}_{2} \mathrm{CF}_{3}(\mathrm{HFC}-125)$.

$3 \mathrm{OH}$ reactivity calculated using the structure activity relationships of DeMore (DeMore, 1996) assuming an E/R of $1700 \mathrm{~K}$.

$4 \mathrm{OH}$ reactivity calculated using the room-temperature rate constant reported by Young et al. (2009a) assuming an E/R of $1700 \mathrm{~K}$, which is similar to that of $\mathrm{CHF}_{2} \mathrm{CF}_{3}$.

5 OH reactivity taken from the IUPAC (Ammann et al., 2017) recommendation.

6 OH reaction rate constant was taken from Chen et al. (2011).

7 Radiative metrics calculated using the infrared spectrum from Baasandorj and Burkholder (2016).

8 No experimental data were available for $\mathrm{OH}$ reaction rate constants, so lifetimes were estimated based on reactivity trends of fluorinated ethenes and propenes.

9 OH reaction rate constant was taken from Zhang et al. (2015).

10 The atmospheric lifetime and radiative efficiency were calculated using the kinetic and infrared data reported by Baasandorj et al. (2018).

$11 \mathrm{OH}$ reactivity assumed the same as $(E)-\mathrm{CF}_{3} \mathrm{CH}=\mathrm{CHCF}_{3}$.

$12 \mathrm{OH}$ reactivity assumed the same as $\mathrm{CH}_{2}=\mathrm{CHCF}_{3}$.

$13 \mathrm{OH}$ reactivity was recommended by JPL Publication 15-10 based on the room temperature rate constant reported by Sulbaek and Andersen et al. (2005) assuming E/R of -170 , which is similar to that of $\mathrm{CH}_{2}=\mathrm{CHCF}_{3}$.

$14 \mathrm{OH}$ reaction rate constant and radiative efficiency values were taken from Papadimitriou and Burkholder (2016).

$15 \mathrm{OH}$ reactivity calculated using the room temperature $\mathrm{OH}$ rate constant reported by Young et al. (2009b) assuming E/R of -415 $\mathrm{K}$, which is similar to that of $\mathrm{CF}_{3} \mathrm{CF}=\mathrm{CF}_{2}$.

16 Industrial Perfluorobut-2-ene is a mixture of two stereo-isomers, (E)-Perfluoro-2-butene and (Z)-Perfluoro-2-butene, with the ratio of $\sim 71 \%$ and $\sim 29 \%$, respectively. Atmospheric lifetimes of individual isomers are given in Table 2-2.

GWP of the mixture was calculated based on estimated GWPs of individual isomers for each time horizon. The radiative efficiency recommended by Hodnebrog et al. (2013) for $\mathrm{CF}_{3} \mathrm{CF}=\mathrm{CFCF}_{3}$ was used to estimate this parameter for each stereo-isomer, after corresponding corrections to account for its dependence upon lifetimes of the individual stereo-isomers.

$17 \mathrm{OH}$ reaction rate constant was taken from Jia et al. (2013). Radiative efficiency was taken from Jia et al. (2013), and lifetime given here includes the correction suggested by Hodnebrog et al. (2013).

$18 \mathrm{OH}$ reaction rate constant was taken from Zhang et al. (2017). Radiative efficiency was taken from Zhang et al. (2017) and lifetime given here includes the correction suggested by Hodnebrog et al. (2013).

19 Radiative efficiency was taken from Le Bris et al. (2017). 

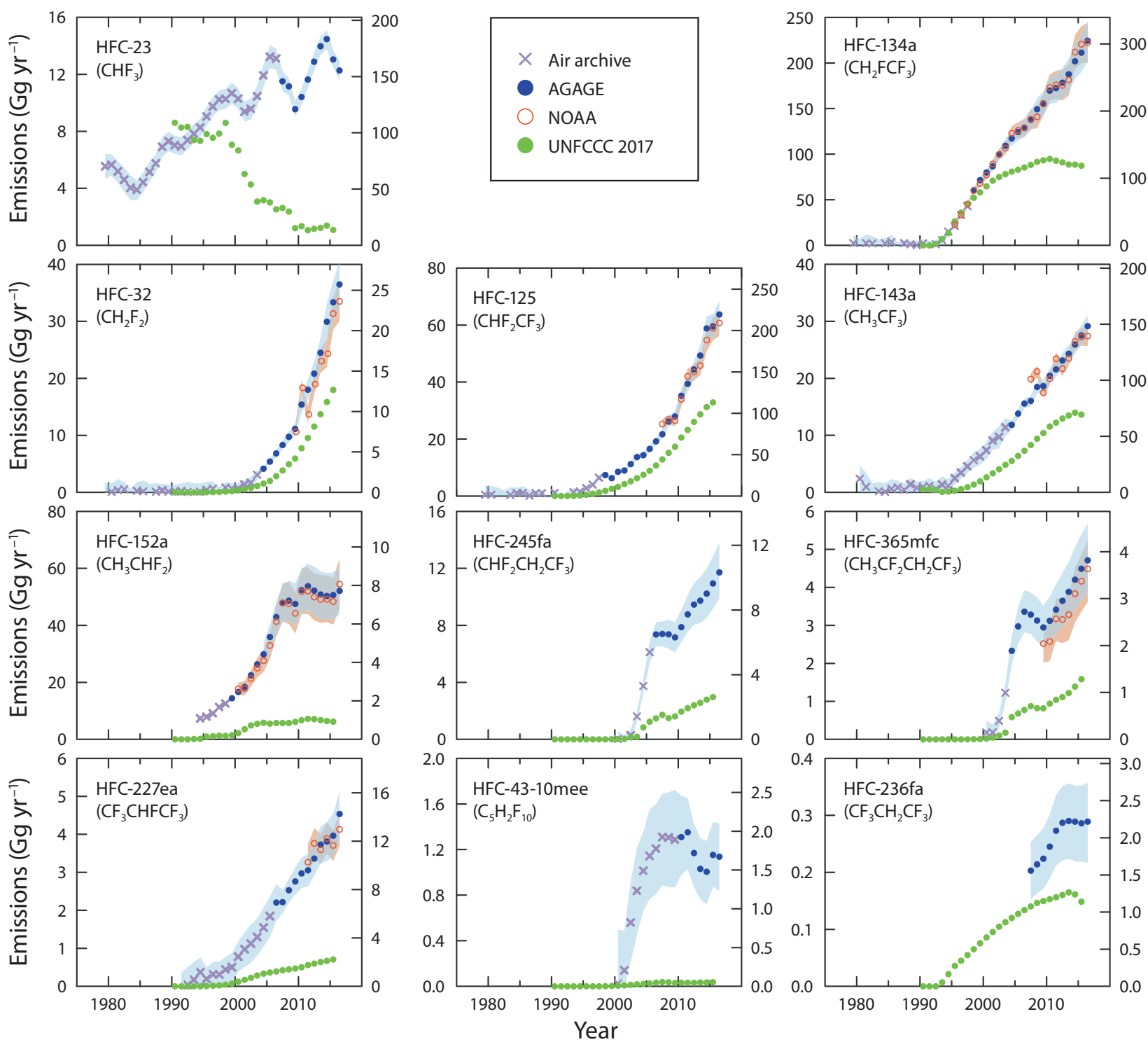

Figure 2-1. Total global emissions estimated from a budget analysis of atmosphere measurements at remote sites (those in Figure 2-2) compared to total emissions reported to UNFCCC (2017). Atmospheric measurement-based emissions are derived with a 12-box model and the lifetimes in Table 2-2; the methods and model

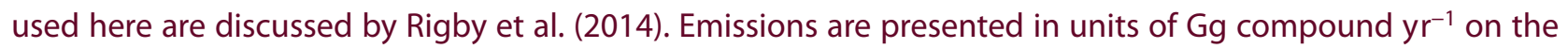
left-hand axis, and the right-hand axis has been scaled by chemical-specific 100-yr GWPs (Table 2-2) to indicate emission magnitudes in $\mathrm{MtCO}_{2}$-eq $\mathrm{yr}^{-1}\left(1 \mathrm{Mt}=10^{12} \mathrm{~g}\right)$. Shaded regions represent 1 standard deviation in global emissions derived from measured mole fractions and a 12-box model (Rigby et al., 2014). Uncertainties in mole fractions and their model representation are propagated through to the posterior emissions estimates using a Bayesian framework. These uncertainties are augmented by lifetime and calibration scale uncertainties following Rigby et al. (2014). The model uses interannually repeating meteorology and, therefore, errors may be underestimated for periods with large circulation changes, although this will likely affect short-term (e.g., annual) variations more than long-term trends. 

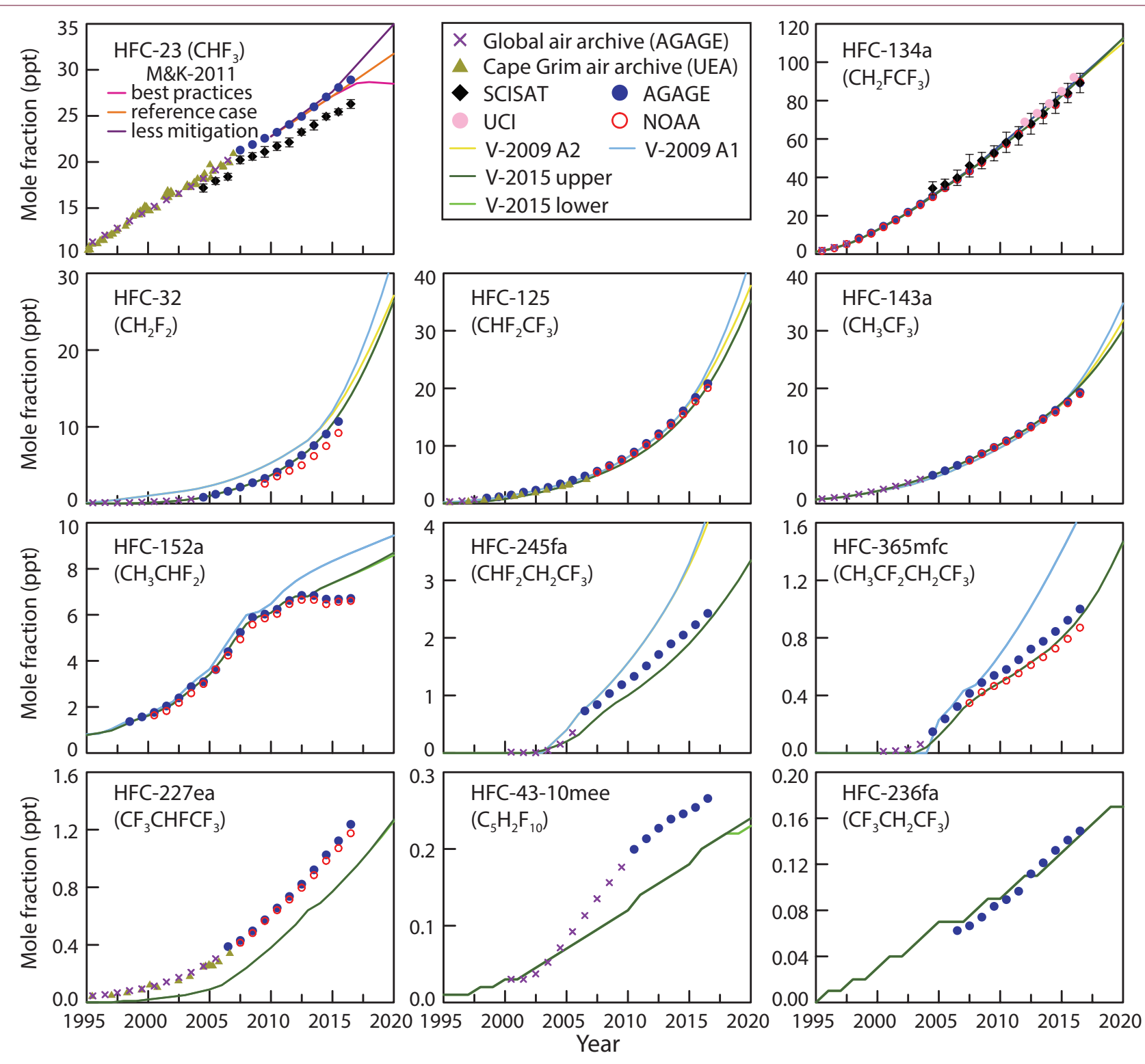

Figure 2-2. Annual mean mole fractions of HFCs and recent projections. Shown are global means estimated from in-situ instrumentation at five remote sites (AGAGE, dark blue filled circles) and independent estimates derived from weekly flasks filled at 8 remote sites (NOAA, open red circles). Global means for HFC-134a from quarterly sampling in the Pacific Basin are also shown (pink filled circles; $\mathrm{UCl}=$ the University of California at Irvine; Simpson et al., 2014). Global means derived from air archives in both hemispheres (AGAGE, purple crosses) (Arnold et al., 2014; O'Doherty et al., 2014; Rigby et al., 2014; Simmonds et al., 2016; Simmonds et al., 2018; Vollmer et al., 2011) are calculated using a 12-box model (Cunnold et al., 1983; Rigby et al., 2013). Results reported for the southern hemisphere from analyses of the Cape Grim Air Archive only are also shown (UEA data, khaki triangles; Oram et al., 1998; Leedham Elvidge et al., 2018). Results from satellite absorption retrievals (SCISAT) represent upper troposphere-lower stratosphere means averaged from $60^{\circ} \mathrm{N}$ to $60^{\circ} \mathrm{S}$ (black diamonds; Nassar et al., 2006; Harrison et al., 2012). Uncertainties on these satellite retrievals represent statistical variability in the data used in the averaging and do not include any systematic errors. Also shown are projections for global means that were considered in the previous Ozone Assessment (V-2009 =Velders et al., 2009; Carpenter and Reimann et al., 2014) and updated projections based on observations through 2012 (V-2015 = Velders et al., 2015; M\&K-2011 = Miller and Kuijpers, 2011). Data are updates to published measurement records (see Table 2-1 for sources not mentioned here). 
Table 2-3. Global surface mean mole fractions of hydrofluorocarbons estimated from ground-based air sampling networks.

\begin{tabular}{|c|c|c|c|c|c|c|c|}
\hline \multirow[t]{2}{*}{ Chemical Formula } & \multirow{2}{*}{$\begin{array}{c}\text { Common or } \\
\text { Industrial Name }\end{array}$} & \multicolumn{3}{|c|}{$\begin{array}{c}\text { Annual Mean } \\
\text { Mole Fraction (ppt) }\end{array}$} & \multicolumn{2}{|c|}{$\begin{array}{c}\text { Change } \\
(2015-2016)\end{array}$} & \multirow[t]{2}{*}{ Network, Method } \\
\hline & & 2012 & 2015 & 2016 & ppt yr ${ }^{-1}$ & $\% y^{-1}$ & \\
\hline $\mathrm{CHF}_{3}$ & HFC-23 & 24.9 & 28.1 & 28.9 & 0.8 & $2.9 \%$ & AGAGE, in situ (Global) \\
\hline \multirow{2}{*}{$\mathrm{CH}_{2} \mathrm{~F}_{2}$} & \multirow{2}{*}{ HFC-32 } & 6.28 & 10.7 & 12.6 & 1.9 & $18 \%$ & AGAGE, in situ (Global) \\
\hline & & 4.97 & 9.18 & 11.2 & 2.0 & $22 \%$ & NOAA, flasks (Global) \\
\hline \multirow{2}{*}{$\mathrm{CHF}_{2} \mathrm{CF}_{3}$} & \multirow{2}{*}{ HFC- 125} & 12.1 & 18.4 & 20.8 & 2.4 & $13.0 \%$ & AGAGE, in situ (Global) \\
\hline & & 11.7 & 17.7 & 20.1 & 2.4 & $13.4 \%$ & NOAA, flasks (Global) \\
\hline \multirow{3}{*}{$\mathrm{CH}_{2} \mathrm{FCF}_{3}$} & \multirow{3}{*}{ HFC-134a } & 67.7 & 83.3 & 89.3 & 6.0 & $7.2 \%$ & AGAGE, in situ (Global) \\
\hline & & 67.5 & 83.4 & 89.6 & 6.1 & $7.4 \%$ & NOAA, flasks (Global) \\
\hline & & 68.9 & 84.9 & 92.1 & 7.2 & $8.5 \%$ & UCl, flasks, (global) \\
\hline \multirow{2}{*}{$\mathrm{CH}_{3} \mathrm{CF}_{3}$} & \multirow{2}{*}{ HFC-143a } & 13.4 & 17.7 & 19.3 & 1.6 & $9.2 \%$ & AGAGE, in situ (Global) \\
\hline & & 13.2 & 17.4 & 19.0 & 1.6 & $9.0 \%$ & NOAA, flasks (Global) \\
\hline \multirow{2}{*}{$\mathrm{CH}_{3} \mathrm{CHF}_{2}$} & \multirow{2}{*}{ HFC-152a } & 6.84 & 6.68 & 6.72 & 0.03 & $0.5 \%$ & AGAGE, in situ (Global) \\
\hline & & 6.65 & 6.57 & 6.61 & 0.04 & $0.6 \%$ & NOAA, flasks (Global) \\
\hline $\mathrm{CHF}_{2} \mathrm{CH}_{2} \mathrm{CF}_{3}$ & HFC-245fa & 1.71 & 2.23 & 2.43 & 0.20 & $8.9 \%$ & AGAGE, in situ (Global) \\
\hline \multirow{2}{*}{$\mathrm{CH}_{3} \mathrm{CF}_{2} \mathrm{CH}_{2} \mathrm{CF}_{3}$} & \multirow{2}{*}{ HFC-365mfc } & 0.72 & 0.92 & 1.00 & 0.08 & $8.4 \%$ & AGAGE, in situ (Global) \\
\hline & & 0.61 & 0.79 & 0.87 & 0.08 & $9.9 \%$ & NOAA, flasks (Global) \\
\hline \multirow{2}{*}{$\mathrm{CF}_{3} \mathrm{CHFCF}_{3}$} & \multirow{2}{*}{ HFC-227ea } & 0.82 & 1.12 & 1.24 & 0.11 & $10.2 \%$ & AGAGE, in situ (Global) \\
\hline & & 0.80 & 1.07 & 1.17 & 0.10 & $9.6 \%$ & NOAA, flasks (Global) \\
\hline $\mathrm{CF}_{3}(\mathrm{CHF})_{2} \mathrm{CF}_{2} \mathrm{CF}_{3}$ & HFC-43-10mee & 0.23 & 0.25 & 0.27 & 0.01 & $4.6 \%$ & AGAGE, in situ (Global) \\
\hline $\mathrm{CF}_{3} \mathrm{CH}_{2} \mathrm{CF}_{3}$ & HFC-236fa & 0.11 & 0.14 & 0.15 & 0.01 & $5.7 \%$ & AGAGE, in situ (Global) \\
\hline
\end{tabular}

Notes:

Stated mole fractions represent independent estimates of global surface means determined by different observational networks at different sampling locations; annual values represent calendar year means. Absolute changes (ppt $\mathrm{yr}^{-1}$ ) are calculated as the difference in annual means; relative changes $\left(\% \mathrm{yr}^{-1}\right)$ are that same difference relative to the 2015 value. Small differences between values from previous Assessments are due to changes in calibration scale and methods for estimating global mean mole fractions from a limited number of sampling sites. These observations are updated from the following sources: Montzka et al., 1996; Miller et al., 2008; Miller et al., 2010; Vollmer et al., 2011; Arnold et al., 2014; Rigby et al., 2014; Simpson et al., 2014; Montzka et al., 2015; Simmonds et al., 2016, 2017, 2018. They are available at http://agage.mit.edu/ (for AGAGE data); at http://www.esrl.noaa.gov/gmd/ dv/site/ (for NOAA data); and at http://ps.uci.edu/ rowlandblake/research_atmos.html (for UCl data). Global mean estimates from AGAGE are calculated using atmospheric data and a 12-box model (Cunnold et al., 1983; Rigby et al., 2013). AGAGE calibrations are as specified in CDIAC (2016) and related primary publications. NOAA-determined values are directly estimated from measurements made at 8 to 12 remote surface sites with cosine-of-latitude weighting.

than global-scale emission estimates. Uncertainties associated with regional-scale inverse analyses, for example, include the inversion setup, the assumed priors, the uncertainty assumed for those priors and for the observations, the geographic extent of the sampling network, and sampling frequency, among other parameters. Furthermore, some emission estimates are derived from observations that have limited spatial coverage and limited sensitivity to emissions across an entire region of interest (countrywide, for example) or incomplete coverage across all seasons. While uncertainties in regional-scale emission estimates would ideally encompass all of these factors, this is often not feasible as this entails estimating uncertainties in parameters with insufficient objective information.

\subsubsection{HFC-134a $\left(\mathrm{CH}_{2} \mathrm{FCF}_{3}\right)$}

HFC-134a remains the most abundant HFC in the global atmosphere and has the largest annual growth rate and emission. The global annual mean mole fraction reached 89.5 ppt in 2016, up from 67.7 ppt in 2012 (AGAGE and NOAA data; UCI results over this period are $\sim 3 \%$ higher; Table 2-3). The rate of increase averaged $5.6 \pm 0.2 \mathrm{ppt} \mathrm{yr}^{-1}\left(7.3 \pm 0.2 \% \mathrm{yr}^{-1}\right)$ during 2012-2016, which is about $0.6 \mathrm{ppt} \mathrm{yr}^{-1}$ larger than the 
mean increase for 2008-2012, as reported in the last Assessment. This observed increase in global mole fraction is similar to that projected nearly a decade ago (Velders et al., 2009) and more recently (Velders et al., 2015); it is also consistent with the largest increases projected in the Representative Concentration Pathways (RCPs), namely RCP8.5 (Figure 2-2; Carpenter and Reimann et al., 2014; Velders et al., 2009; Meinshausen et al., 2011).

Mixing ratios of HFC-134a have been estimated from the ACE-FTS instrument on board SCISAT for recent years (updates to Nassar et al., 2006) using updated absorption cross sections (Harrison, 2015). The upper tropospheric annual means derived for HFC-134a from SCISAT are very consistent with mean mole fractions measured by the surface networks; differences between results from SCISAT and the surface networks are much smaller than the uncertainties associated with the satellite retrievals. Rates of change in HFC-134a mixing ratios determined for 2012-2016 from these independent measurements systems are also consistent, with $7.0 \pm 0.8 \% \mathrm{yr}^{-1}$ derived from annual changes in SCISAT results, $7.3 \pm 0.1 \% \mathrm{yr}^{-1} \mathrm{de}-$ rived from NOAA data, and $7.2 \pm 0.2 \% \mathrm{yr}^{-1}$ derived from AGAGE data (Figure 2-2).

Globally, HFC-134a contributed a radiative forcing (RF) of $14.3 \mathrm{~mW} \mathrm{~m}^{-2}$ in 2016 . This is the largest radiative forcing contributed by any other HFC or other fluorinated gas (i.e., $\mathrm{PFCs}, \mathrm{SF}_{6}, \mathrm{SO}_{2} \mathrm{~F}_{2}$, and $\mathrm{NF}_{3}$; see Chapter 1). The mean rate of increase has been slight-

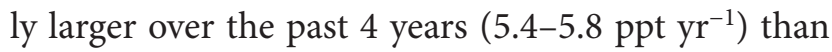

during 2008-2012 (4.9-5.1 ppt $\mathrm{yr}^{-1}$ ). HFC-134a has been used as a substitute for CFC-12 since the mid1990s in mobile air conditioning (MAC), in stationary refrigeration and air conditioning, in metered-dose inhalers, and in foam-blowing applications; it has also been used as a fire suppressant and for dry etching. Due to its high GWP (Table 2-2), controls on HFC134a use have been adopted in some sectors in the E.U., USA, Japan, and other countries (see Section 2.5.1). Refrigerants with substantially lower GWPs such as HFC-1234yf and HFC-1234ze(E), among others, are starting to replace HFC-134a in various applications (see below) (UNEP, 2017a).

Total global emissions of HFC-134a estimated from a budget analysis of measured mole fractions at remote sites increased nearly linearly from $177 \pm 17 \mathrm{Gg}$ $\mathrm{yr}^{-1}$ in 2012 to $223 \pm 22 \mathrm{Gg} \mathrm{yr}^{-1}$ in 2016 (Figure 2-1; update from Rigby et al., 2014; Montzka et al., 2015; Simmonds et al., 2017; AGAGE and NOAA data). Global emissions have increased by an average of 10 $\mathrm{Gg} \mathrm{yr}^{-1}$ since 2008, faster than emissions of any other HFC. Global emissions derived with different modeling frameworks (but these same network data) are consistent with the emissions derived here (FortemsCheiney et al., 2015; Lunt et al., 2015; Xiang et al., 2014).

The total global emissions derived for HFC-134a from atmospheric observations are over two times larger than total emissions reported to UNFCCC from Annex I countries (see Figure 2-3). Furthermore, this emission gap has become larger over time; the

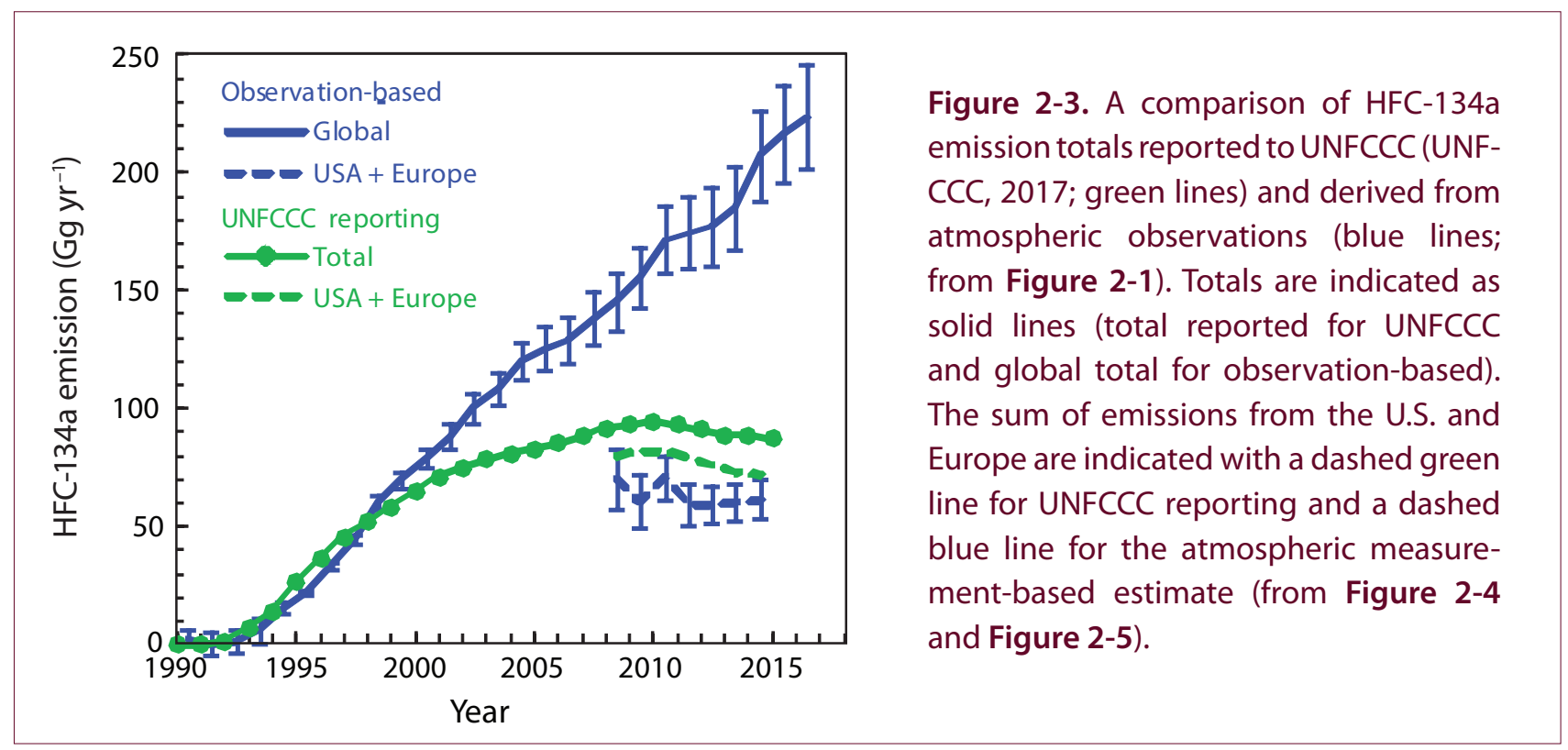


HFC-134a totals reported to UNFCCC have decreased slightly since 2010, in contrast to the increases derived for global total emissions from the atmospheric data (Figure 2-1 and Figure 2-3).

The difference between UNFCCC reporting and atmosphere-based global total emission is not likely from underreporting of emissions from the USA and Europe, the two regions that account for most $(\sim 80 \%)$ emissions reported to the UNFCCC (Figure 2-3). Regional emissions derived from inverse modeling analysis of measurements within the USA and Europe suggest that the inventory-based reporting from these regions is accurate or slightly high (Graziosi et al., 2017; $\mathrm{Hu}$ et al., 2017; Say et al., 2016) (Figure 2-4, Figure 2-5). A similar conclusion was derived for HFC-134a from all Annex I countries from an inverse modeling analysis of measurements at globally-distributed sites (Lunt et al., 2015). For 2014, emissions of HFC-134a from the USA and Europe summed together were 71 $\mathrm{Gg} \mathrm{yr}^{-1}$ in UNFCCC reporting, and they were $61 \pm 8$ $\mathrm{Gg} \mathrm{yr}^{-1}$ from inversion-based modeling analyses of atmospheric observations. The observation-based emissions derived for the USA totaled $43 \pm 6 \mathrm{Gg} \mathrm{yr}^{-1}$ (Hu et al., 2017) and for Europe totaled $18 \pm 6 \mathrm{yr}^{-1}$ (Graziosi et al., 2017) in 2014. Other inversion-based analyses of atmospheric data in Europe suggest European HFC134a emissions that are consistent with those derived in Graziosi et al. for 2009 (Keller et al., 2012); they are between 9 and $16 \mathrm{Gg} \mathrm{yr}^{-1}$ higher in other years (Brunner et al., 2017 for 2011; and Fortems-Cheiney et al., 2015 for multiple years). Slightly higher European emissions
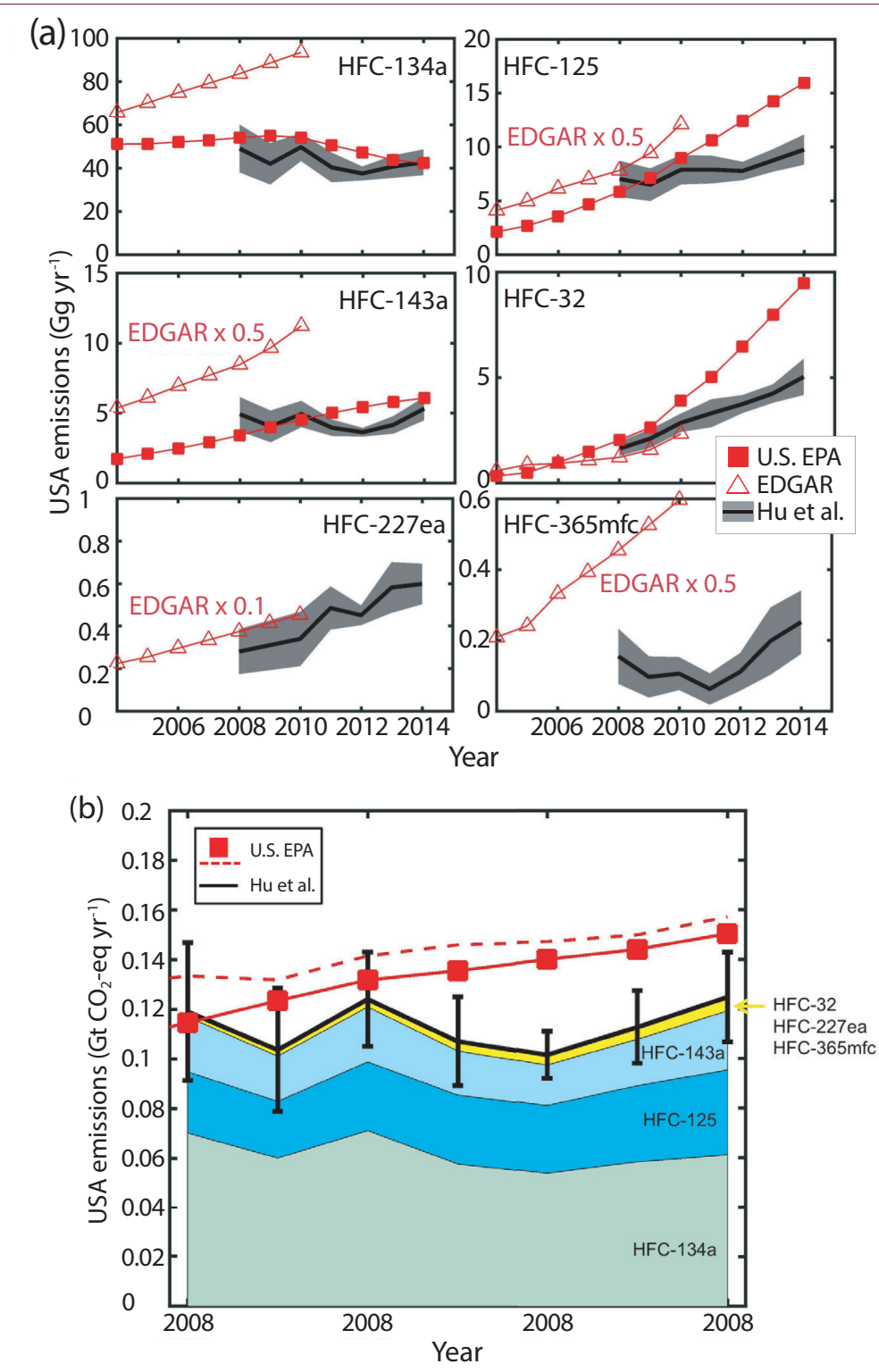

Figure 2-4. USA national HFC emissions estimated from an atmospheric sampling network and from two inventory-based analyses: EDGAR (Emissions Database for Global Atmospheric Research) and U.S. EPA, which is subsequently reposted by UNFCCC (adapted from Hu et al., 2017). a) These six panels show results by compound. b) Aggregated results as $\mathrm{Gt}_{\mathrm{CO}_{2}}$-eq emissions $\mathrm{yr}^{-1}$, with contributions from these six different gases indicated by the different colors. The EPA inventory result for these six gases (solid red line and red-filled symbols in both panels) is shown for comparison, as is the contribution to the inventory totals of additional HFCs not included in the $\mathrm{Hu}$ et al., 2017 study (dashed red line). Uncertainties in both panels represent ranges in derived emissions based on multiple inversions, given uncertainties associated with the sampling network, assumed prior emissions, upwind mole fractions (background conditions), transport models, and meteorology. 

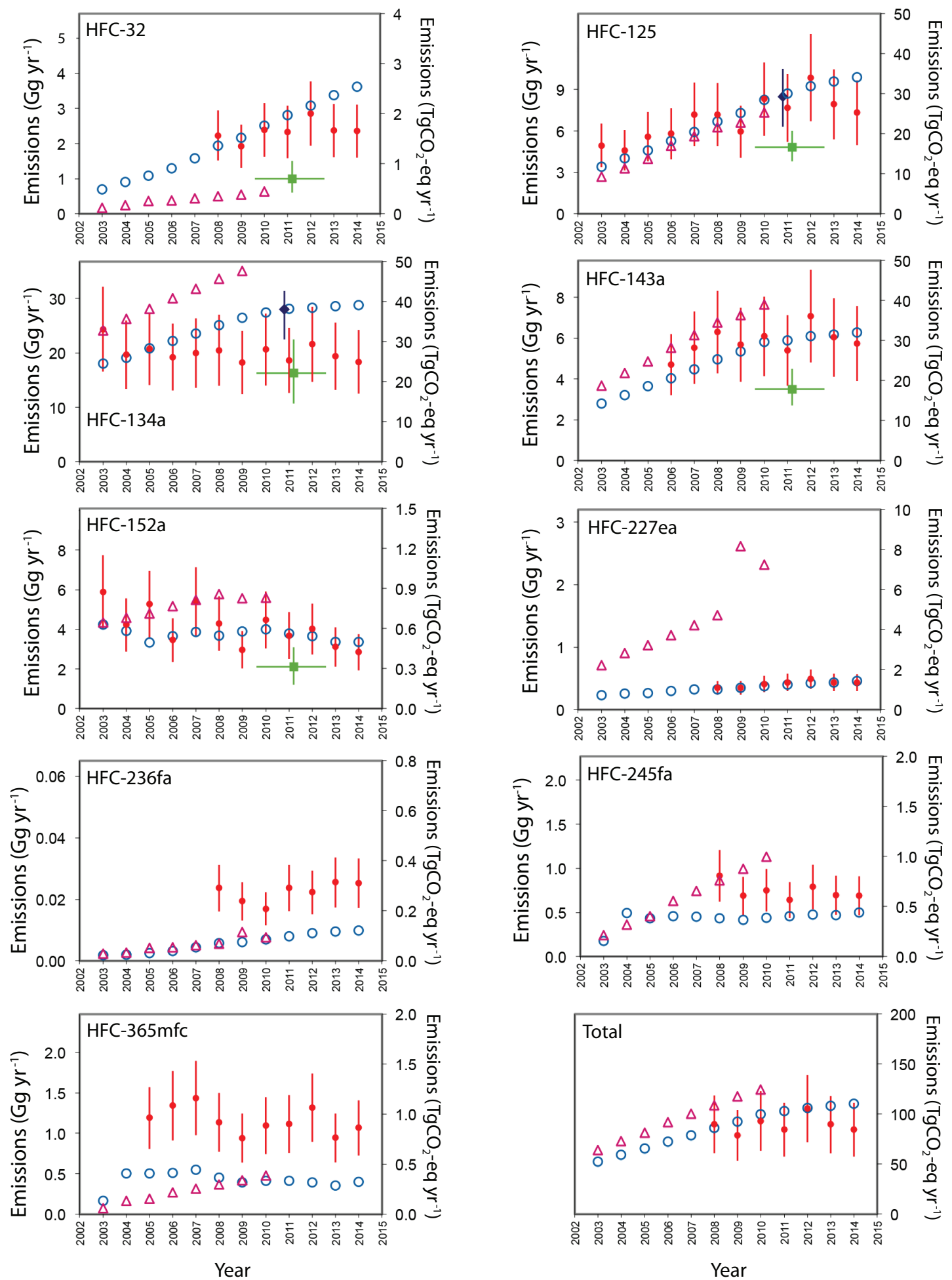

Figure 2-5. Emissions of nine HFCs from the European geographic domain, and related uncertainties, from January 2003 to December 2014. Emissions are given in $\mathrm{Gg} \mathrm{yr}^{-1}$ (left axis) and in $\mathrm{TgCO}_{2}$-eq $\mathrm{yr}^{-1}$ (right axis). The lower right panel (labeled "total") shows aggregated $\mathrm{CO}_{2}$-eq emissions $\mathrm{yr}^{-1}$ from the nine HFCs. Emissions derived from atmospheric measurements are given as red filled circles: Graziosi et al. (2017); green filled squares: Lunt et al. (2015); and dark blue filled diamonds: Brunner et al. (2017). Emissions derived from inventories are shown as light blue unfilled circles (UNFCCC) and purple unfilled triangles (EDGAR v4.2 FT2010). Note that Lunt et al. (2015) and Brunner et al. (2017) data are shifted slightly in time for clarity; the Lunt et al. data are a 3-yr average and the Brunner et al. (2017) data refer to a smaller domain. Note that $100 \mathrm{Tg}=0.1 \mathrm{Gt}$. 
of HFC-134a would make the sum of European and USA emissions more consistent with reporting to the UNFCCC (Figure 2-3). The only other recent analysis of USA emissions based on USA observations (Fortems-Cheiney et al., 2015) suggests between 10 and $20 \mathrm{Gg} \mathrm{yr}^{-1}$ larger emissions than derived in $\mathrm{Hu}$ et al. for the overlapping years of 2008-2010, but these higher values may be less representative of the USA total as they are derived from observations at a smaller number of USA sites.

Most of the remaining HFC-134a emissions reported to the UNFCCC (20\% of reported total) come from Canada, Japan, Australia, and Russia and have ranged from 1.5 to $4 \mathrm{Gg} \mathrm{yr}^{-1}$ per country in recent years. Of these countries, atmosphere measurement-based estimates are available for Japan and Australia. Japanese emissions during 2008 have been estimated at $3.1 \pm$ $0.2 \mathrm{Gg} \mathrm{yr}^{-1}$ in one study (Stohl et al., 2010) and 4.7 (4.5-5) $\mathrm{Gg} \mathrm{yr}^{-1}$ in another (Li et al., 2011); emissions during 2010-2012 were estimated at 3.7 (0.6-7.4) Gg $\mathrm{yr}^{-1}$ in one study (Lunt et al., 2015) and between 2.1 and $4.3 \mathrm{Gg} \mathrm{yr}^{-1}$ in another (Saito et al., 2015). These estimates are not significantly different from the 2.5 to $2.9 \mathrm{Gg} \mathrm{yr}^{-1}$ reported to UNFCCC by Japan in these years, although higher amounts were inferred for 2010 in one study (12 $\pm 2 \mathrm{Gg} \mathrm{yr}^{-1}$; Fortems-Cheiney et al., 2015). Atmosphere-based estimates for Australia for 2006 (4.5 Gg yr ${ }^{-1}$; Stohl et al., 2009) indicate comparable emissions to Japan's, but they are higher than the $1.9 \mathrm{Gg}$ reported by Australia to UNFCCC for that year.

The absence of substantial underestimates in national emissions reported to UNFCCC, as is implied from the above discussion, indicates that the factor of approximately two difference $\left(>100 \mathrm{Gg}^{-1}\right)$ between totals reported to UNFCCC and atmosphere-based global totals likely stems from significant emissions of HFC134a from non-reporting countries (i.e., non-Annex I, developing countries). Regional atmospheric studies in Asia support this conclusion. Emissions for 2008 from East Asia were estimated to be $15-20 \mathrm{Gg} \mathrm{yr}^{-1}$ (based on values from $\mathrm{Li}$ et al., 2011 of 15.2 [12.5-18.6] Gg $\mathrm{yr}^{-1}$ and from Stohl et al., 2010 of $19.2 \pm 2.5 \mathrm{Gg} \mathrm{yr}^{-1}$ ). Atmosphere-based estimates suggest that emissions from China accounted for $8-13 \mathrm{Gg}$ of these East Asian HFC-134a emissions during 2008 (based on estimates of 8.3 [6.2-11] Gg yr${ }^{-1}$ from Li et al., 2011, 8.7 [6.5-12] $\mathrm{Gg} \mathrm{yr}^{-1}$ from Kim et al., 2010, and $12.9 \pm 1.7 \mathrm{Gg} \mathrm{yr}^{-1}$ from Stohl et al., 2010). Emissions at the higher end of this range were derived for 2010-2012 (12 [5-21] Gg $\mathrm{yr}^{-1}$ in Lunt et al., 2015). Based on emissions derived from atmospheric observations, South Korea has accounted for approximately 1-3 Gg yr ${ }^{-1}$ of HFC-134a in recent years (1.5-2.2 $\mathrm{Gg} \mathrm{yr}^{-1}$ for 2008 [Stohl et al., 2010 and Li et al., 2011] and (1.83 [0.58-3.13] Gg yr $\mathrm{r}^{-1}$ for 2010-2012 [Lunt et al., 2015]).

An analysis of HFC production and consumption in China also indicates significant Chinese emissions of HFC-134a and suggests increasing emissions over time with 9.2-11 Gg in 2008 and 33 Gg in 2013 (Su et al., 2015 and Fang et al., 2016). These results and the atmosphere measurement-based estimates, however, suggest that emissions from China account for less than half of the difference between global emissions and totals reported to UNFCCC from Annex I countries (Figure 2-6). As such, they imply that significant emissions of HFC-134a, perhaps as much of $30 \%$ of the global total, are currently arising from non-Annex I countries other than China that are not required to report HFC emissions to the UNFCCC.

\subsubsection{2 $\mathrm{HFC}-23\left(\mathrm{CHF}_{3}\right)$}

HFC-23 is emitted into the atmosphere primarily as a by-product from over-fluorination during HCFC-22 production; much smaller emissions are associated with HFC-23 use as feedstock for halon-1301 production, in semiconductor fabrication (plasma etching and chamber cleaning), in very low-temperature refrigeration, and in specialty fire suppression systems (Miller et al., 2010; Montzka et al., 2010; Oram et al., 1998; Simmonds et al., 2018; US EPA, 2017).

Atmospheric mole fractions of HFC-23 continue to increase in the global atmosphere and reached $28.9 \mathrm{ppt}$ in 2016 (up from 25 ppt in 2012; AGAGE data only; Table 2-3). This global abundance accounted for 5.2 $\mathrm{mW} \mathrm{m} \mathrm{m}^{-2}$ in 2016, the second largest radiative forcing of all individual HFCs and other F-gases (PFCs, $\mathrm{SF}_{6}, \mathrm{NF}_{3}, \mathrm{SO}_{2} \mathrm{~F}_{2}, \mathrm{SF}_{5} \mathrm{CF}_{3}$; see Chapter 1). The HFC-23 global mole fraction increased by $0.83 \mathrm{ppt} \mathrm{yr}^{-1}(2.9 \%$ $\mathrm{yr}^{-1}$ ) in 2015-2016, similar to the $0.9 \mathrm{ppt} \mathrm{yr}^{-1}$ increase measured for 2011-2012 (Carpenter and Reimann et

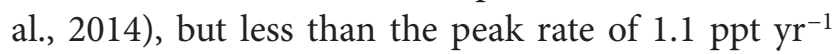
observed during 2014. The average rate of increase for 2012-2016 was $1.0 \mathrm{ppt} \mathrm{yr}^{-1}$, which is slightly faster than

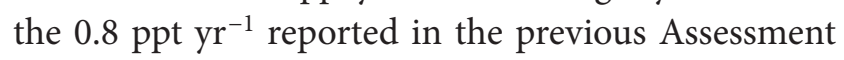
for 2008-2012. In recent years, observed global mole 


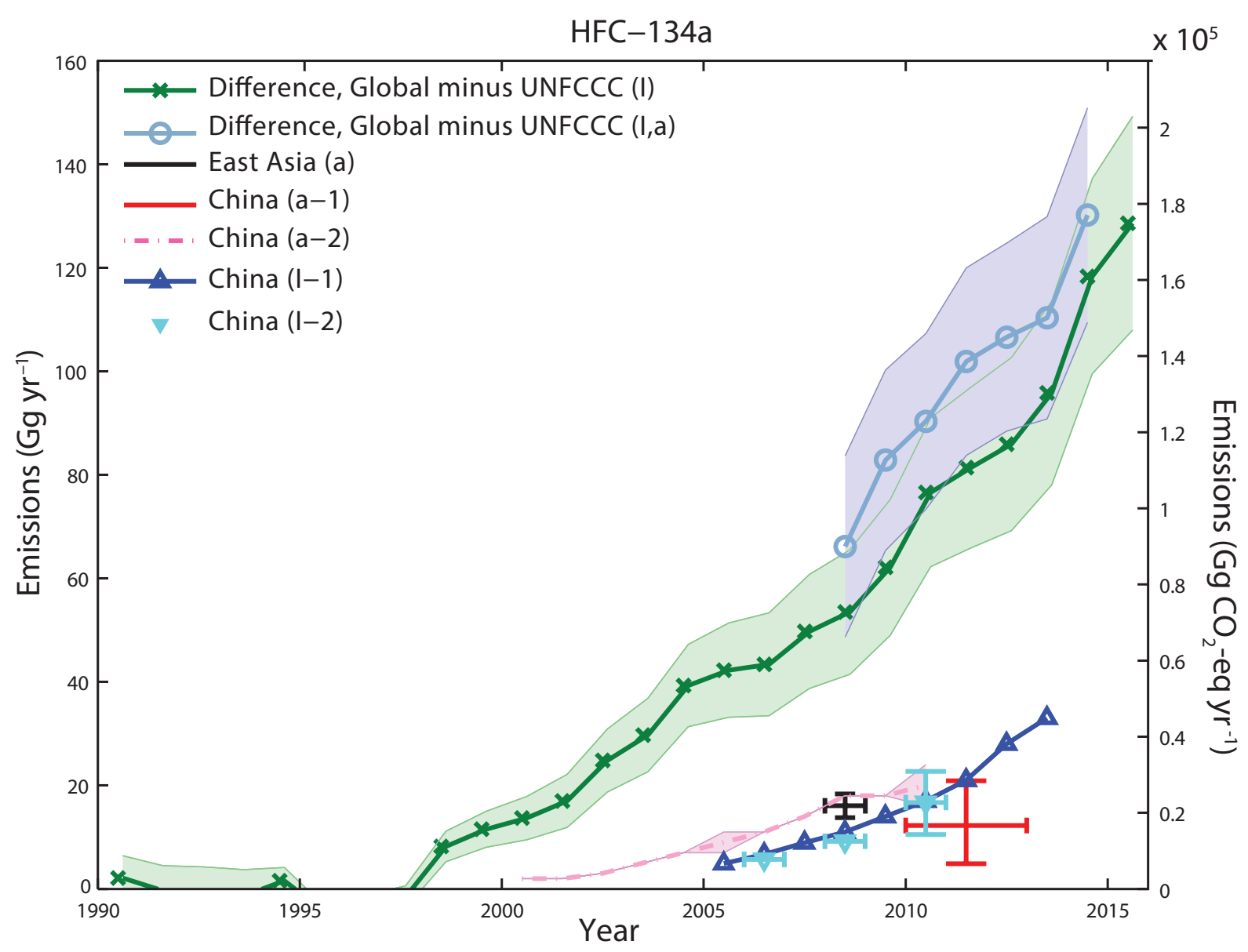

Figure 2-6. Differences between the global emissions derived from atmospheric measurements and the total emissions reported to UNFCCC (UNFCCC, 2017) for HFC-134a. Annual differences between atmosphere-based global total HFC-134a emissions (from Figure 2-1) and inventory-reported totals (UNFCCC, 2017) are plotted as the green line and shading (Global minus UNFCCC(I); shading reflects global emission uncertainties); the dark blue line with shading (Global minus UNFCCC $(I, a))$ represents a similar quantity, but with UNFCCC reporting for the USA and Europe replaced by the regional emission estimates supplied by atmospheric observations in these regions (Hu et al., 2017; Graziosi et al., 2017). Also shown are emissions derived from atmospheric measurements (or other inventory-based estimates) for China and East Asia, which are not obligated to report emissions to the UNFCCC. (These estimates do not represent emissions from all regions not obligated to report to the UNFCCC). East Asian (Stohl et al., 2010, a, black) and Chinese emissions are from inventory-based and atmosphere-based approaches (Lunt et al., 2015, a-1, red; Fortems-Cheiney et al., 2015, a-2, pink and shading; Su et al., 2015, I-2, light blue upside down triangles; Fang et al., 2016, I-1, dark blue triangles).

fractions of HFC-23 are also consistent with the largest emissions projected in the RCPs, which are in RCP8.5 (Meinshausen et al., 2011).

Mixing ratios of HFC-23 have been estimated over time from the ACE-FTS instrument on board the SCISAT satellite (Harrison et al., 2012) using updated absorption cross sections (Harrison, 2013). The upper tropospheric means are approximately 2 ppt below those estimated from surface-based data (AGAGE), although the relative rate of change averaged over 20122016 from the two independent measurements is not significantly different $\left(3.1 \pm 0.8 \% \mathrm{yr}^{-1}\right.$ from SCISAT versus $3.8 \pm 0.6 \% \mathrm{yr}^{-1}$ from AGAGE) (Figure 2-2). 
Total global HFC-23 emissions derived from a budget analysis of measured mole fractions at remote sites show gradual increases before 1999 and then substantial variations, with minima in 2001-2002 and in 2009-2010 and maxima in 2005-2006 and 2013-2014. Derived peak emissions were $14.5 \pm$ $0.7 \mathrm{Gg} \mathrm{yr}^{-1}$ in 2014, and have since decreased, with $12.3 \pm 0.7 \mathrm{Gg} \mathrm{yr}^{-1}$ estimated for 2016 (Figure 2-1, Simmonds et al., 2018).

A comparison between atmospheric measurement-based global emission estimates and Annex I country totals reported to UNFCCC shows fairly good consistency during 1990-1995 (Figure 2-1). After 2000, however, UNFCCC totals decrease and atmospheric measurement-derived global emissions increase. UNFCCC totals were between 1 and $1.5 \mathrm{Gg}$ $\mathrm{yr}^{-1}$ for 2009-2015 while measurement-based global emission totals ranged between 9.5 and $15 \mathrm{Gg} \mathrm{yr}^{-1}$. This difference increased concurrently with the substantial increases in HCFC-22 production and associated HFC-23 emission from developing countries not required to report HFC emissions to the UNFCCC (i.e., non-Annex I countries) (Miller et al., 2010; Montzka et al., 2010; Simmonds et al., 2018).

Inventory-based emissions of HFC-23 from countries not obligated to report emissions to the UNFCCC are derivable from information provided to the Montreal Protocol's Multilateral Fund (MLF) by these countries (UNEP, 2017b; Simmonds et al., 2018). These inventory emissions of HFC-23 are estimated in some countries and, in others, are derived from a combination of country-based reporting of HCFC-22 production for all uses, HFC-23 production rates, and quantities of HFC-23 destroyed or otherwise transformed as feedstock.

The sum of inventory-based emissions derived from reporting to the UNFCCC and estimated using the information collected by the Montreal Protocol's MLF fairly closely tracks the wide swings in global emissions derived from atmospheric mole fraction measurements (Figure 2-7), although emissions in a few years (e.g., 2008,2013 , and 2015) are significantly underestimated by these inventories (Simmonds et al., 2018). This overall consistency suggests that the inventory-derived HFC-23 emissions associated with HCFC-22 production are fairly accurately estimated (within $\pm 2 \mathrm{Gg}$ in total) in both developed and developing countries.
This consistency also provides an understanding of HFC-23 emission changes over the past decade. The minimum in emissions centered around 2009-2010 stems from a significant decrease in the ratio of HFC23 emission relative to HCFC-22 production $\left(\mathrm{E}_{23} / \mathrm{P}_{22}\right)$ (Figure 2-7), which was primarily the result of HFC23 destruction facilitated by the UNFCCC's CDM projects (Miller et al., 2010; Montzka et al., 2010). The subsequent increase in HFC-23 emissions after 2010 appears to be the result of increases in total HCFC22 production and slight increases in the $\mathrm{E}_{23} / \mathrm{P}_{22}$ ratio as the CDM projects were terminated. The $\sim 2 \mathrm{Gg}$ decrease in annual emissions after 2014 is associated with slightly reduced total HCFC-22 production as dispersive-use production was capped in 2013, although a much larger emission decline was expected in 2015 from inventory reporting than is apparent in the measurement-derived emission estimate for that year. The decline in reported emissions in 2015 is due primarily to a drop in the reported $\mathrm{E}_{23} / \mathrm{P}_{22}$ ratio (Figure 2-7).

The inventory-based reporting totals also suggest a significant shift in regions emitting HFC-23 in the past. Emissions were primarily from the USA, Russia, the UK, and Japan during the early 1990s. Since 2009, however, between $84 \%$ and $89 \%$ of global HFC-23 emissions have come from China, which is consistent with China being the largest producer of HCFC-22 in recent years in reporting to the UN Environment Ozone Secretariat (UNEP, 2017b; Simmonds et al., 2018).

Independent evidence for substantial HFC-23 emissions from non-Annex I countries in recent years comes from a number of observational studies, although measurements have not been conducted near all developing countries reporting HFC-23 emission (i.e., Argentina, China, India, Mexico, North Korea, and Venezuela). Emissions from China, for example, were estimated for 2008 from observations in eastern Asian countries and different data analysis methods and range between 6 and $12 \mathrm{Gg} \mathrm{yr}^{-1}$ (based on estimates from Stohl et al. [2010] of $6.2 \pm 0.7 \mathrm{Gg}$ $\mathrm{yr}^{-1}$, Fang et al., [2015] of $6.2 \pm 0.6 \mathrm{Gg} \mathrm{yr}^{-1}$, Li et al. [2011] of 10 (7.2-13) $\mathrm{Gg} \mathrm{yr}^{-1}$, and Kim et al. [2010] of $\left.12(8.6-15) \mathrm{Gg} \mathrm{yr}^{-1}\right)$. The lower end of this range is in good agreement with the inventory-based estimates provided to the MLF from China of $5.7 \mathrm{Gg}$ $\mathrm{yr}^{-1}$ for 2008 (UNEP, 2017b; Simmonds et al., 2018). For comparison, total global emissions derived from 


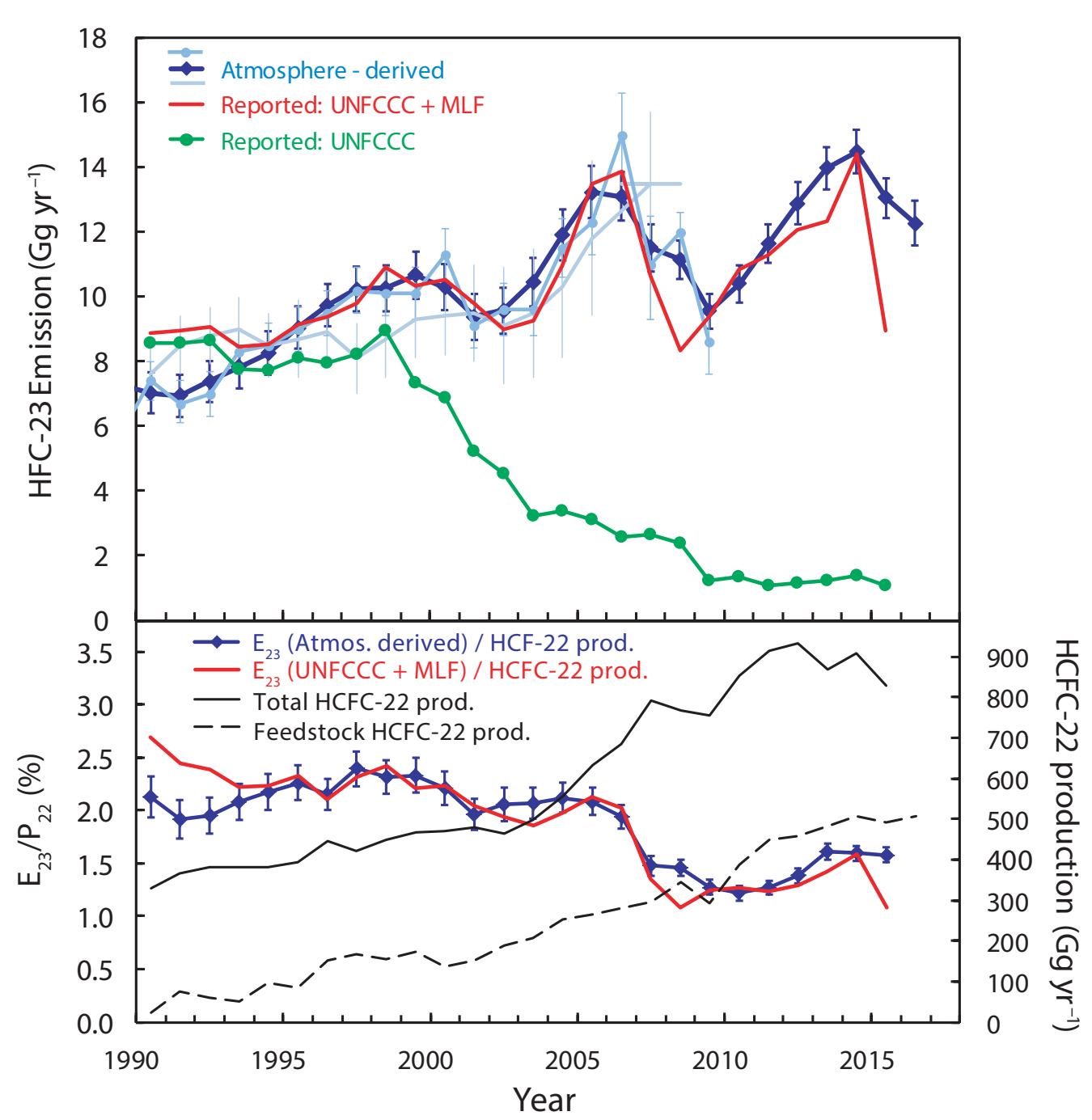

Figure 2-7. Top panel: Emissions of HFC-23 derived from atmospheric measurements (blue lines) and inventories (red and green lines). Measurement-based emissions are derived from analyses of southern-hemispheric firn air (light-blue line; Montzka et al., 2010), a southern-hemispheric air archive before 2007 coupled with ongoing results from multiple sites during 2007-2009 (light blue circles; Miller et al., 2010), and from a combination of air-archive, firn air, and ongoing measurements (dark blue diamonds; Simmonds et al., 2018). Uncertainties are one standard deviation of estimates. Inventory results are from Annex I reporting to UNFCCC (green line with filled circles; UNFCCC, 2017) and from the sum of reporting to UNFCCC and to the Montreal Protocol's Multilateral Fund (MLF; red line, Simmonds et al., 2018). Bottom panel: the ratio of HFC-23 emissions relative to HCFC-22 production for all uses $\left(E_{23} / P_{22}\right.$ by mass, left-hand axis; with emissions being the total from inventories (red) or global magnitudes estimated from atmospheric measurements and their uncertainty (blue line) from the upper panel, and total global HCFC-22 production reported for all uses (black line; right-hand axis) and for feedstock only (black dashed line; right-hand axis).

measured atmospheric changes at remote sites was $11.2 \pm 0.6 \mathrm{Gg} \mathrm{yr}^{-1}$ in 2008 .

By 2012, atmospheric measurement-based analyses indicated that HFC-23 emissions from China accounted for at least two-thirds of global HFC-23 emissions. Atmospheric observations in that year suggest Chinese emissions of $8.8 \pm 0.8 \mathrm{Gg} \mathrm{yr}^{-1}$ (Fang et al., 2015) compared to the $10.8 \mathrm{Gg} \mathrm{yr}^{-1}$ estimate provided to the MLF (UNEP, 2017b; Simmonds et al., 2018), while the atmosphere measurement-based global estimate in 2012 was $12.9 \pm 0.7 \mathrm{Gg} \mathrm{yr}^{-1}$ and UNFCCC 
Annex I reporting totaled $1.2 \mathrm{Gg} \mathrm{yr}^{-1}$. A small fraction of the global emission arises from other non-Annex I countries such as South Korea and Taiwan (Stohl et al., 2010; Li et al., 2011; Fang et al., 2015), 0.1-0.2 Gg $\mathrm{yr}^{-1}$ in 2008 (compared to the estimates derived from information provided to the MLF of less than $0.1 \mathrm{Gg}$ $\mathrm{yr}^{-1}$ for South Korea). Analyses of atmospheric observations also indicate that emissions from Japan were 0.2-0.3 Gg yr ${ }^{-1}$ in 2008 (Stohl et al., 2010; Li et al., 2011; Fang et al., 2015), somewhat larger than the 0.04 $\mathrm{Gg} \mathrm{yr}^{-1}$ reported to UNFCCC, while European emissions (Keller et al., 2011; Simmonds et al., 2018) are similar or slightly larger than the UNFCCC submission values.

\subsubsection{HFC-32 $\left(\mathrm{CH}_{2} \mathrm{~F}_{2}\right)$, $\mathrm{HFC}-125\left(\mathrm{CHF}_{2} \mathrm{CF}_{3}\right)$, HFC-143a $\left(\mathrm{CH}_{3} \mathrm{CF}_{3}\right)$}

Global mean mole fractions of HFC-32, HFC-125, and HFC-143a continue to rise in the atmosphere primarily because these chemicals are used as HCFC substitutes in major refrigeration blends (HFC-125 also has a minor application for fire protection) (O'Doherty et al., 2014; Montzka et al., 2015; Simmonds et al., 2015, 2017; US EPA, 2017). In 2016, average global mean mole fractions were 11.9 (11.2-12.6) ppt for HFC-32, 20.4 (20.1-20.8 ppt) for HFC-125, and 19.2 (19.019.3) ppt for HFC-143a (NOAA and AGAGE data; Table 2-3). These mole fractions are approximately twice the 2012 values for HFC-32 and HFC-125, and are $50 \%$ higher for HFC-143a. Mole fractions of these HFCs increased during 2012-2016 by an average of 1.6

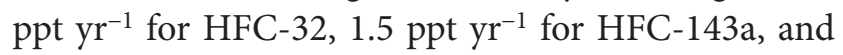

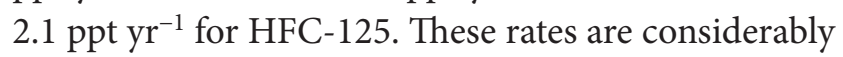
larger than measured during 2008-2012 as reported in the previous Assessment, by a factor of 1.7 for HFC-32 and HFC-125, and by a factor of 1.2 for HFC-143a.

The mole fraction increases observed for these gases since 2007 are similar to the scenario projections discussed in the previous Assessment (Figure 2-2; Carpenter and Reimann et al., 2014; Velders et al., 2009) and to those in newer scenarios (Velders et al., 2015), although projected HFC-32 mole fractions were slightly higher than observed.

The radiative forcings associated with these 2016 global mole fractions were $1.31(1.23-1.39) \mathrm{mW} \mathrm{m}^{-2}$ from HFC-32, 4.70 (4.62-4.79) $\mathrm{mW} \mathrm{m}^{-2}$ from HFC-125, and $3.06(3.04-3.09) \mathrm{mW} \mathrm{m}^{-2}$ from HFC-143a.
Total global emissions of these three HFCs derived from a budget analysis of measured mole fractions at remote sites continue to increase, with estimates for 2016 of $35 \pm 4 \mathrm{Gg} \mathrm{yr}^{-1}$ for HFC-32, $62 \pm 5 \mathrm{Gg} \mathrm{yr}^{-1}$ for HFC-125 and $28 \pm 2 \mathrm{Gg} \mathrm{yr}^{-1}$ for HFC-143a. These were higher than their 2012 emissions of $20 \mathrm{Gg} \mathrm{yr}^{-1}$, $44 \mathrm{Gg} \mathrm{yr}^{-1}$, and $22 \mathrm{Gg} \mathrm{yr}^{-1}$, respectively (Figure 2-1; update from O'Doherty et al., 2009, 2014; Rigby et al., 2014; Lunt et al., 2015; Montzka et al., 2015; and Simmonds et al., 2017). In 2014, the global emission estimates for each of these three gases were about two times higher than the corresponding UNFCCC totals from reporting countries.

As was true for HFC-134a, the difference between UNFCCC reporting and atmosphere-based global total emission for these three gases is not likely from underreporting of emissions from the USA and Europe, the two regions that account for most emissions reported to UNFCCC ( 83-90\%). Regional emission magnitudes derived from measurements within the USA and Europe suggest that the inventory-based reporting from these regions is accurate or even overestimated. In Europe, atmosphere-based emissions estimated for these gases have been consistent with values reported to UNFCCC in most recent years; an exception is that UNFCCC reporting for HFC-32 has increased above the atmosphere-based estimates in the most recent years (Figure 2-5) (Graziosi et al, 2017; Brunner et al., 2017). A similar divergence is observed in the USA for HFC-32 and HFC-125, with the UNFCCC inventory increasing faster than atmosphere-based estimates (Figure 2-4); this divergence is less pronounced for HFC-143a. For Japan, both atmosphere-based estimates (Saito et al., 2015; Lunt et al., 2015) and UNFCCC reporting suggest Japanese emissions are $<2 \mathrm{Gg} \mathrm{yr}^{-1}$ for each of these gases.

The absence of substantial underestimates in national emissions reported to UNFCCC for these three HFCs indicates that the factor of approximately two difference in reporting totals versus atmosphere-based global totals likely stems from significant emissions from developing countries not required to report their emissions to UNFCCC (non-Annex I). This conclusion has also been reached in an analysis of production estimates and market demand in developing countries, based on the Montreal Protocol phase-out schedules for ODSs (Fang et al., 2016; Zhang and Wang, 2014; Velders et al., 2015). 
Emissions estimates based on atmospheric measurements in East Asia confirm substantial HFC-32 emissions from non-Annex I countries. Averaged over 2010-2012, Chinese emissions of HFC-32 were estimated to be 7.0 (4.9-9.2) $\mathrm{Gg} \mathrm{yr}^{-1}$ and those from South Korea were estimated at $0.43(0.1-0.52) \mathrm{Gg} \mathrm{yr}^{-1}$ (Lunt et al., 2015). These Chinese emissions are larger than the mean emissions estimated for the USA of 3.3 $\pm 0.5 \mathrm{Gg} \mathrm{yr}^{-1}$ (Hu et al., 2017) or for Europe of $2.5 \pm 0.9$ $\mathrm{Gg} \mathrm{yr}^{-1}$ (Graziosi et al., 2017) during these same years. They also are significantly larger than those from Japan (0.5-0.7 Gg yr ${ }^{-1}$ ) (Lunt et al., 2015; Saito et al., 2015).

Consideration of HFC-32 production and consumption magnitudes along with use patterns has allowed inventory-based emission estimates in China. This analysis suggests emissions of $12 \mathrm{Gg} \mathrm{yr}^{-1}$ of HFC-32 in 2013 and $7.7 \mathrm{Gg} \mathrm{yr}^{-1}$ for 2010-2012 (Fang et al., 2016), consistent with the atmosphere-based regional estimate from Lunt et al. quoted above (7.0 [4.9-9.2]

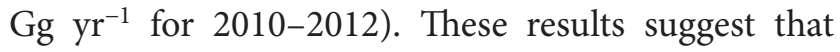
substantial emissions of HFC-32 have arisen from China as a result of the phase-out of ODSs and that these Chinese emissions explain most if not all of the difference between global estimates and totals being reported to UNFCCC for this chemical (Figure 2-8).

Atmosphere-based studies also suggest substantial emissions of HFC-125 from non-Annex I countries (Figure 2-9). Emissions from China averaged over 2010-2012 were 5.7 (4.0-7.7) $\mathrm{Gg} \mathrm{yr}^{-1}$, and those from South Korea were substantially smaller $(0.5$ [0.3-0.7]

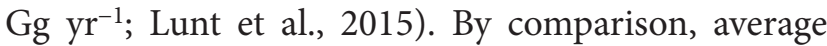
emission during this period was estimated to be $7.9 \pm$ $1.2 \mathrm{Gg} \mathrm{yr}^{-1}$ from the USA (Hu et al., 2017) and $8.6 \pm$ $2.7 \mathrm{Gg} \mathrm{yr}^{-1}$ from Europe (Graziosi et al., 2017). Smaller emissions of 0.8 (0.3-1.5) $\mathrm{Gg} \mathrm{yr}^{-1}$ were estimated from Japan for 2010-2012 (Lunt et al., 2015).

Consideration of HFC-125 production and consumption magnitudes along with use patterns has allowed inventory-based emission estimates in China. This analysis suggests emissions of $6.3 \mathrm{Gg} \mathrm{yr}^{-1}$ averaged over 2010-2012 and $12 \mathrm{Gg} \mathrm{yr}^{-1}$ of HFC-125 in 2013 (Fang et al., 2016), consistent with the atmosphere-based regional estimate from Lunt et al. (2015). While these

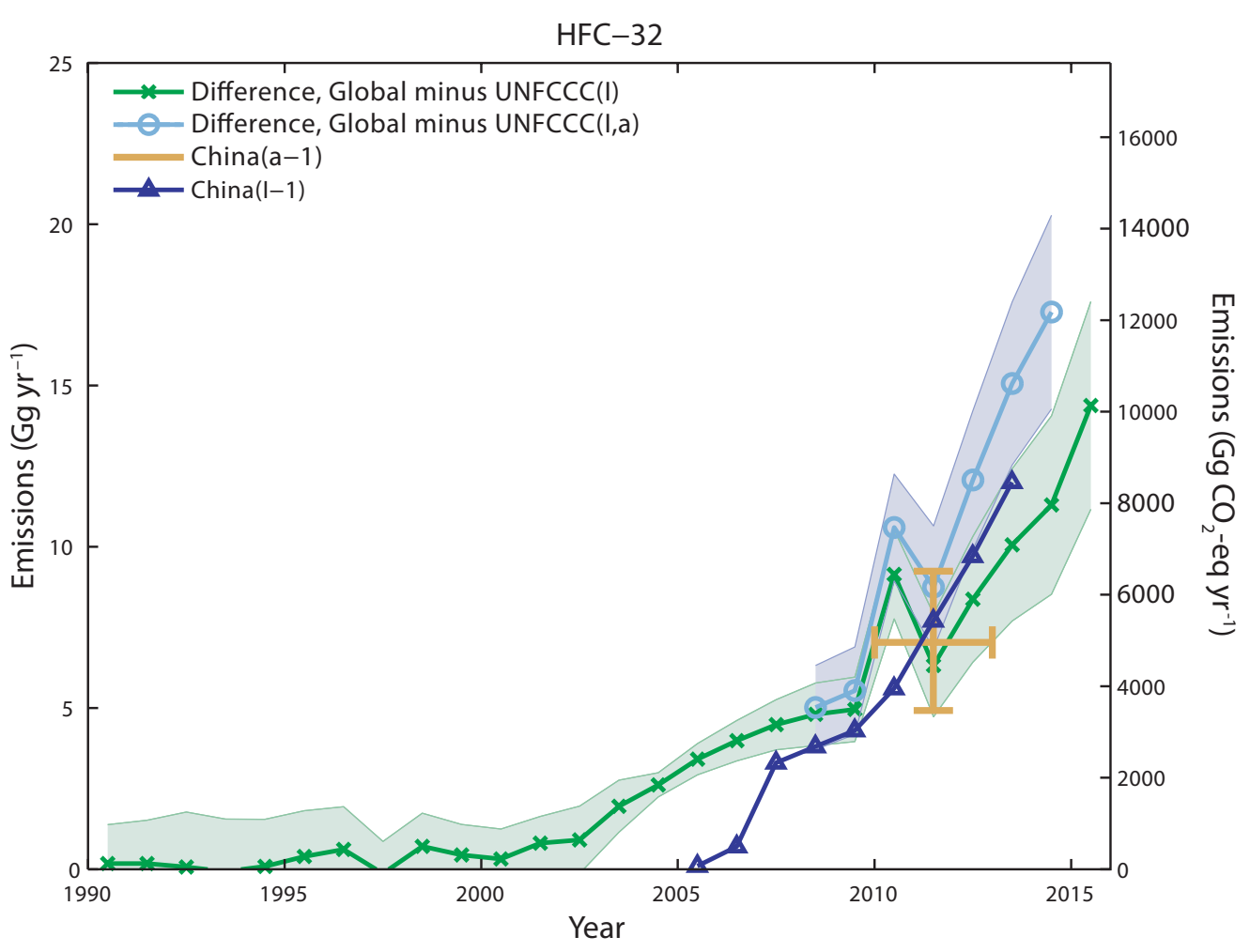

Figure 2-8. As in Figure 2-6, but for HFC-32. Here Chinese emissions are from inventory-based (Fang et al., 2016; I-1, blue triangles) and atmosphere-based (Lunt et al., 2015, a-1, yellow) estimates. 


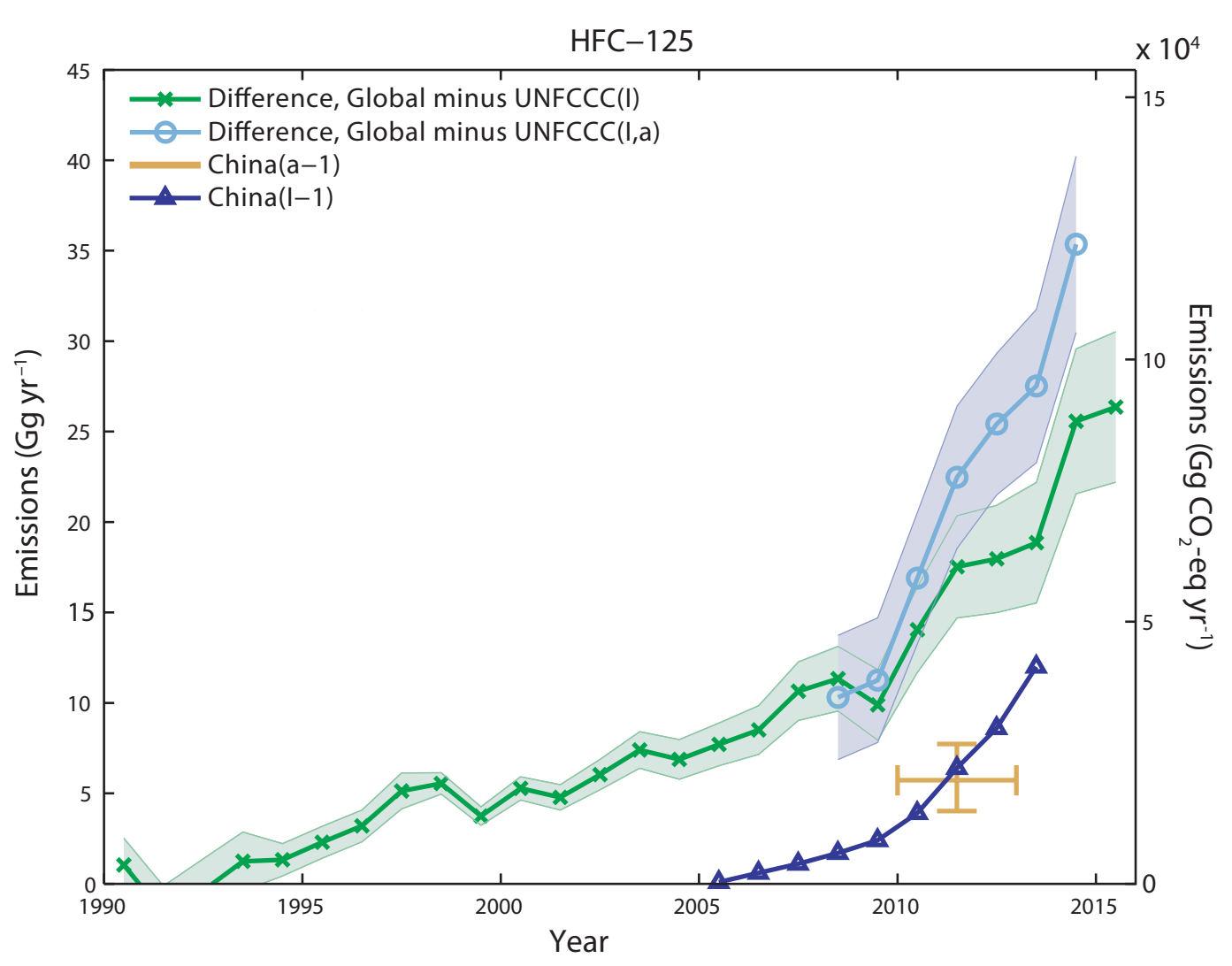

Figure 2-9. As in Figure 2-8, but for HFC-125.

results indicate increasing emissions of HFC-125 from China during the phase-out of ODSs, they also demonstrate that Chinese emissions explain only approximately half of the difference between global emissions of HFC-125 and totals reported to UNFCCC (Figure 2-9). This difference suggests substantial emissions of HFC-125 from other non-Annex I countries not required to report emissions to the UNFCCC.

Atmosphere-based studies also suggest substantial emissions of HFC-143a from non-Annex I countries (Figure 2-10). Emissions from China averaged over 2010-2012 were 2.1 (1.3-3.1) $\mathrm{Gg} \mathrm{yr}^{-1}$, and those from South Korea were 0.13 (0.06-0.21) $\mathrm{Gg} \mathrm{yr}^{-1}$ (Lunt et al., 2015). By comparison, during this period emissions of $4.2 \pm 0.7 \mathrm{Gg} \mathrm{yr}^{-1}$ were estimated from the USA (Hu et al., 2017) and $6.2 \pm 2.1 \mathrm{Gg} \mathrm{yr}^{-1}$ from Europe (Graziosi et al., 2017). Smaller emissions were estimated from Japan (0.3 [0.1-0.6] $\left.\mathrm{Gg} \mathrm{yr}^{-1}\right)$ and S.E. Australia (0.2 [0.1-0.5] $\mathrm{Gg} \mathrm{yr}^{-1}$ ) for 2010-2012 (Lunt et al., 2015).

Consideration of HFC-143a production and consumption magnitudes along with use patterns has allowed inventory-based emission estimates in China. This analysis suggests Chinese emissions of $3 \mathrm{Gg} \mathrm{yr}^{-1}$ of HFC-143a in 2012 (Fang et al., 2016), consistent with the atmosphere-based regional estimate from Lunt et al. (2015), likely as a result of the phase-out of ODSs. As was true for HFC-125, Chinese emissions account for less than half of the difference between global estimates and totals being reported to UNFCCC for HFC143a (Figure 2-10).

\subsubsection{HFC-152a $\left(\mathrm{CH}_{3} \mathrm{CHF}_{2}\right)$}

The global annual average HFC-152a mole fraction has varied relatively little over the past 4 years, between 6.5 and $6.8 \mathrm{ppt}$ (AGAGE and NOAA data; $6.8 \mathrm{ppt}$ was measured in 2012; Carpenter and Reimann et al., 2014). This is notably different from projections, which have suggested HFC-152a mole fractions would increase over time (Figure 2-2; Carpenter and Reimann et al., 2014; Velders et al., 2009, 2015). The global abundance in 2014 contributed a radiative forcing of $0.67 \mathrm{~mW}$ $\mathrm{m}^{-2}$, relatively little compared to the HFCs discussed above. HFC-152a is used as a foam-blowing agent, 


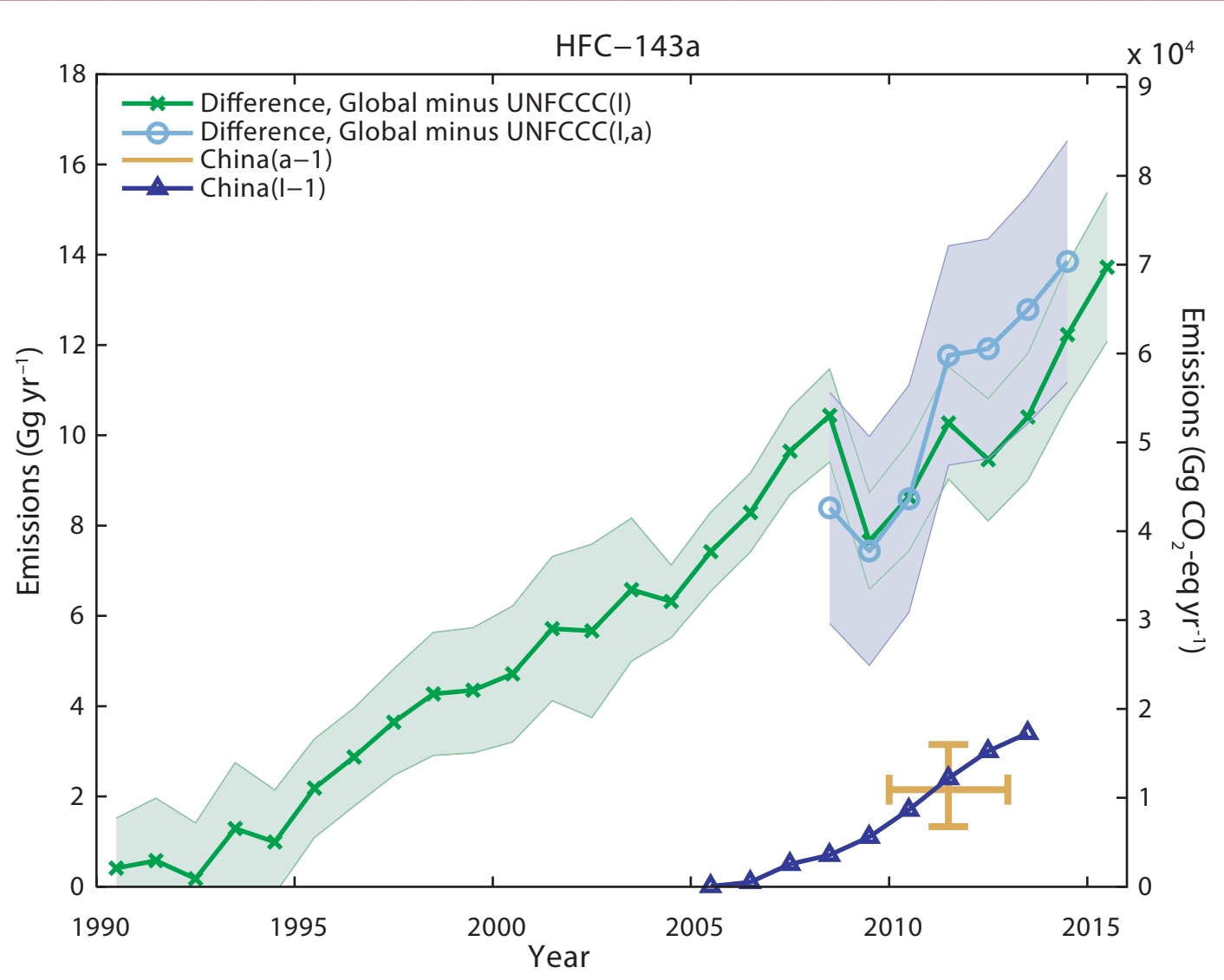

Figure 2-10. As in Figure 2-8, but for HFC-143a.

aerosol propellant, and in some refrigeration blends to replace CFCs, HCFCs, and recently HFC-134a in automobile air conditioners (Simmonds et al., 2016; UNEP, 2017a; US EPA, 2017).

Total global HFC-152a emission derived from a budget analysis of measured mole fractions at remote sites was $53 \mathrm{Gg} \mathrm{yr}^{-1}$ in 2016, not appreciably different from the $51 \pm 8 \mathrm{Gg} \mathrm{yr}^{-1}$ estimated for all years since 2010 (Figure 2-1, update from Rigby et al., 2014, Lunt et al., 2015, Montzka et al., 2015 and Simmonds et al., 2016). While HFC-152a emissions are larger than most other HFCs, its impact on atmospheric concentrations and climate is relatively small because its lifetime (1.6 yr) and associated GWP $(100-y r$ GWP $=148)$ are small compared to most other HFCs whose production and consumption is also controlled by the Kigali Amendment to the Montreal Protocol.

HFC-152a emissions reported to UNFCCC account for only 10 to $15 \%$ (6 to $7 \mathrm{Gg} \mathrm{yr}^{-1}$ for 2009-2015) of the global totals derived from measured atmospheric changes in the remote atmosphere. A likely reason for this large difference is that emissions of HFC-152a from the USA are not included in UNFCCC totals considered here and displayed in Figure 2-1. This is because emissions totals of HFC-152a are only reported by the U.S. Environmental Protection Agency (EPA) to the UNFCCC together with other chemicals (HFC-227ea, HFC-245fa, HFC-43-10mee, some hydrofluoroolefins (HFOs), and some minor PFCs) owing to confidentiality issues. If half of the $10.7 \mathrm{MtCO}_{2}$-eq total reported by the USA for this mix in 2015 was due to emissions of HFC-152a, it would account for approximately 36 $\mathrm{Gg} \mathrm{yr}^{-1}$ of HFC-152a emission, or most of the $\sim 45 \mathrm{Gg}$ difference shown in Figure 2-1 between reported and atmosphere measurement-derived estimates in recent years.

Atmospheric observations from limited regions using different modeling/inversion techniques provide evidence for substantial USA HFC-152a emissions in recent years: $10-15 \mathrm{Gg} \mathrm{yr}^{-1}$ in 2005-2006 (Stohl et al., 2009), 25 (11-50) Gg yr ${ }^{-1}$ in 2004-2009 (Miller et al., 2012), $32 \pm 4 \mathrm{Gg} \mathrm{yr}^{-1}$ in 2008 (Barletta et al., 2011), 28 
(23-33) $\mathrm{Gg} \mathrm{yr}^{-1}$ in 2007-2009 and 32 (25-39) $\mathrm{Gg} \mathrm{yr}^{-1}$ in 2010-2012 (Lunt et al., 2015; Simmonds et al., 2016).

HFC-152a emissions from Europe have been estimated at $2.9 \mathrm{Gg} \mathrm{yr}^{-1}$ in 2009 (Keller et al., 2012), 4.1-7.5 Gg $\mathrm{yr}^{-1}$ in 2007-2012 (Lunt et al., 2015; Simmonds et al., 2016), and an average of $4.1 \pm 1.0 \mathrm{Gg} \mathrm{yr}^{-1}$ over 20032014, with a slight decreasing trend over this period (Graziosi et al., 2017; uncertainty represents 1 standard deviation of annual estimates). These magnitudes and the decreasing trend are consistent with values reported to UNFCCC over this period (Graziosi et al., 2017).

Evidence exists for substantial HFC-152a emissions from countries not required to report emissions to the UNFCCC. Atmospheric measurements in eastern Asia suggest emissions of $\sim 5 \mathrm{Gg} \mathrm{yr}^{-1}$ (Stohl et al., 2010) and $6.8 \mathrm{Gg} \mathrm{yr}^{-1}$ (Li et al., 2011) in 2008, 6.2 (5-9) $\mathrm{Gg} \mathrm{yr}^{-1}$ in 2007-2009 and 7.0 (5-10) $\mathrm{Gg} \mathrm{yr}^{-1}$ in 2010-2012 (Lunt et al., 2015; Simmonds et al., 2016). A sizable fraction of these eastern Asian emissions arises from China, with estimates of 2.0-2.9 Gg yr ${ }^{-1}$ in 2010-2011 (Yao et al., 2012) and 3.4-5.7 $\mathrm{Gg} \mathrm{yr}^{-1}$ in 2004-2005 (Yokouchi et al., 2006) and 2008 (Kim et al., 2010; Stohl et al., 2010).

\subsubsection{HFC-245fa $\left(\mathrm{CHF}_{2} \mathrm{CH}_{2} \mathrm{CF}_{3}\right)$, HFC-365mfc $\left(\mathrm{CH}_{3} \mathrm{CF}_{2} \mathrm{CH}_{2} \mathrm{CF}_{3}\right)$, HFC-227ea $\left(\mathrm{CF}_{3} \mathrm{CHFCF}_{3}\right)$, $\mathrm{HFC}-236 \mathrm{fa}\left(\mathrm{CF}_{3} \mathrm{CH}_{2} \mathrm{CF}_{3}\right)$}

HFC-245fa and HFC-365mfc (normally blended with HFC-227ea to reduce flammability) replace HCFC$141 \mathrm{~b}$ in polyurethane structural foam blowing, and they have potential uses in solvent applications and medical aerosols; HFC-245fa is also used in small quantities in centrifugal chillers (Vollmer et al., 2006; Stemmler et al., 2007; Laube et al., 2010; UNEP, 2010; Vollmer et al., 2011; UNEP, 2016b). The global mean mole fraction of both gases continues to steadily increase. The global mean estimated for HFC-245fa (AGAGE data) for 2016 was $2.4 \mathrm{ppt}$, up from $1.7 \mathrm{ppt}$ in 2012, with an annual increase of $+0.2 \mathrm{ppt} \mathrm{yr}^{-1}(8.9 \%$ $\mathrm{yr}^{-1}$ ) from 2015 to 2016 (Table 2-3). For HFC-365mfc, networks report a global average of 0.94 (0.87-1.00) ppt, up from $0.67 \mathrm{ppt}$ in 2012, with a growth rate of $+0.08 \mathrm{ppt} \mathrm{yr}^{-1}\left(9.2 \% \mathrm{yr}^{-1}\right)$ (NOAA and AGAGE data; Table 2-3).

HFC-227ea and HFC-236fa are used as fire retardants to replace halon-1211 and halon-1301; HFC-227ea is also used in mixtures with other HFCs as a propellant in metered-dose inhalers and in blends with HFC$365 \mathrm{mfc}$ in polyurethane foam blowing; HFC-236fa is also used as a coolant in specialized applications (UNEP, 2010; Vollmer et al., 2011; UNEP, 2014b, 2016b; US EPA, 2017). Global mean mole fractions of both compounds are relatively small but continue to increase steadily in the atmosphere. For 2016, a global average of $1.21(1.17-1.24)$ ppt is estimated for HFC227ea, up from $0.81 \mathrm{ppt}$ in 2012 (NOAA and AGAGE data). The global mean estimated for HFC-236fa in 2016 was 0.15 ppt (AGAGE data), up from $0.11 \mathrm{ppt}$ in 2012. Growth rates were $0.11 \mathrm{ppt} \mathrm{yr}^{-1}\left(9.9 \% \mathrm{yr}^{-1}\right)$ for HFC-227ea and $0.01 \mathrm{ppt} \mathrm{yr}^{-1}\left(8.9 \% \mathrm{yr}^{-1}\right)$ for HFC236fa in 2015-2016 (Table 2-3). In 2016, the radiative forcings from these four HFCs were still very small with $0.58 \mathrm{~mW} \mathrm{~m}^{-2}$ from HFC-245fa, $0.21 \mathrm{~mW} \mathrm{~m}^{-2}$ from HFC-365mfc, $0.31 \mathrm{~mW} \mathrm{~m}^{-2}$ from HFC-227ea, and $0.04 \mathrm{~mW} \mathrm{~m}^{-2}$ from HFC-236fa.

Increases projected for global mole fractions of HFC227ea and HFC-236fa have been fairly accurate over time, whereas those for HFC-245fa and HFC-365mfc were initially overestimated (Figure 2-2; Carpenter and Reimann et al., 2014; Velders et al., 2009, 2015) because of the lack of observations and production statistics for these HFCs being available when the initial projections were developed.

Total global emissions derived from a budget analysis of measured mole fractions at remote sites have increased nearly linearly in recent years for HFC-245fa (from $9.5 \pm 1.5 \mathrm{Gg} \mathrm{yr}^{-1}$ in 2012 to $11.7 \pm 1.9 \mathrm{Gg} \mathrm{yr}^{-1}$ in 2016), HFC-365 mfc (from $3.4 \pm 0.7 \mathrm{Gg} \mathrm{yr}^{-1}$ in 2012 to $4.6 \pm 0.9 \mathrm{Gg} \mathrm{yr}^{-1}$ in 2016), and HFC-227ea (from 3.6 $\pm 0.4 \mathrm{Gg} \mathrm{yr}^{-1}$ in 2012 to $4.3 \pm 0.5 \mathrm{Gg} \mathrm{yr}^{-1}$ in 2016). By contrast, HFC-236fa emissions have remained at 0.29 $\pm 0.07 \mathrm{Gg} \mathrm{yr}^{-1}$ since 2012 (Figure 2-1, update from Vollmer et al., 2011, Rigby et al., 2014 and Montzka et al., 2015).

Emissions reported to UNFCCC for these HFCs account for only a small fraction of global totals inferred from measurements at remote sites (Figure 2-1). Some of these discrepancies may arise because several countries report significant $\mathrm{CO}_{2}$-eq emissions of "unspecified mix of HFCs" and "unspecified mix of HFCs and PFCs", likely due to confidentiality concerns. For example, the U.S. National Inventory Reports specifies that the latter category includes HFC-227ea and HFC245fa emissions. 
Few regional emission estimates exist for these four HFCs, and they only explain a small fraction of global emissions.

HFC-245fa emissions in 2014 from Europe were estimated to be $0.7 \pm 0.5 \mathrm{Gg} \mathrm{yr}^{-1}$ from observations at European sites (Graziosi et al., 2017) compared to $\sim 10$ $\mathrm{Gg} \mathrm{yr}^{-1}$ globally in that year. An inventory-based analysis suggests Chinese emissions of $0.07 \mathrm{Gg} \mathrm{yr}^{-1}$ in 2009 (Fang et al., 2016) compared to $\sim 7 \mathrm{Gg} \mathrm{yr}^{-1}$ globally in that year.

HFC-365mfc emissions in 2014 were estimated to be $1.1 \pm 0.4 \mathrm{Gg} \mathrm{yr}^{-1}$ from Europe (Graziosi et al., 2017) and $0.25 \pm 0.1 \mathrm{Gg} \mathrm{yr}^{-1}$ from the USA (Hu et al., 2017), based on observations in these regions, compared to $\sim 4 \mathrm{Gg} \mathrm{yr}^{-1}$ globally in that year. For 2008 , Li et al. (2011) estimated East Asian emissions of $0.2-0.3 \mathrm{Gg}$ $\mathrm{yr}^{-1}$ based on atmospheric measurements in that region, mostly from Japan, compared to global estimates of $\sim 3 \mathrm{Gg} \mathrm{yr}^{-1}$ in that year.

HFC-227ea emissions in 2014 were estimated at $0.6 \pm$ $0.1 \mathrm{Gg} \mathrm{yr}^{-1}$ from the USA (Hu et al., 2017) and $0.4 \pm$ $0.2 \mathrm{Gg} \mathrm{yr}^{-1}$ from Europe (Graziosi et al., 2017) based on atmospheric measurements in those regions, compared to $\sim 3.9 \mathrm{Gg} \mathrm{yr}^{-1}$ globally for that year. For 2009, Fang et al. (2016) estimated $0.5 \mathrm{Gg} \mathrm{yr}^{-1}$ from China based on an analysis of inventories and markets, compared to the global estimate of $\sim 2.8 \mathrm{Gg} \mathrm{yr}^{-1}$ for that year.

HFC-236fa emissions in 2014 were $0.025 \pm 0.019 \mathrm{Gg}$ $\mathrm{yr}^{-1}$ from Europe compared to $\sim 0.29 \mathrm{Gg} \mathrm{yr}^{-1}$ globally for that year (Graziosi et al., 2017).

\subsubsection{HFC-43-10mee $\left(\mathrm{CF}_{3} \mathrm{CHFCHFCF}_{2} \mathrm{CF}_{3}\right)$}

HFC-43-10mee is used for cleaning applications in the electronics industry where it replaces CFC-113, methyl chloroform, and HCFC-141b; it is also used in aerosol sprays and is an alternative to PFCs in certain applications (Arnold et al., 2014; UNEP, 2016b; Le Bris et al., 2017). It continues to slowly accumulate in the atmosphere. In 2016, a global mean mole fraction of $0.27 \mathrm{ppt}$ was measured, slightly up from $0.23 \mathrm{ppt}$ in

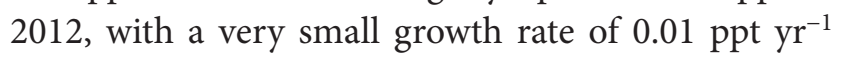
(4.6\% $\mathrm{yr}^{-1}$ ) in 2015-2016 (AGAGE data only; Table 2-3). In 2016, the resulting radiative forcing was still small at $0.10 \mathrm{~mW} \mathrm{~m}^{-2}$ relative to the other HFCs discussed here. Total global emissions derived from a budget analysis of measured mole fractions at remote sites were $1.1 \pm 0.3 \mathrm{Gg} \mathrm{yr}^{-1}$ in 2016 and have not increased appreciably since 2007 (Figure 2-1, update from Arnold et al., 2014).

\subsubsection{Summed Radiative Forcing and $\mathrm{CO}_{2}$-eq Emissions Attributable to HFCs}

The contribution to climate change from the atmospheric concentration of a long-lived trace gas at a particular point in time is expressed as a radiative forcing (Myhre and Shindell et al., 2013). Radiative forcing from all HFCs in the atmosphere approximately doubled over the past decade, reaching $30 \mathrm{~mW} \mathrm{~m}^{-2}$ in 2016 (Figure 2-11); this climate warming influence is $36 \%$ larger than the $22 \mathrm{~mW} \mathrm{~m}^{-2}$ reported for 2012 in the last Assessment (Carpenter and Reimann et al., 2014). Nearly half (47\%) of the radiative forcing from HFCs in 2016 is attributable to HFC-134a; the next three largest contributors are HFC-23, HFC-125, and HFC-143a, which together account for $42 \%$ of the total. Total radiative forcing from HFCs in 2016 accounted for $\sim 10 \%$ of the $0.33 \mathrm{~W} \mathrm{~m}^{-2}$ from ODSs (see Chapter 1), and it was approximately $1.0 \%$ of the $3 \mathrm{~W}$ $\mathrm{m}^{-2}$ supplied in recent years by all long-lived GHGs combined, including $\mathrm{CO}_{2}, \mathrm{CH}_{4}, \mathrm{~N}_{2} \mathrm{O}$, ozone-depleting substances, and HFCs (Myhre and Shindell et al., 2013; more recent values are posted at: https://www. esrl.noaa.gov/gmd/aggi/aggi.html).

The time-integrated radiative forcing supplied from the emission of a given HFC includes consideration of the persistence or lifetime of HFCs. The GWP is the metric commonly used to express the time-integrated forcing from the emission of a trace gas relative to the forcing arising from the equivalent emission of $\mathrm{CO}_{2}$ over a given time interval. One-hundred years is often the time interval considered, although GWPs considered over shorter time intervals (e.g., 20-yr GWPs) are substantially larger for all HFCs except one, HFC-23 (see Table 2-2). $\mathrm{CO}_{2}$-eq emissions of HFCs have increased over time (Figure 2-12) and totaled $0.88 \pm 0.07$ $\mathrm{GtCO}_{2}$-eq yr ${ }^{-1}$ emissions in 2016, up 23\% from the 0.72 $\pm 0.05 \mathrm{GtCO}_{2}$-eq yr ${ }^{-1}$ estimated for 2012 (Carpenter and Reimann et al., 2014). HFC-134a accounted for $0.30 \pm 0.03 \mathrm{GtCO}_{2}$-eq $\mathrm{yr}^{-1}$ in 2016 , or $34 \%$ of the $\mathrm{CO}_{2}$ eq emissions from all HFCs considered here. The next three largest contributors were HFC-125 (0.21 \pm 0.02 $\mathrm{GtCO}_{2}$-eq $\left.\mathrm{yr}^{-1}\right)$, HFC-143a $\left(0.14 \pm 0.01 \mathrm{GtCO}_{2}\right.$-eq $\left.\mathrm{yr}^{-1}\right)$, and HFC-23 $\left(0.16 \pm 0.01 \mathrm{GtCO}_{2}\right.$-eq $\left.\mathrm{yr}^{-1}\right)$; these 

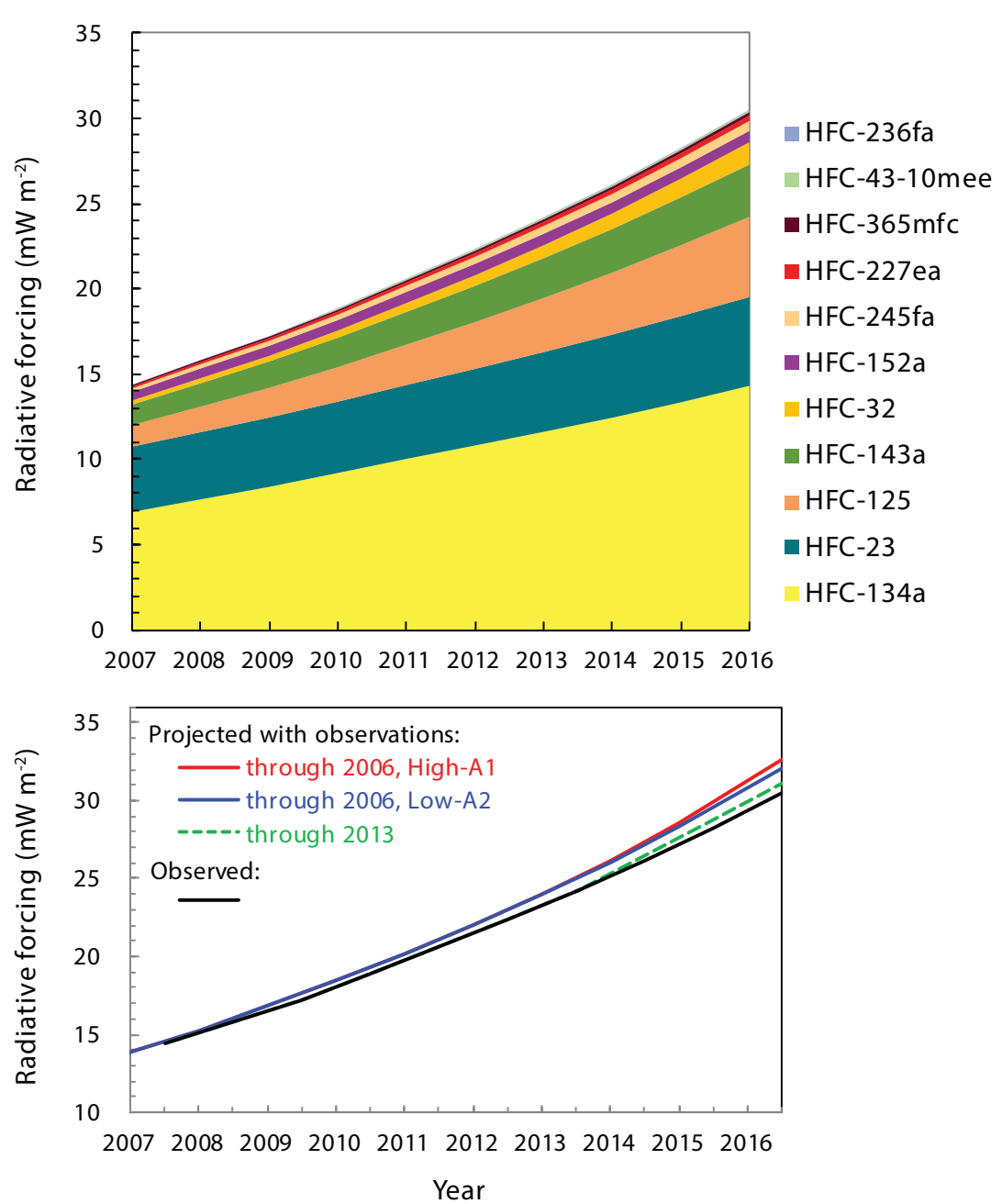

Figure 2-11. Upper panel: Radiative forcing supplied by individual HFCs and their sum during the past decade based on observed global mole fractions and their change over time (as given in Figure 2-2). These forcings are derived by multiplying measured mole fractions by radiative efficiencies (Tables 2-1 and 2-2). Lower panel: the overall observed increase in summed radiative forcing from HFCs in the upper panel (black line) was slightly less rapid than was projected nearly a decade ago based on observations through the end of 2006 and a market analysis done at that time (high and low projections from baseline scenarios in Velders et al., 2009; see Section 2.5). This projection analysis was updated in 2015 based on observations through 2013 (Velders et al., 2015; high and low projections overlay one another on this time scale). Radiative forcings for HFCs are derived assuming pre-industrial concentrations of zero ppt, which is consistent with the atmospheric measurement records and no known natural sources of HFCs.

top four contributors accounted for $93 \%$ of total $\mathrm{CO}_{2^{-}}$ eq $\mathrm{yr}^{-1}$ emissions from HFCs in 2016.

In 2016, $\mathrm{HFC} \mathrm{CO}_{2}$-eq emissions were comparable to those of CFCs $\left(0.8 \pm 0.3 \mathrm{GtCO}_{2}\right.$-eq $\left.\mathrm{yr}^{-1}\right)$ and HCFCs $\left(0.76 \pm 0.11 \mathrm{GtCO}_{2}\right.$-eq $\mathrm{yr}^{-1}$; see Chapter 1$)$, and the emissions of these HFCs represent $\sim 1.5 \%$ of the sum all emissions from long-lived greenhouse gases in recent years $\left(\mathrm{CO}_{2}, \mathrm{CH}_{4}, \mathrm{~N}_{2} \mathrm{O}\right.$, and halocarbons; Montzka et al., 2011, updated).

\subsubsection{Comparison of Recent Observed Changes Versus Projections Made in the Past}

Large increases in emissions, mole fractions, and radiative forcing from HFCs were projected for the future before an amendment to the Montreal Protocol was agreed in Kigali in 2016 (Velders et al., 2009; Gschrey et al., 2011; Velders et al., 2015; UNEP, 2014c; see Section 2.3). Atmospheric measurements through 


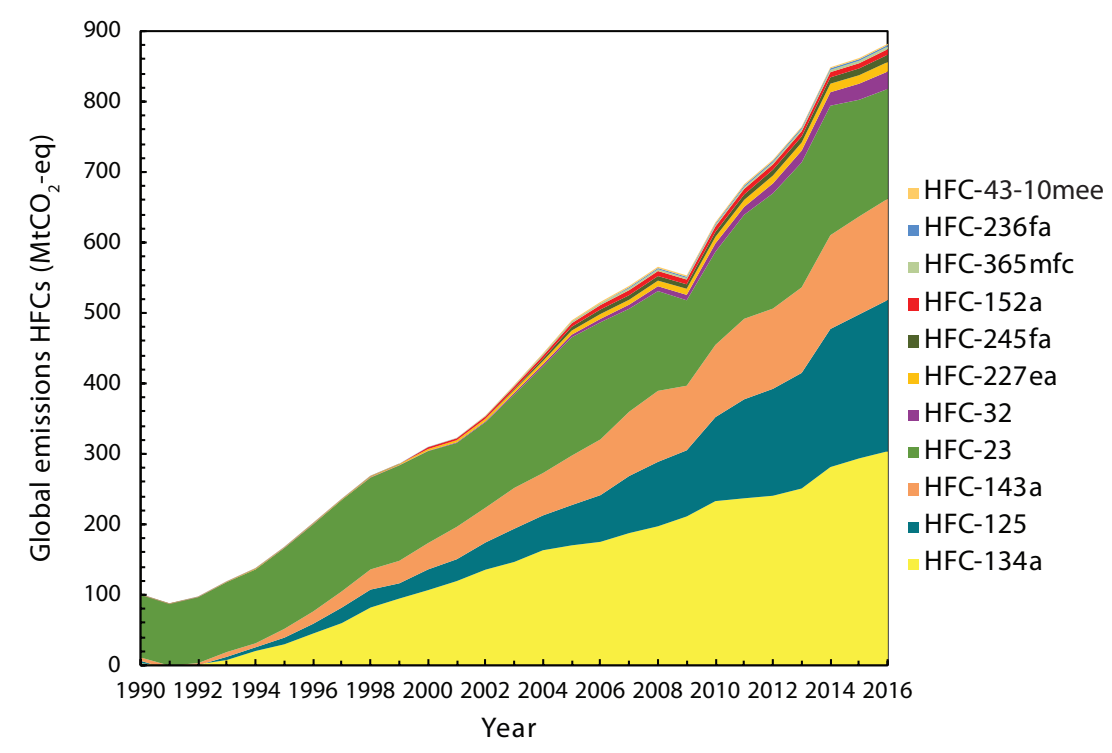

Figure 2-12. Global emissions of $\mathrm{HFCs}\left(\mathrm{MtCO}_{2}\right.$-eq) derived from a budget analysis of global observations (see Figure 2-1; mean of AGAGE \& NOAA network results when both are available) using the AGAGE 12-box model (Rigby et al., 2016). Emissions are weighted by 100-yr GWP to consider the heating supplied by these chemicals integrated over a 100-yr period relative to an equivalent emission of $\mathrm{CO}_{2}$.

2016 show that mole fractions of most HFCs increased over the previous decade at rates similar to those projected in a baseline scenario created nearly a decade earlier based on an analysis of atmospheric data and market trends through 2006 (Velders et al., 2009). This baseline scenario has been updated to include data through 2012 (Velders et al., 2015). This consistency is noted for those HFCs currently contributing the most to radiative forcing and $\mathrm{CO}_{2}$-eq emissions (Figures 2-1 and 2-2). Some less abundant HFCs (e.g., HFC152a, HFC-245fa, and HFC-365mfc) have increased substantially more slowly than was projected. As a result, radiative forcing from the sum of HFCs used as ODS substitutes (i.e., not including HFC-23) increased slightly more slowly than in the baseline projections created nearly a decade ago (Figure 2-11).

These results indicate that mole fractions and emissions for most HFCs have continued to change in a fairly predictable manner during the global phaseout of CFC and HCFC production and consumption. These projections included a slowdown in the HFC emission increases from non-Article 5 countries (also referred to as Article 2 countries or Parties to the Montreal Protocol) and, beginning in the mid-2000s, significant contributions from Article 5 countries that were projected to increase substantially after the 2013 cap on global HCFC production. These projections did not include country- and region-specific controls that were introduced or were being considered during that decade (see Section 2.5.1.2), except the 2006 EU MAC directive (EU, 2006), and this likely explains in part the slightly slower increases in summed radiative forcing from HFCs in observations compared to projections in Figure 2-11. While production and consumption of some HFCs are capped in the future by controls outlined in the Kigali Amendment (see Section 2.5.1.3 and Table 2-1), they may temporarily increase in some countries in the future, particularly those countries for which caps on production and consumption limit these quantities beginning in 2024 or 2028 based on baseline magnitudes determined for future years (e.g., 2020-2022 or 2024-2026, depending on developing country Group; Table 2-1).

\subsubsection{Aggregate Sums of HFC Emissions Reported to the UNFCCC and Contributions from Non-Reporting Countries}

Throughout Section 2.3, substantial differences were noted for all HFCs between total emissions reported to the UNFCCC and global total emissions estimated from atmospheric data. Those differences have 


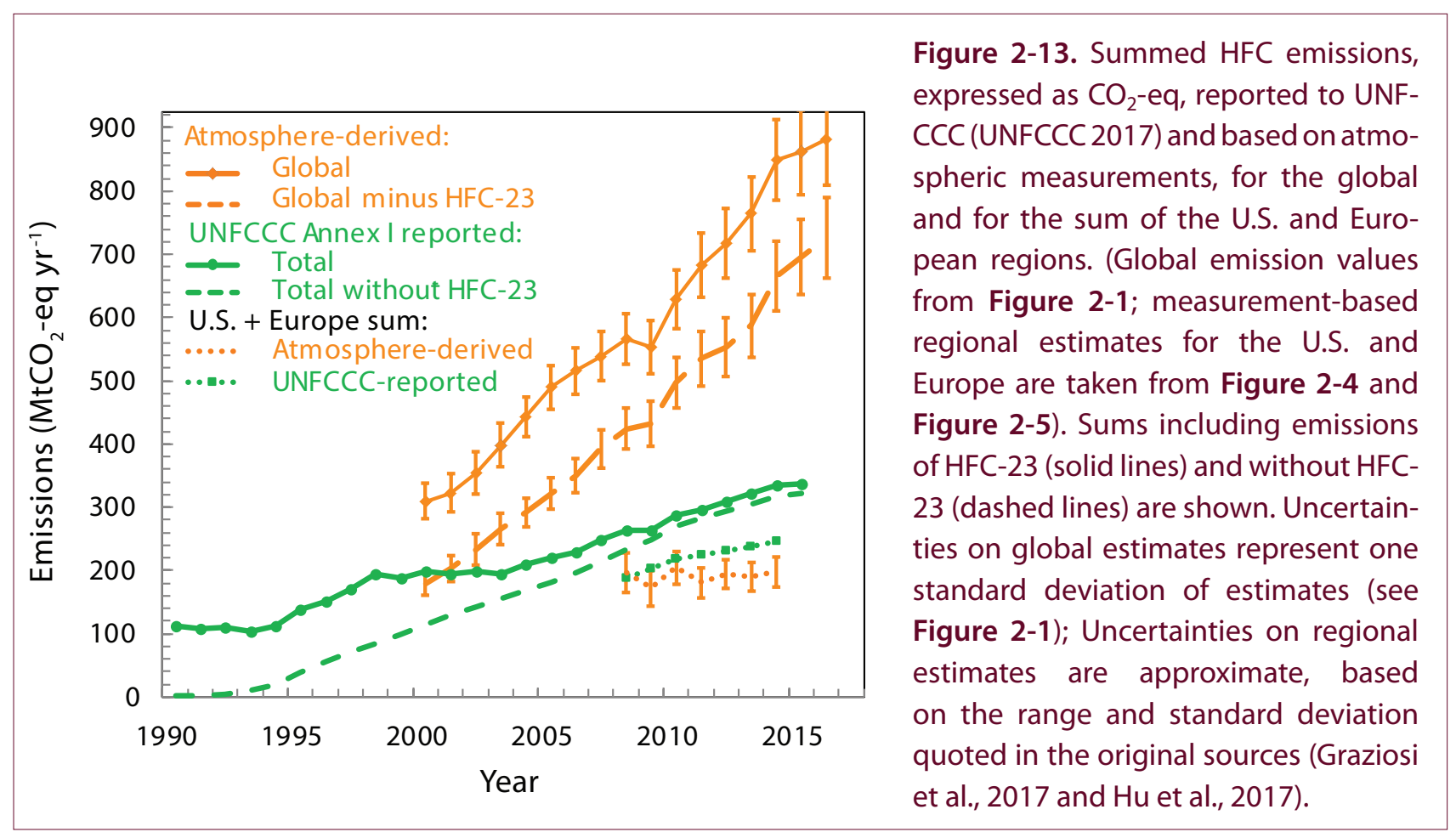

continued to grow over time for most gases (Figure 2-1) and in the aggregate of total HFC emission (Figure 2-13). On a $\mathrm{CO}_{2}$-eq basis, aggregate $\mathrm{HFC}$ emissions reported to the UNFCCC in 2015, the latest year for which UNFCCC reporting is available, accounted for only $39 \%$ of the total global HFC emissions derived from global atmospheric mole fraction changes measured in the remote atmosphere; this value increases to $46 \%$ if emissions of only those HFCs used as ODS substitutes are considered (i.e., not HFC-23) (Figure 2-13).

Inverse analyses of atmospheric measurements made in the USA and in Europe suggest aggregate HFC emissions from these regions may actually be somewhat lower (by 10 to $20 \%$ in recent years, excluding HFC23 emissions) than the totals reported to UNFCCC. Given that HFC emissions from the USA and Europe accounted for over $80 \%$ of total HFC emission reported to the UNFCCC for 2015 (excluding HFC-23; Figure 2-13), it is unlikely that inaccurate emission reporting from Annex I countries explains the increasing gap between global emissions derived from atmospheric data and totals reported to UNFCCC.

The dramatic increase in this emission gap over time is consistent with substantial increases in HFC use in developing countries not obligated to report emissions to the UNFCCC, as had been projected (Velders et al., 2009, 2015; Gschrey et al., 2011). Inverse analyses of atmospheric measurements of HFCs in East Asia support this conclusion (see Section 2.3.1). Furthermore, for some HFCs, such as HFC-23 and HFC-32, emissions from China or East Asia explain most, if not all, of the unreported emissions (see Figures 2-7 and 2-8). For other HFCs (HFC-134a, HFC-125, and HFC143a), emissions from China or East Asia account for only a fraction of unreported emissions (see Figures 2-9 and 2-10).

\subsubsection{Next Generation Substitutes}

\subsubsection{HFC-1234yf $\left(\mathrm{CF}_{3} \mathrm{CF}=\mathrm{CH}_{2}\right)$ AND $\mathrm{HFC}-1234 z e(E)\left((E)-\mathrm{CF}_{3} \mathrm{CH}=\mathrm{CHF}\right)$}

Unsaturated HFCs, also known as hydrofluoroolefins (HFOs), are being used as substitutes for higher GWP-HFCs in a number of applications. Given their short lifetimes and small GWPs, they are not included as controlled substances in the Kigali Amendment to the Montreal Protocol. HFC-1234yf and HFC$1234 z e(E)$ are hydrofluoroolefins with estimated tropospheric $\mathrm{OH}$-lifetimes of 12 days and 19 days, respectively, (Table 2-2) and 100-yr GWPs of less than 1 (Hodnebrog et al., 2013). HFC-1234yf has been identified as the main replacement for HFC-134a in MAC 
Table 2-4. Composition of HFC blends referenced in this chapter

\begin{tabular}{|c|c|c|}
\hline HFC Blend & Composition & $100-y r$ GWP * \\
\hline $\mathrm{R}-404 \mathrm{~A}$ & 44\% HFC-125, 52\% HFC-143a, 4\% HFC-134a & 4,210 \\
\hline $\mathrm{R}-407 \mathrm{~A}$ & $20 \%$ HFC-32, 40\% HFC-125, 40\% HFC-134a & 2,070 \\
\hline $\mathrm{R}-407 \mathrm{C}$ & $23 \%$ HFC-32, 25\% HFC-125, 52\% HFC-134a & 1,730 \\
\hline $\mathrm{R}-407 \mathrm{~F}$ & $30 \%$ HFC-32, 30\% HFC-125, 40\% HFC-134a & 1,790 \\
\hline $\mathrm{R}-410 \mathrm{~A}$ & $50 \%$ HFC- $32,50 \%$ HFC- 125 & 2,080 \\
\hline $\mathrm{R}-446 \mathrm{~A}$ of $\mathrm{L}-41$ or L-41-1 & $68 \%$ HFC-32, 29\% HFC=1234ze(E), 3\% isobutane & 480 \\
\hline $\mathrm{R}-447 \mathrm{~A}$ or L-41-2 & 68\% HFC-32, 3.5\% HFC-125, 28.5 HFC-1234ze(e) & 600 \\
\hline $\mathrm{R}-448 \mathrm{~A}$ & $\begin{array}{l}26 \% \text { HFC-32, 26\% HFC-125, 20\% HFC-1234yf, 21\% HFC-134a, } \\
7 \% \text { HFC-1234ze(E) }\end{array}$ & 1,370 \\
\hline $\mathrm{R}-449 \mathrm{~A}$ & 24.3\% HFC-32, 24.7\% HFC-125, 25.3\% HFC-1234yf, 25.7\% HFC-134a & 1,370 \\
\hline $\mathrm{R}-449 \mathrm{~B}$ & 25.2\% HFC-32, 24.3\% HFC-125, 23.2\% HFC-1234yf, 27.3\% HFC-134a & 1,390 \\
\hline $\mathrm{R}-450 \mathrm{~A}$ & $58 \%$ HFC-1234ze(E), 42\% HFC-134a & 570 \\
\hline R-452B or DR55 & $67 \%$ HFC-32, 7\% HFC-125, 26\% HFC-1234yf & 715 \\
\hline R-459A or ARM71a & $68 \%$ HFC-32, 26\% HFC-1234yf, 6\% HFC-1234ze(E) & 480 \\
\hline $\mathrm{R}-513 \mathrm{~A}$ & $56 \%$ HFC-1234yf, 44\% HFC-134a & 600 \\
\hline DR5 & $72.5 \%$ HFC-32, 27.5\% HFC-1234yf & 510 \\
\hline L-41a & 73\% HFC-32, 15\% HFC-1234yf, 12\% HFC-1234ze(E) & 515 \\
\hline$L-41 b$ & 73\% HFC-32, 27\% HFC-1234ze(E) & 515 \\
\hline ARM70a & $50 \%$ HFC-32, 10\% HFC-134a, 40\% HFC-1234yf & 490 \\
\hline D2Y60 & $40 \%$ HFC-32, 60\% HFC-1234yf & 282 \\
\hline HPR2A & 76\% HFC-32, 6\% HFC-134a, 18\% 1234ze(E) & 615 \\
\hline HPR1D & $60 \%$ HFC-32, $6 \% \mathrm{CO}_{2}, 34 \%$ HFC-1234ze(E) & 425 \\
\hline
\end{tabular}

systems in Europe, the USA (US EPA, 2017), and other countries, although use in developing countries may be limited because of current high production costs (UNEP, 2017a). HFC-1234ze(E) could replace HFC134a for extruded polystyrene foam blowing (possibly in blends) and perhaps in metered-dose inhalers if toxicology, flammability, and cost concerns can be addressed (US EPA, 2017; UNEP, 2017a). Both compounds are also being investigated for use in refrigeration blends with saturated HFCs to replace fluids with high GWPs (UNEP, 2017a); various blends have been found to be non-flammable and acceptable for use (R-448A, R-449A, R-449B, R-450A, R-513A) even in domestic applications (US EPA, 2015b; 2016). See Table 2-4 for the composition of HFC blends.

The first ambient-air measurements of these new olefinic HFCs were reported by Vollmer et al. (2015) from two sites in Switzerland (see Figure 2-14). In 2011, HFC-1234yf was undetectable at the high-altitude Jungfraujoch observatory, but by mid-2016 observed mole fractions were often in the 0.02-0.20 ppt range; higher values were observed at the urban Dübendorf site where they were often in the 1-4 ppt 


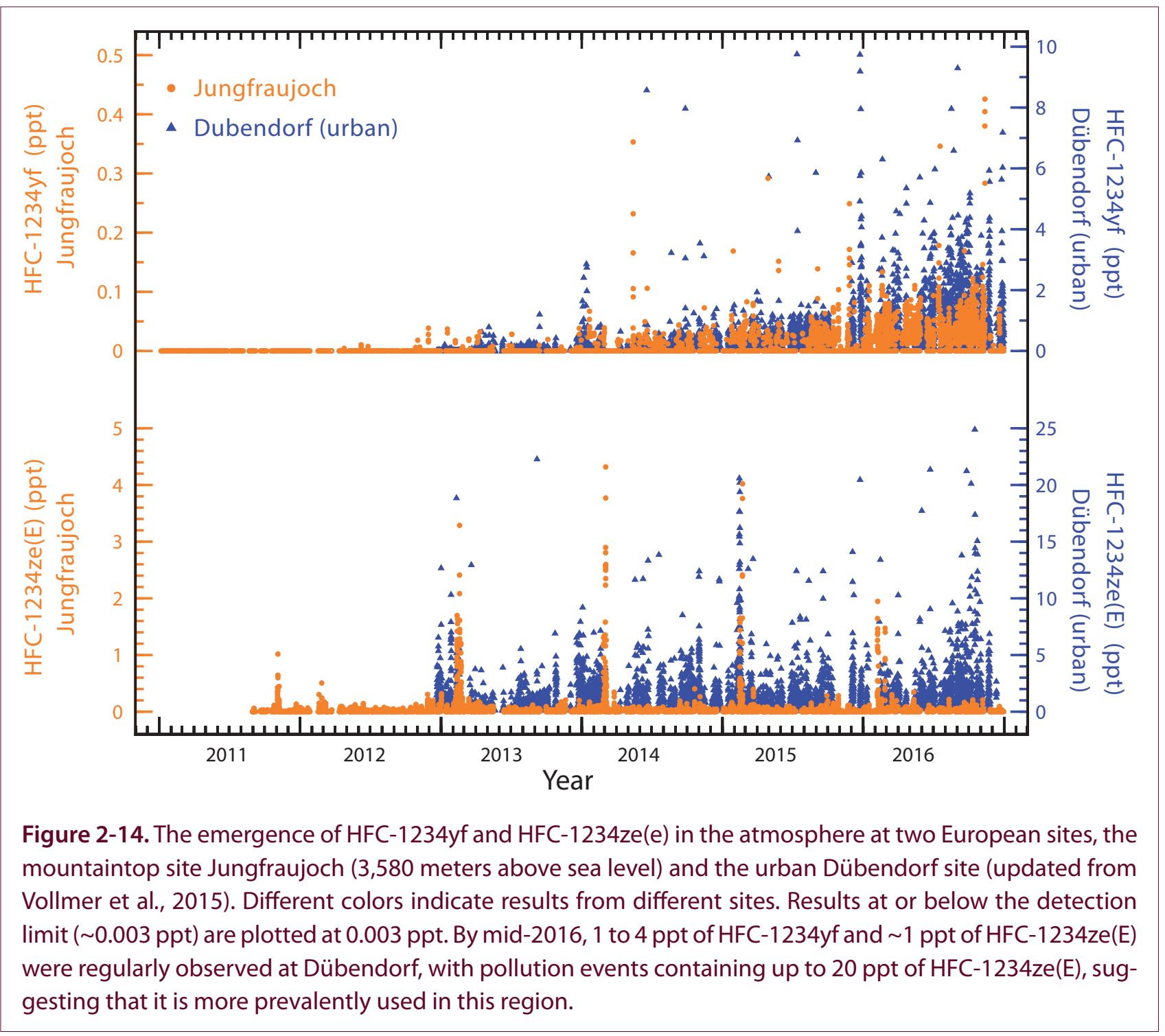

range. HFC-1234ze(E) has been observed in most samples since the beginning of dedicated ongoing observations. By mid-2016, 0.025 ppt was commonly observed at Jungfraujoch and $\sim 1$ ppt at Dübendorf, where pollution events containing up to $20 \mathrm{ppt}$ of this HFC have been seen, suggesting more prevalent use of HFC-1234ze(E) in this region (Vollmer et al., 2015).

\subsection{ATMOSPHERIC CHEMISTRY OF HFCs}

\subsubsection{New Developments on Loss Rates and Lifetimes}

HFCs are removed from the atmosphere mainly by their reactions with hydroxyl radicals $(\mathrm{OH})$ in the troposphere. The residence times of HFCs in the atmosphere determined by reaction with tropospheric $\mathrm{OH}$, $\tau_{H F C}^{O H}$, are derived from the corresponding lifetime of methyl chloroform, $\mathrm{CH}_{3} \mathrm{CCl}_{3}$, (Spivakovsky et al., 2000) as described in previous Assessments (e.g., Box 1-1 in Carpenter and Reimann et al., 2014).

Although HFCs do not absorb stratospheric UV radiation, stratospheric loss processes, such as reactions with $\mathrm{OH}$ and $\mathrm{O}\left({ }^{1} \mathrm{D}\right)$, can contribute to the loss rate of long-lived HFCs and, therefore, slightly affect their lifetimes. Photolysis at the Lyman-a wavelength $(121.6 \mathrm{~nm})$ can only affect lifetimes of very long-lived species (such as perfluorinated compounds) that are inert enough to reach the mesosphere $(\geq 70 \mathrm{~km})$ in appreciable quantities; it has a negligible effect on the lifetimes of HFCs. Recent intensive modeling efforts (SPARC, 2013) provide detailed information on model-derived total lifetimes for a number of compounds, partial lifetimes due to specific photochemical 
removal processes (reactions with $\mathrm{OH}$, reactions with $\mathrm{O}\left({ }^{1} \mathrm{D}\right)$, and photolysis), and partial lifetimes associated with the atmospheric removal regions (troposphere and stratosphere). These results have been used to derive empirical correlations for estimating partial lifetimes due to stratospheric reactions of other HFCs, $\tau_{H F C}^{s t r}$. The total atmospheric lifetimes, $\tau_{H F C}$, reported in Table 2-2 have been calculated as $\left(\tau_{H F C}\right)^{-1}=\left(\tau_{H F C}^{O H}\right)^{-1}+$ $\left(\tau_{H F C}^{s t r}\right)^{-1}$ to account for the stratospheric loss of HFCs.

Table 2-2 presents updated estimates of the lifetimes for partially fluorinated alkanes (HFCs), partially fluorinated olefins (HFCs that are also called HFOs) and perfluorinated olefins. The abundances of HFOs and perfluorinated olefins are also primarily controlled by their reactions with the hydroxyl radical. Compounds with atmospheric lifetimes shorter than $\sim 0.5$ years have been designated as very short-lived substances (VSLSs) as in previous Assessments. These compounds generally have non-uniform tropospheric distributions because their lifetimes are comparable to or shorter than the characteristic time of mixing processes in the troposphere.

The lifetime of VSLSs released into the atmosphere depends on local atmospheric conditions at the emission location and, therefore, the concept of a single global lifetime is inappropriate (e.g., Hodnebrog et al., 2013 and previous Ozone Assessment reports). Hence, the VSLS lifetimes presented in Table 2-2 (with units of days) should not be considered as the global average atmospheric lifetime of a VSLS once emitted. Nevertheless, these estimates provide a useful scaling among such compounds and distinguish them from longer-lived HFCs that are well mixed in the troposphere. It should be noted that the local lifetimes of VSLSs tabulated in this report are $\sim 10-20 \%$ longer than in previous Assessments primarily because they have now been calculated with the same approach that is used for longer-lived HFCs (i.e., relative to the global mean lifetime of methyl chloroform against $\mathrm{OH}$ oxidation), thereby avoiding arbitrary differences arising from the use of two different approaches.

For a few compounds in Table 2-2, experimental data on $\mathrm{OH}$ reactivity are not available. Lifetimes for these gases have been estimated based on either structure activity relationships or reactivity trends among similar compounds and appear in italics in Table 2-2.
$\mathrm{OH}$ reactivity for several compounds has been revised since the last Assessment based on new experimental data and/or analyses. However, these revisions do not substantially change the recommended atmospheric lifetimes. Other changes since the previous Assessment are listed below. (References related to these updates can be found in the notes to Table 2-2):

- $\mathrm{HFC}-72-17 \mathrm{p}, \mathrm{CHF}_{2}\left(\mathrm{CF}_{2}\right)_{6} \mathrm{CF}_{3}$, has been added.

- The lifetime of HFC-245cb is $15 \%$ shorter than estimated previously based on an analogy to HFC143a. This revision reflects a new recommendation (Burkholder et al., 2015b), which is now based on laboratory-measured $\mathrm{OH}$ reactivity data.

- The estimated lifetime of HFC-272ca $\left(\mathrm{CH}_{3} \mathrm{CF}_{2} \mathrm{CH}_{3}\right)$ is based on $\mathrm{OH}$ reactivity calculated using the structure activity relationships. There are no experimental data.

- Lifetimes of shorter-lived HFC-152 $\left(\mathrm{CH}_{2} \mathrm{FCH}_{2} \mathrm{~F}\right)$, HFC-161 $\left(\mathrm{CH}_{3} \mathrm{CH}_{2} \mathrm{~F}\right)$, and HFC-281ea $\left(\mathrm{CH}_{3} \mathrm{CHFCH}_{3}\right)$ are estimated to be $\sim 18 \%$ longer than previous estimates. This revision is the result of the estimates now being made in a manner consistent with other HFCs.

- The list of fluorinated olefins has been expanded to include 7 new chemicals including stereo-isomers with different lifetimes and cyclic unsaturated fluorocarbons.

- The lifetimes of (E) $-\mathrm{CF}_{3} \mathrm{CH}=\mathrm{CHCF}_{3}$ and (E)$\mathrm{CF}_{3} \mathrm{CH}=\mathrm{CHCF}_{2} \mathrm{CF}_{3}$ are a factor of $\sim 6$ longer because experimental data on the $\mathrm{OH}$ reactivity of (E) $-\mathrm{CF}_{3} \mathrm{CH}=\mathrm{CHCF}_{3}$ became available for the first time since the last Assessment.

- The lifetime of perfluorocyclopentene is more than an order of magnitude longer because experimental data on its reactivity toward $\mathrm{OH}$ became available for the first time since the last Assessment.

\subsubsection{Updates on TFA Formation and Tropospheric Ozone Formation}

Trifluoroacetic acid (TFA; $\mathrm{CF}_{3} \mathrm{COOH}$ ) is produced as the result of the breakdown in the atmosphere of several HCFCs and HFCs, such as HCFC-123 and HCFC124, HFC-134a, HFC-143a, HFC-1234yf, and possibly HFC-1234ze (Burkholder et al., 2015a; Wallington et 
al., 2015; Javadi et al., 2008). TFA is also produced as a breakdown product of a large number of other chemicals and is produced synthetically by the chemical industry, resulting, in many cases, in direct release to the atmosphere (Solomon et al., 2016). TFA also arises from natural processes. TFA is a stable compound that can accumulate in lakes and the ocean. As an acid or as a salt, TFA is of low to moderate toxicity to a range of organisms. The salts of TFA are inert and not of toxicological or environmental concern in the small concentrations $\left(\sim 200 \mathrm{ng} \mathrm{L}^{-1}\right)$ that are present in the ocean (UNEP, 2014a). The contribution of most sources to the total TFA budget is uncertain, although the source strength from atmospheric oxidation of HCFCs and HFCs is now better quantified.

Solomon et al. (2016) estimated TFA added to the oceans as a result of unregulated use of HCFCs and HFCs (including HFOs) up to 2050. Under an upper range scenario of global HFC use (Velders et al., 2015), it was estimated that by 2050 the total additional contribution of TFA to the oceans would be less than $7.5 \%$ of the approximately $200 \mathrm{ng}$ acid equivalents $\mathrm{L}^{-1}$ estimated to be present at the start of the millennium (Solomon et al., 2016). With the 2016 Kigali Amendment to the Montreal Protocol, the projected use of HFCs is expected to be much lower (see Section 3.1) with consequently lower estimated TFA production from HFCs. Increased use of HFOs could augment TFA production and partially offset reductions in TFA production from saturated HFCs. The environmental effects of TFA, from the breakdown of HCFCs and HFCs, are therefore considered too small to be a risk to the environment over the next few decades (Solomon et al., 2016). However, potential longer-term impacts could require future evaluation due to the environmental persistence of TFA, uncertainty in future uses of HFOs, and because of uncertainties in the global budget of TFA. See Section 6.2.6 for more information on TFA.

The atmospheric degradation of HFC-1234yf (an HFO) can also contribute tropospheric ozone and thereby contribute to reduced air quality. Luecken et al. (2010) showed that the additional tropospheric ozone from the conversion of HFC-134a to HFC$1234 y f$ in mobile air conditioners in the USA is small compared with ambient ozone levels in cities in the USA.

\subsection{POTENTIAL FUTURE CHANGES}

Projections have suggested that the use and emissions of HFCs could increase substantially with the phase-out of HCFCs in developed countries by 2030 and in developing countries by 2040 (Velders et al., 2009; Gschrey et al. 2011; Rigby et al., 2014; Velders et al., 2015; UNEP, 2014c; Fang et al., 2016; Purohit and Höglund-Isaksson, 2017). Because many HFCs in use currently have high GWPs and these HFCs leak from appliances and other applications, they contribute to the radiative forcing (RF) of climate. The 2016 Kigali Amendment requires large reductions (up to $85 \%$ by 2035 or 2045 relative to a base level) for GWPweighted HFC production and consumption for all developed and developing countries.

\subsubsection{Scenarios}

In this section, HFC scenarios developed elsewherewith and without the implementation of the Kigali Amendment-are discussed, including their implications for radiative forcing of climate. Also discussed are alternatives to HFCs and factors that might be relevant for future HFC use.

\subsubsection{HFC Scenarios Without Consideration of Controls: "Baseline" Scenarios}

The Kigali Amendment of October 2016, assuming global implementation, will significantly affect the future demand for HFCs in developed and developing countries and consequently their emissions, mixing ratios, and radiative forcing of climate. The effects of the Amendment can be viewed relative to HFC baseline scenarios that were constructed in the past without including specific global control measures on HFC production or consumption. Here the results of several of these HFC baseline scenarios are compared before discussing the effects of the Kigali Amendment on future HFC emissions (Section 2.5.1.3). HFC-23 is not considered in these scenarios since it is not used as a replacement compound in applications that traditionally used ODSs, and it is also in a separate group in the Kigali Amendment (see Section 2.5.1.5).

In Figure 2-15 the GWP-weighted emissions and corresponding radiative forcings are shown for HFCs in several of these baseline scenarios. The projected emissions in Velders et al. (2015) are an update of 

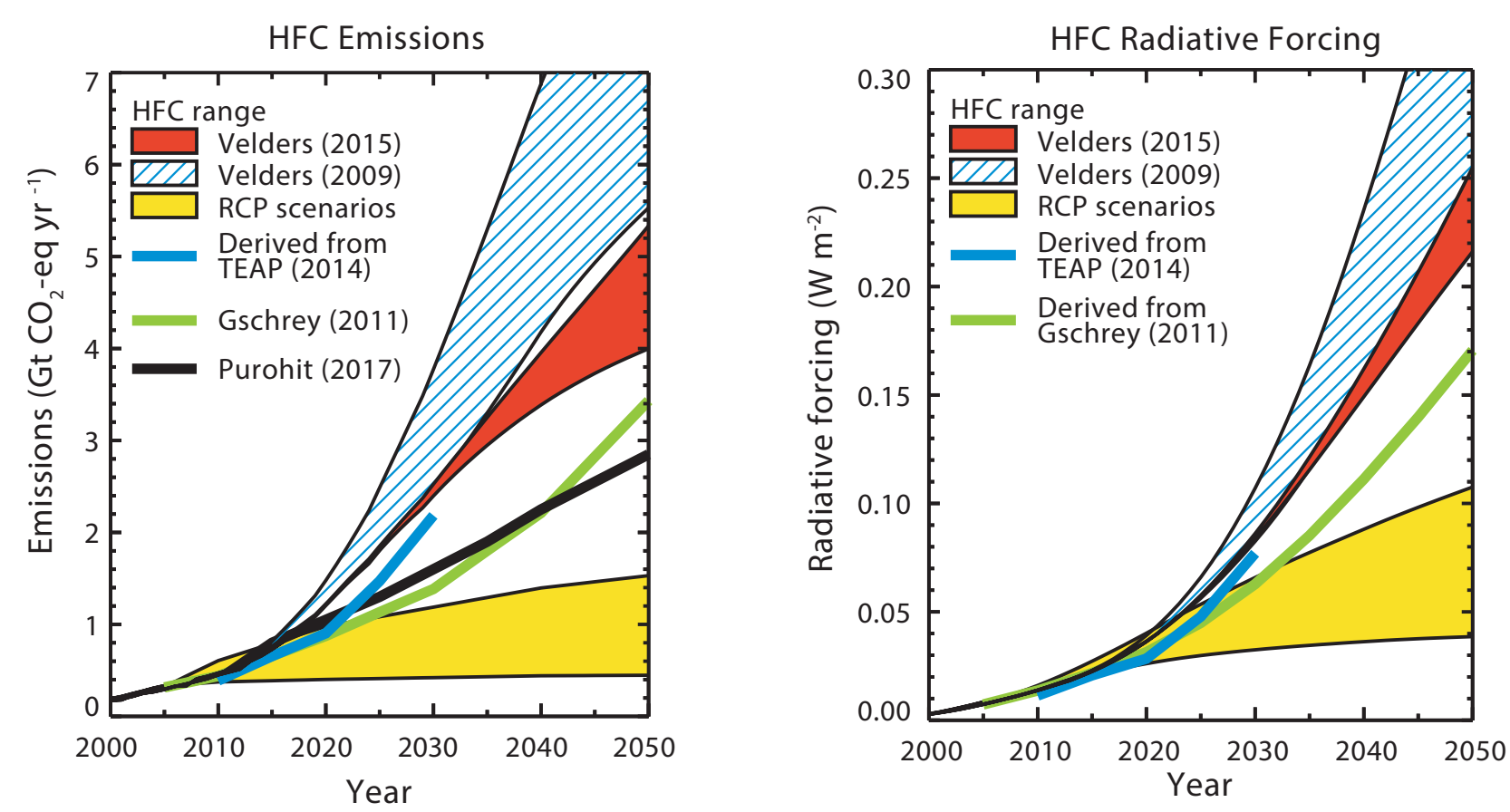

Figure 2-15. HFC emissions and radiative forcing scenarios from baseline scenarios (excluding HFC-23) from Velders et al. (2009), Gschrey et al. (2011), RCPs (Meinshausen et al., 2011), UNEP (2014c), Velders et al. (2015), and Purohit and Höglund-Isaksson (2017). The Velders et al. (2009) scenarios are shown, because they were the reference scenarios in the previous (2014) Assessment. The emissions and radiative forcing shown here are based on the GWPs and radiative efficiencies in the corresponding publications, which may differ from those in Table 2-2; the difference in $\mathrm{CO}_{2}$-eq emissions is less than $1 \%$.

those of Velders et al. (2009) based on more detailed and more current information on HFC use by sector and region. The scenarios of Velders et al. (2009) are shown here because they were the reference scenarios in the previous Assessment (Harris and Wuebbles et al., 2014). The HFC emissions in Velders et al. (2015) are similar to those in UNEP (2014c); they are slightly higher than projected in other sector-specific scenarios (Gschrey et al., 2011; Purohit and Höglund-Isaksson, 2017; Höglund-Isaksson et al., 2017); and they are significantly higher than in the Representative Concentration Pathways (RCPs) scenarios (Meinshausen et al., 2011). The latter two scenarios included different assumptions for the HCFC replacement pattern and/or different growth rate projections for HFC use in applications. In these scenarios, the lifetimes of the HFCs are kept constant. Model calculations show that HFC lifetimes might change towards 2100 due to changes in temperatures and $\mathrm{OH}$ abundances. Most models show a decrease in lifetime by $5-10 \%$ in 2100 relative to 2000 (SPARC, 2013). These changes depend on the future greenhouse gas abundances and are highly uncertain.

The recent sector- and region-specific HFC baseline scenarios of Velders et al. (2015) (Figure 2-16) assume that current uses (substances and technologies) of HFCs for specific sectors would continue without control measures and that developing countries would follow the same transitions from HCFCs to HFCs and not-in-kind alternatives as has occurred in developed countries, but at a later time. So these scenarios do not take into account the 2016 Kigali Amendment or the recent regulations of HFC use in the EU (revised F-gas regulation of the European Union; EU, 2014), USA (US EPA, 2015a) and Japan (METI, 2015). The scenarios are based on (1) robust historical HFC consumption data by sector for developed countries derived from their UNFCCC National Inventory Submissions (UNFCCC, 2014), (2) historical HFC consumption 

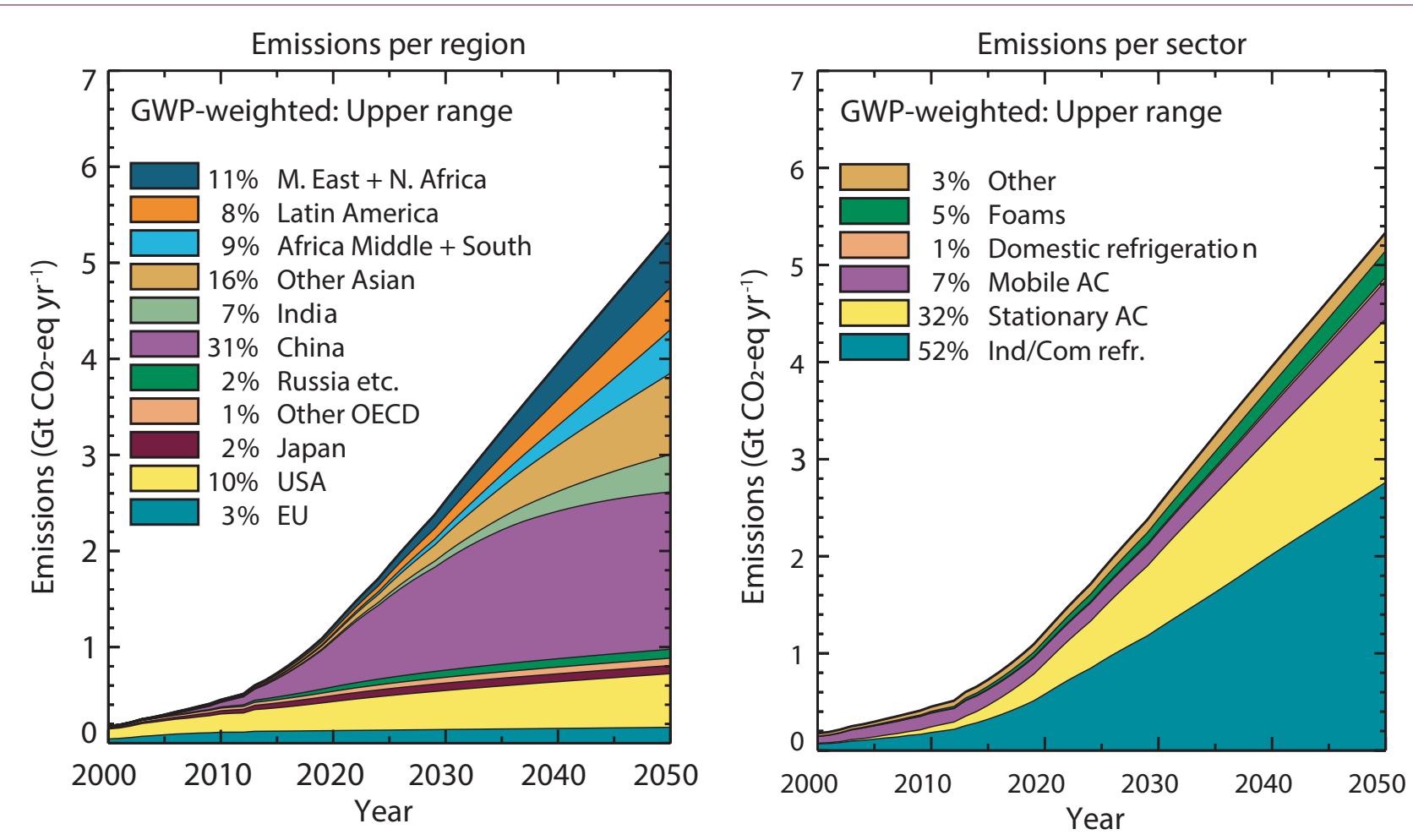

Figure 2-16. Regional and sectoral contributions to HFC GWP-weighted emissions for the upper-range baseline scenario of Velders et al. (2015), excluding HFC-23. The percentages refer to the global average relative contributions of each sector to the total GWP-weighted emissions in 2050. In the scenario, $10 \mathrm{HFCs}$ are considered. The 11 regions are Europe, USA, Japan, other OECD countries, States of the former Soviet Republics and Yugoslavia (Russia), China, India, other Asian countries, Middle and Southern Africa, Latin America, and the Middle East plus Northern Africa. The six use sectors are (1) industrial, commercial (open compressor), commercial (hermetically sealed compressor), and transport refrigeration, (2) stationary AC, (3) mobile AC, (4) domestic refrigeration, (5) foams-extruded polystyrene, polyurethane, and open cell foams, and (6) other-aerosol products, fire extinguishing systems, and solvents. The emissions shown here are based on the GWPs used in Velders et al. (2015), which differ somewhat from those in Table 2-2; the difference in $\mathrm{CO}_{2}$-eq emissions is less than $1 \%$.

data for China (Zhang and Wang, 2014) and some other developing countries, (3) historical HCFC consumption data from UNEP (2015), (4) replacements pattern of HCFCs by HFCs and not-in-kind technologies (Velders et al., 2009; 2015), (5) scenarios of gross domestic product (GDP) and population from Shared Socioeconomic Pathway (SSP) projections (O’Neill et al., 2012) as drivers for the demand for HFCs, (6) observed atmospheric abundances of HFCs from 1990 to the beginning of 2013 as constraints on the historical consumption data, and (7) leakage rates (i.e., emission factors) derived from the UNFCCC National Inventory Submissions; these are kept constant over time in the scenarios.
The largest historical HFC use and emissions are in the developed countries, primarily the USA, EU, and Japan (Figure 2-16). In the baseline scenario, China is projected to become the largest emitter of HFCs by 2020, and Chinese emissions are projected to reach $31 \%$ of total $\mathrm{CO}_{2}$-eq emissions (100-yr time horizon) of all HFCs by 2050 in the upper range HFC scenario (Velders et al., 2015). In all countries or regions, the largest contributions in $\mathrm{CO}_{2}$-eq emissions come from industrial and commercial refrigeration (range of $40-58 \%$ for the different regions by 2050), because of the large use of HFCs and relatively large leakage rates from these applications, while the second largest HFC source comes from stationary air conditioning (AC) (21-40\% by 2050) (Figure 2-16). Historically, mobile 
$\mathrm{AC}$ has been responsible for the largest fraction of $\mathrm{CO}_{2}$-eq $\mathrm{HFC}$ emissions, but this sector is projected to account for only $10-18 \%$ of developed country emissions by 2050 . In developing countries in these scenarios, mobile AC contributes only $3-12 \%$ of total $\mathrm{CO}_{2}$-eq HFC emissions in 2050. It should be noted that this baseline scenario does not include the effects in the EU and potentially around the globe of the EU MAC directive which has recently banned the use of HFC-134a in new cars (see Section 2.5.1.2).

In 2050, in the scenarios of Velders et al. (2015), $\mathrm{CO}_{2}^{-}$ eq HFC emissions (excluding HFC-23) sum to $0.8-1.0$ $\mathrm{GtCO}_{2}$-eq $\mathrm{yr}^{-1}$ for the developed countries and 3.2-4.4 $\mathrm{GtCO}_{2}$-eq $\mathrm{yr}^{-1}$ for the developing countries, resulting in a global total of 4.0-5.3 $\mathrm{GtCO}_{2}$-eq $\mathrm{yr}^{-1}$. In comparison, these values are equivalent to $5-11 \%$ of the global $\mathrm{CO}_{2}$ emissions in 2050 in the RCP6.0 and RCP8.5 scenarios. The HFC radiative forcing (RF) (excluding HFC-23) in 2050 in these scenarios is $0.22-0.25 \mathrm{~W}$ $\mathrm{m}^{-2}$. In comparisons of projected growth, the 20152050 increase in $\mathrm{HFC} \mathrm{CO}_{2}$-eq emissions is $9-29 \%$ of that for $\mathrm{CO}_{2}$ over the same time period in the RCP scenarios. These $\mathrm{CO}_{2}$-eq emissions represent only the direct emissions of the HFCs. Indirect $\mathrm{CO}_{2}$ emissions associated with the production of fossil fuel-derived energy used by the appliances or in other applications need to also be considered for the overall impact of HFCs on radiative forcing (see Section 2.5.2.3).

In the refrigeration and air conditioning sectors, pure HFCs or blends of HFCs are used as refrigerants. The most-used HFC refrigerants in the scenarios are HFC-134a and the blends R-404A (mix of HFC-125, HFC-134a, HFC-143a) and R-410A (mix of HFC-32 and HFC-125). Consequently, these HFCs are projected to have the largest future emissions by mass or $\mathrm{CO}_{2}$-eq (Figure 2-17). See Table 2-4 for more detail about the composition of HFC blends.

The assumptions about market saturation are important aspects for the projections of HFCs. In the scenarios of Velders et al. (2015) the demand for HFCs per capita in developing countries is limited to the demand per capita in the developed countries. These scenarios do not take into account the potentially higher future demand for stationary AC as a result of increased ambient temperatures due to climate change. They also do
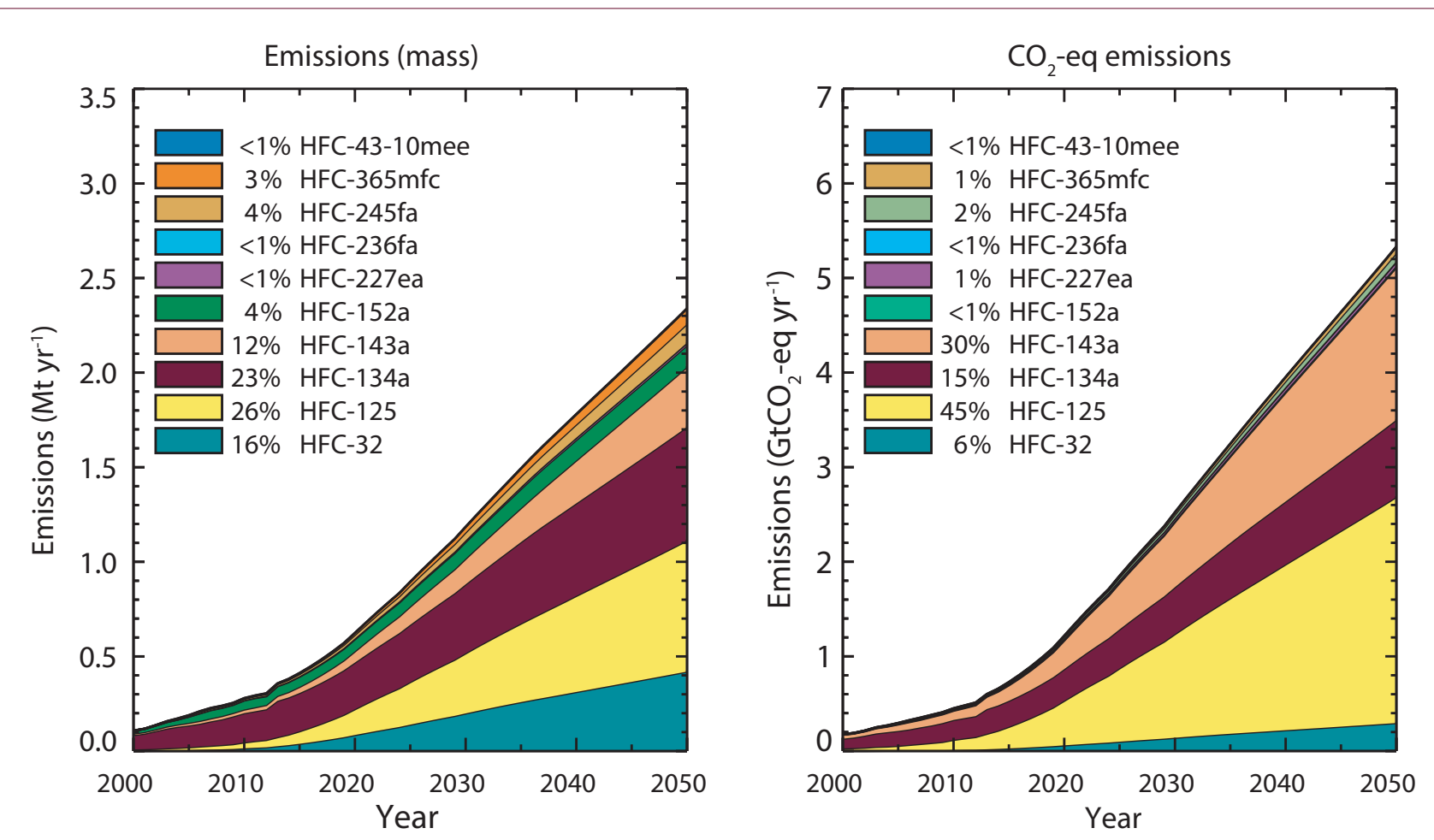

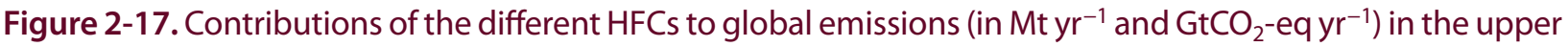
range baseline scenario of Velders et al. (2015). The percentages refer to the relative contributions in 2050. 
not consider the fact that many developing countries have higher ambient temperatures than the developed countries and could, therefore, have a higher demand for stationary AC and higher emissions per capita.

\subsubsection{Effect of National and Regional HFC Control Measures on Future Projections}

In the EU, the 2006 MAC Directive, which addresses the use of mobile air conditioning (EU, 2006), and the 2014 revised F-gas Regulation (EU, 2014) ban the use of high-GWP HFCs in certain sectors. Although there is no common definition of high- or low-GWP, in the European Union Fluorinated Greenhouse Gas Regulations, a value of 150 or higher is often referred to as high. In addition to these bans on specific HFC use, there is an HFC phasedown schedule reducing the allowable amount (GWP-weighted) of HFCs placed on the EU market starting from a cap at the 2009-2012 average in 2015 and reaching a 79\% reduction by 2030 relative to that average. The USA has already implemented incentive credits for use of low-GWP refrigerants (US EPA, 2012) in support of greenhouse gas emission standards for light duty vehicles; it also removed certain high-GWP HFCs from the Significant New Alternatives Policy (SNAP) list of allowable technologies for specific sectors as of 2015 (US EPA, 2015a) $)^{3}$. Japan also adopted a regulation in 2015 to limit the use of high-GWP HFCs for specific sectors (METI, 2015).

The regulations in the EU, USA, Japan, and elsewhere likely will drive changes in sector technologies (i.e., technologies and HFC-blends that currently use high-GWP HFCs) such as refrigeration, stationary and mobile AC, and foams. Consequently, these new technologies will likely also be available for other countries, thereby increasing the climate benefits of these national regulations. With global adoption of these technologies in a revised scenario, the 2050 emissions (excluding HFC-23) in the baseline scenario of 4.0-5.3 $\mathrm{GtCO}_{2}$-eq $\mathrm{yr}^{-1}$ are reduced to 1.5-1.9 $\mathrm{GtCO}_{2}$-eq $\mathrm{yr}^{-1}$ following the regulations in the $\mathrm{EU}$, to 1.9-2.5 $\mathrm{GtCO}_{2}$-eq $\mathrm{yr}^{-1}$ following the regulations in

\footnotetext{
3 In the USA, a process in the U.S. Court of Appeals is underway for SNAP rule 20, related to enabling a transition away from HFCs under Section 612 of the Clean Air Act. Implementation of the Court's direction is unclear under the EPA SNAP structure, so EPA has provided guidance stating that they will not enforce the HFC aspects of the rule while it is rewritten in compliance with the decision. (US EPA, 2018).
}

the USA, and to $2.0-2.6 \mathrm{GtCO}_{2}$-eq $\mathrm{yr}^{-1}$ following the regulations in Japan (Figure 2-18). These regulations will also lead to slower increases in radiative forcing from HFCs. The GWP-weighted emissions following the regulations are anticipated to more or less level off after 2030, at slightly more than half (reduction of $51-65 \%)$ the emissions of the baseline scenario; however, the radiative forcing continues to increase and is only reduced by $28-41 \%$ in 2050 compared to the baseline scenario because of the long atmospheric lifetimes (5-50 years) of the major high-GWP HFCs (Figure 2-18).

\subsubsection{Projected Impact of the Kigali Amendment}

Under the Kigali Amendment there are different base level years and phasedown schedules for developed countries (non-A5 Parties) and two groups of developing countries (A5 Parties) (Table 2-1). Following the Amendment, the allowable GWP-weighted HFC production and consumption will have to be reduced to $15-20 \%$ of the base level by $2045-2047$ for developing countries and to $15 \%$ of the base level by 2036 for developed countries.

The Kigali Amendment requires global implementation to significantly limit future radiative forcing from HFCs. The national (e.g., USA and Japan) and regional (EU) regulations (see Section 2.5.1.3) that are already in place will aid and accelerate developed and developing countries' efforts to meet the provisions of the Amendment. The largest effect from the Kigali Amendment, though, is expected from the reductions in HFC production and consumption in developing countries. Some reductions in HFC use might have occurred in developing countries as a result of regulations in developed countries through technology transfer, but quantifying such reductions is difficult. Instead, the Kigali Amendment ensures legally binding reductions in HFC production for the first time in both developed and developing countries. Therefore, we discuss here the reductions in emissions and radiative forcing that result from applying the phasedown of the Kigali Amendment to the global baseline scenario, acknowledging that national and regional regulations also play an important role in limiting future climate forcing from HFCs.

With compliance to the Kigali Amendment controls (Table 2-1) and national and regional regulations, the 

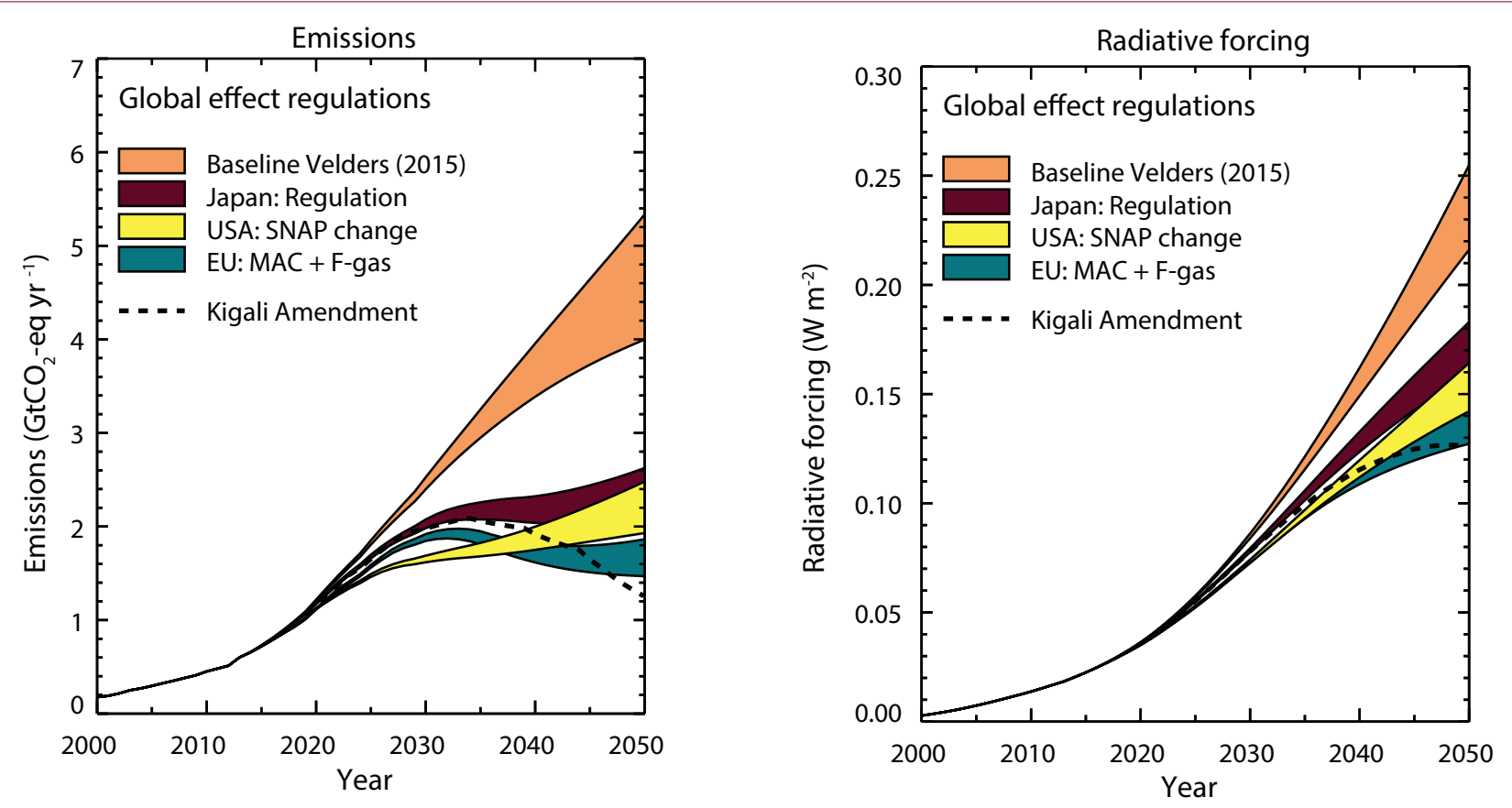

Figure 2-18. Response of global HFC emissions $\left(\mathrm{GtCO}_{2}\right.$-eq $\left.\mathrm{yr}^{-1}\right)$ and global radiative forcing $\left(\mathrm{W} \mathrm{m}^{-2}\right)$ in the baseline scenario of Velders et al. (2015) to global implementation of three national regulations and of the Kigali Amendment (HFC-23 not included). In each case, the national regulation is applied to all countries, with a 5-year delay of the regulations for developing countries. The emissions and radiative forcing shown here are based on the GWPs and radiative efficiencies used in Velders et al. (2015), which differ somewhat from those in Table 2-2. (Note: see Section 2.5.1.2 for the status of the HFC regulations under SNAP).

peak in global production and consumption of HFCs is expected to occur around 2025. HFC emissions are projected to peak about a decade later (Figures 2-18 and 2-19; note these figures do not include HFC-23) because HFCs used as refrigerants in refrigeration and air conditioning systems are emitted gradually over a period of about a decade from the equipment during and after use (so-called banks). The total HFC bank, therefore, represents a potentially substantial source of emissions and radiative forcing even after production ceases (Velders et al., 2014). Despite this bank, adherence to controls in the Kigali Amendment results in HFC emissions from developed countries that are reduced from the baseline scenario level of $0.8-1.0 \mathrm{GtCO}_{2}$-eq $\mathrm{yr}^{-1}$ to $0.16 \mathrm{GtCO}_{2}$-eq $\mathrm{yr}^{-1}$ by 2050 , and in developing countries, emissions are reduced from 3.2-4.4 $\mathrm{GtCO}_{2}$-eq $\mathrm{yr}^{-1}$ to $1.1 \mathrm{GtCO}_{2}$-eq yr${ }^{-1}$, for a total reduction from $4.0-5.3 \mathrm{GtCO}_{2}$-eq $\mathrm{yr}^{-1}$ to 1.3 $\mathrm{GtCO}_{2}$-eq $\mathrm{yr}^{-1}$. The total reduction by 2100 is from 6.1-9.3 $\mathrm{GtCO}_{2}$-eq $\mathrm{yr}^{-1}$ to $0.6 \mathrm{GtCO}_{2}$-eq $\mathrm{yr}^{-1}$. So, the estimated benefit of the Amendment is the avoidance of 2.8-4.1 $\mathrm{GtCO}_{2}$-eq $\mathrm{yr}^{-1}$ emissions by 2050 and 5.6$8.7 \mathrm{GtCO}_{2}$-eq yr${ }^{-1}$ by 2100 . For comparison, total $\mathrm{CH}_{4}$ emissions are projected to be $7.0-25 \mathrm{GtCO}_{2}$-eq yr ${ }^{-1}$ by 2100 in the RCP6.0 and RCP8.5 scenarios and total $\mathrm{N}_{2} \mathrm{O}$ emissions $5.0-7.0 \mathrm{GtCO}_{2}$-eq $\mathrm{yr}^{-1}$ by 2100 (RCP emissions from Meinshausen et al., 2011; GWPs of $\mathrm{N}_{2} \mathrm{O}$ and $\mathrm{CH}_{4}$ from Myhre and Shindell et al., 2013).

Radiative forcing from HFCs is projected to peak around the middle of the century, or a decade after the peak in emissions, due to continued emissions from the banks and the slow breakdown of the HFCs in the atmosphere (i.e., lifetimes up to about 50 years for HFCs used as ODS substitutes). The response of the global HFC radiative forcing to the Kigali Amendment and national controls is a reduction from $0.22-0.25 \mathrm{~W}$ $\mathrm{m}^{-2}$ in the baseline scenario to $0.13 \mathrm{~W} \mathrm{~m}^{-2}$ by 2050 , and from $0.48-0.77 \mathrm{~W} \mathrm{~m}^{-2}$ to $0.08 \mathrm{~W} \mathrm{~m}^{-2}$ by 2100 . The effects of the Kigali Amendment on global emissions and RF through 2050 are similar to the effects of the different national regulations (discussed above) when implemented globally (Figure 2-18). 

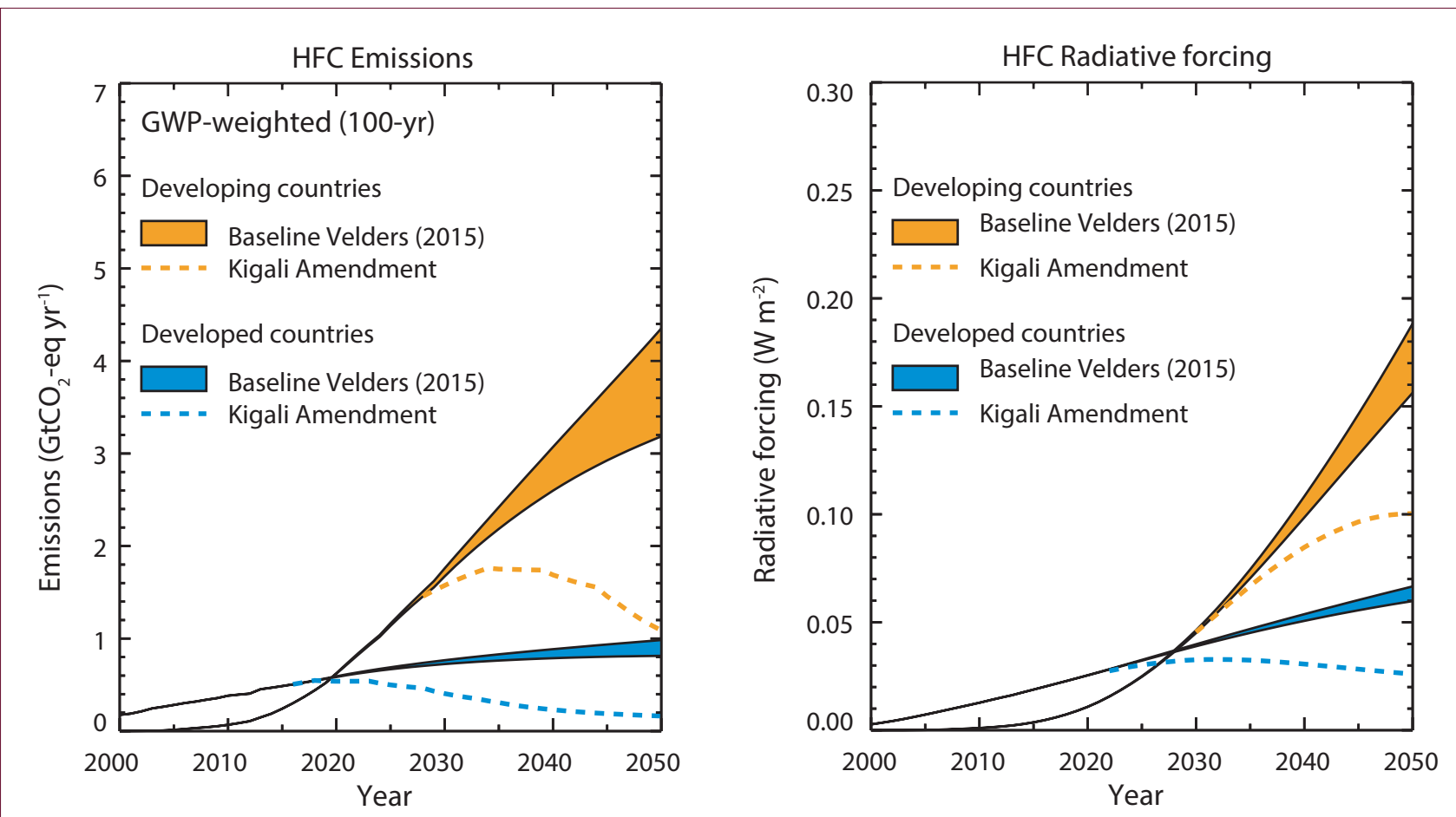

Figure 2-19. Response of $\mathrm{HFC}$ emissions $\left(\mathrm{GtCO}_{2}\right.$-eq $\left.\mathrm{yr}^{-1}\right)$ and radiative forcing in the baseline scenario (Velders et al., 2015) for developed and developing countries to implementation of the Kigali Amendment to the Montreal Protocol (excluding HFC-23). Extending the scenarios beyond 2050 under the same assumptions gives a radiative forcing for the baseline scenario of $0.07-0.12 \mathrm{~W} \mathrm{~m}^{-2}$ and $0.40-0.65$ $\mathrm{W} \mathrm{\textrm {m } ^ { - 2 }}$ in 2100 for the developed and developing countries, respectively. The 2100 radiative forcing under the Kigali Amendment is $0.01 \mathrm{~W} \mathrm{~m}^{-2}$ and $0.06-0.07 \mathrm{~W} \mathrm{~m}^{-2}$ for the developed and developing countries, respectively. The emissions and radiative forcing shown here are based on the GWPs and radiative efficiencies used in Velders et al. (2015), which differ somewhat from those in Table 2-2.

\subsubsection{Climate Impacts OF HFCs}

The radiative forcing from HFCs contributes to changes in atmospheric circulation, temperature, and sea level (see Chapter 5). Atmospheric changes in temperature and circulation arising from HFC emissions lead to a weak, indirect depletion of stratospheric ozone (Hurwitz et al. 2015). Ozone Depletion Potentials (ODPs) of the most relevant HFCs range from 0.00039 for HFC-32 to 0.03 for HFC-23 (see Chapter 1).

Xu et al. (2013) calculate, using a parameterized integrated carbon and radiant energy balance model, a global average surface warming by HFCs of about $0.1^{\circ} \mathrm{C}$ by 2050 and $0.35-0.50^{\circ} \mathrm{C}$ by 2100 , based on the scenarios of Velders et al. (2009) (Figure 2-20). With a different parameterized climate model, they calculated a surface temperature change of $0.10-0.12^{\circ} \mathrm{C}$ for
2050 and $0.28-0.44^{\circ} \mathrm{C}$ for 2100 based on the scenarios of Velders et al. (2015). These scenarios differ in their assumption for the projections of the demand for HFCs past 2050 and the way potential market saturation is taken into account. To calculate the temperature response of HFCs in 2100, the emissions over the whole period from 2000 to 2100 are important. In Figure 2-20 HFC emissions and temperature changes are shown based on the Velders et al. (2015) scenario in which the same assumptions and model are used for the period past 2050 as for 2000-2050.

With the Kigali Amendment and national and regional regulations, the future production and consumption of HFCs is strongly limited (Table 2-1). Under the provisions of the Amendment, the contribution of HFCs to the global average surface temperature is projected to reach a maximum around 2060, after which it slowly decreases to about $0.06^{\circ} \mathrm{C}$ by 2100 (Figure 

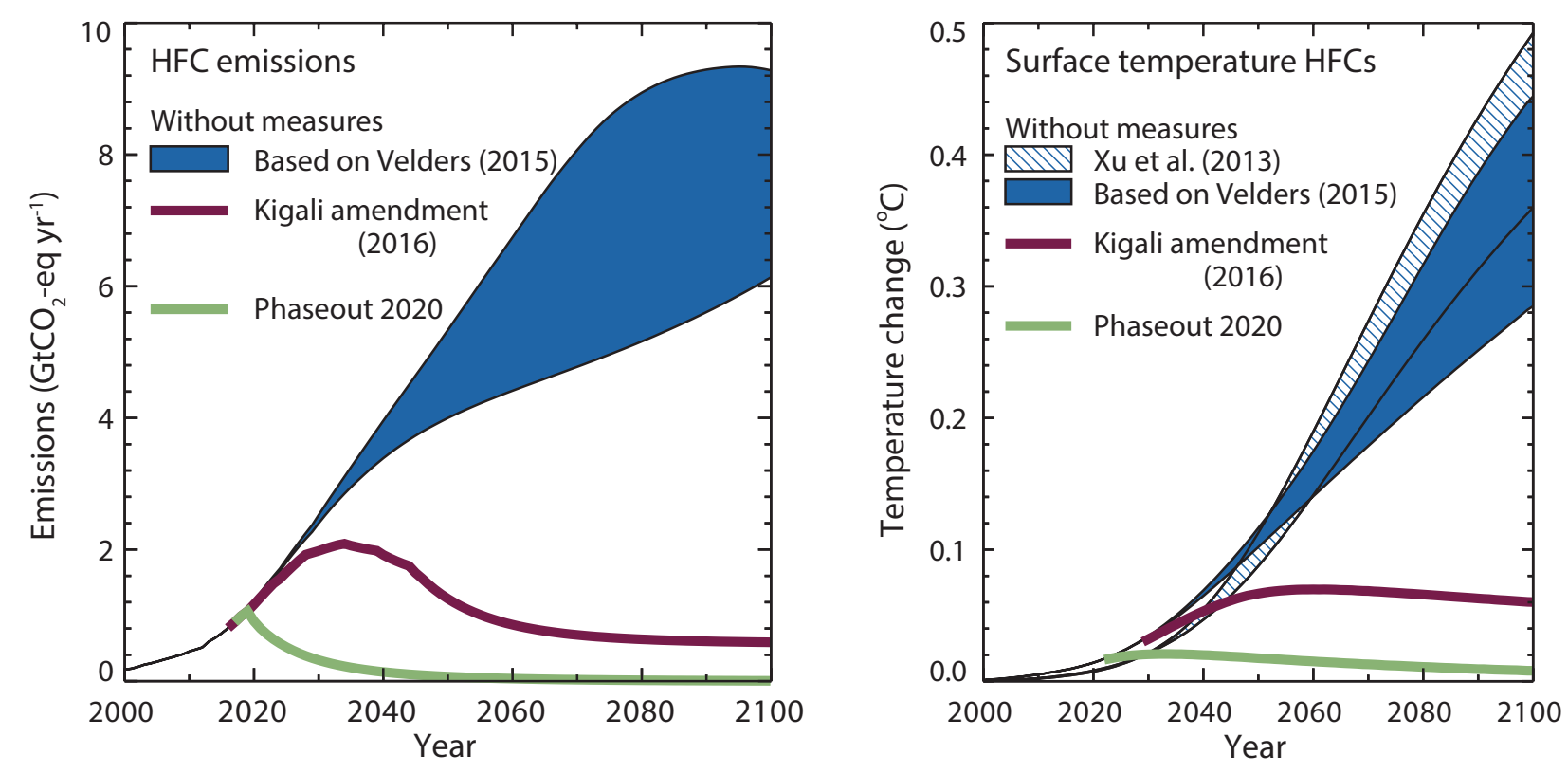

Figure 2-20. HFC emissions and the contribution of HFCs to the global average surface warming of Earth with and without the Kigali Amendment. The scenarios without the measures are based on Xu et al. (2013) and Velders et al. (2015) which differ in their assumptions for the projections of the demand for HFCs past 2050. Also shown is a hypothetical scenario assuming that the global production of HFCs would cease in 2020. The surface temperature change based on Velders et al. (2015) is calculated using the MAGICC6 model. For comparison, the total warming from all greenhouse gases is projected to be $1.4-4.8^{\circ} \mathrm{C}$ by the end of the 21st century following the RCP6.0 and RCP8.5 scenarios (Collins and Knutti et al., 2013). The contribution from HFC-23 is not included here. The emissions shown here are based on the GWPs used in Velders et al. (2015), which differ somewhat from those in Table 2-2; the difference in $\mathrm{CO}_{2}$-eq emissions is less than $1 \%$.

2-20). In contrast, the surface temperature contribution from HFCs in the baseline scenario is $0.3-0.5^{\circ} \mathrm{C}$ in 2100 (based on Xu et al., 2013 and Velders et al., 2015). The difference in projected temperatures is relevant in the context of the 2015 UNFCCC Paris Agreement, which aims to limit the global temperature increase to well below $2^{\circ} \mathrm{C}$ relative to pre-industrial levels.

In Figure 2-20, the effects are also shown of a hypothetical scenario in which the global production of HFCs ceases in 2020. In this case, the emissions start decreasing immediately and the surface temperature contribution of the accumulated HFC emissions is projected to stay below $0.02^{\circ} \mathrm{C}$ for the whole $21 \mathrm{st}$ century. These calculated surface warmings do not include emissions from HFC-23.

Due to the thermal inertia of the ocean, the response of surface temperature and even more so sea level rise through thermal expansion is even slower than changes in radiative forcing from the controls on HFC production. After HFCs, or any other greenhouse gas, stop being emitted, the climate system is not initially in equilibrium with radiative forcing, and the ocean will continue to take up heat until equilibrium is reached (see, e.g., Zickfeld et al., 2017 and $\mathrm{Hu}$ et al., 2013).

Historical and projected concentrations, emissions, and contributions to climate change have been calculated for ODSs, high-GWP HFCs, and low-GWP alternatives (Figure 2-21), assuming full compliance with the Montreal Protocol, including the Kigali Amendment. The phase-down schedule for HFC production and consumption substantially reduces future projected global HFC emissions. Summed HFC emissions are expected to peak before 2040 and decline to less than $1 \mathrm{GtCO}_{2}$-eq $\mathrm{yr}^{-1}$ by 2100 . This peak emission is well below summed ODS emissions at their peak 

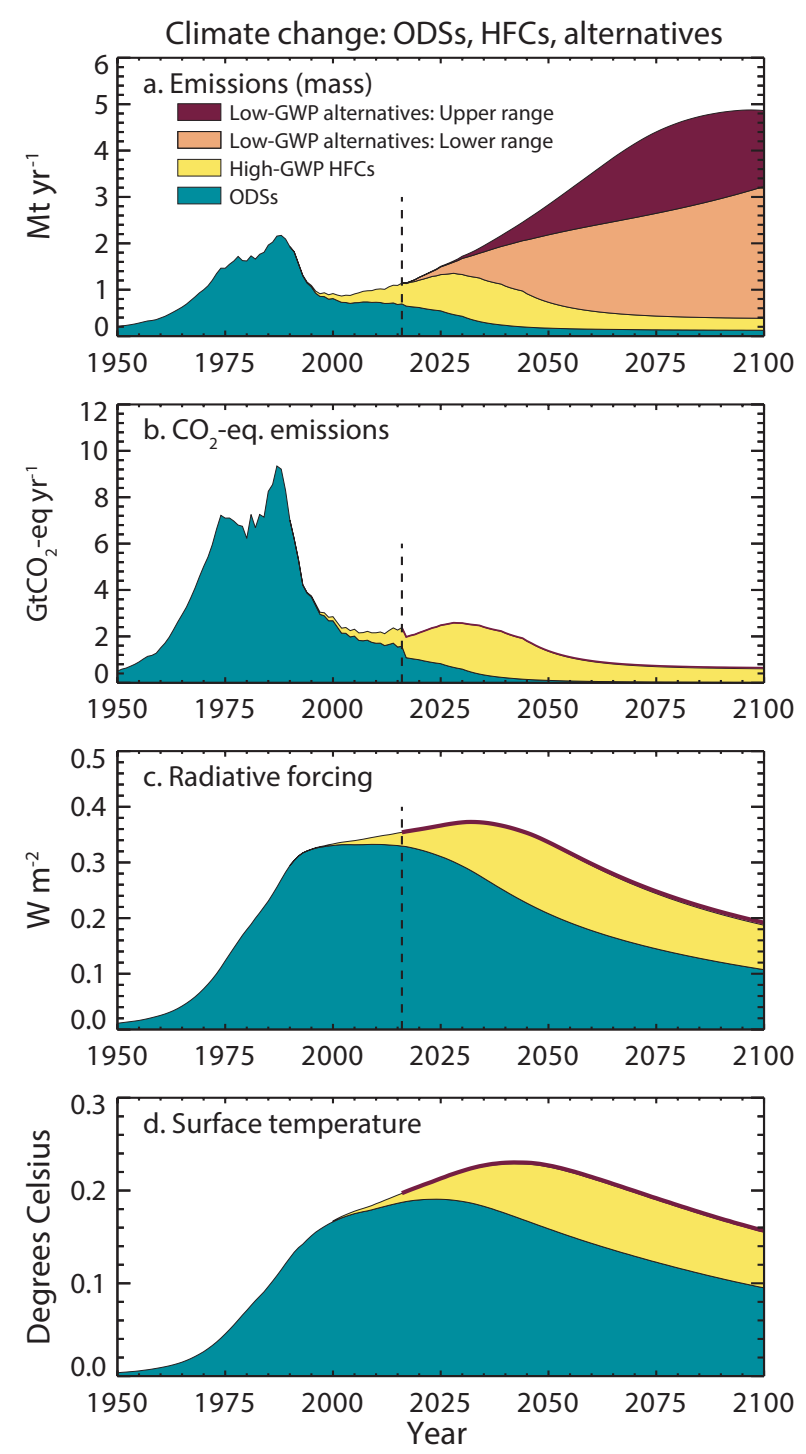

Figure 2-21. Projected contributions to climate change from ODSs, high-GWP HFCs, and low-GWP alternatives assuming full compliance to the provisions of the Montreal Protocol, including the Kigali Amendment. Shown are (a) emissions by mass, (b) $\mathrm{CO}_{2}$-eq emissions, (c) radiative forcing, and (d) average surface temperature contributions. Only the direct GWP-weighted emissions, radiative forcing, and temperature effects of the ODSs and HFCs are shown. The ODS data are from the baseline (A1) scenario of Chapter 6 of this Assessment. The ODS emissions from around 1980 through 2016 are derived from atmospheric observations and after 2016 are from the scenario (distinction indicated by dashed vertical lines). The projected HFC quantities follow the controls of the Kigali Amendment assuming full compliance (Figure 2-20). The projections of the low-GWP alternatives result from imposing the controls of the Kigali Amendment to the HFC baseline scenario (curve in Figure 2-20 labeled 'without measures'; Velders et al., 2015). The difference between the HFC baseline scenario and the Kigali Amendment scenario are assigned here to the low-GWP alternatives. These could be chemicals with a GWP of less than 20 or alternative technologies. The low-GWP alternatives scenario assumes that the alternatives use the same amount (by mass) per application as the HFCs they replace. The curve with the low-GWP alternatives is based on the upper and lower range scenarios from Velders et al. (2015) and Figure 2-20. The contributions of the low-GWP alternatives in panels b, c, and d are smaller than the thickness of the green curves. Not included here are contributions from HFC-23, indirect radiative effects from ozone depletion, and indirect effects associated with the energy used by equipment and the associated $\mathrm{CO}_{2}$ emissions. 
in the 1980s. Only marginal increases are projected for $\mathrm{CO}_{2}$-eq emissions of the low-GWP alternatives despite substantial projected increases in the mass of their emissions.

A more complete understanding of the climate impact of refrigerant-using equipment can be accomplished through more detailed analysis of, for example, the Life Cycle Climate Performance (LCCP), which includes direct and indirect emissions (i.e., those associated with energy use) as well as associated emissions from production and disposal (see e.g., Papasavva et al., 2010; Section 2.5.2.3).

\subsubsection{HFC-23 PROJECTION}

Emissions of HFC-23 originate predominantly as a by-product of HCFC-22 production, and they have continued despite mitigation efforts. HFC-23 is a strong infrared absorber and has the longest lifetime (228 years) and highest GWP (12,690 for a 100-year time horizon; Table 2-2; see Section 2.3) of the HFCs considered in this Assessment. The amount of HFC23 emitted depends on the amount of HCFC-22 produced, the yield of HFC-23 from the production process, and the degree to which produced HFC-23 is incinerated. Although HFC-23 is included under the phasedown schedule with other HFCs (Table 2-1), a separate provision is additionally included for HFC-23 in the Amendment that states: "Each country manufacturing HCFC-22 or HFCs shall ensure that starting in 2020 the emissions of HFC-23 generated in production facilities are destroyed to the extent practicable using technology approved by the Montreal Protocol" (UNEP, 2016a). Without abatement, HFC23 emissions were projected to increase to $\sim 20 \mathrm{Gg} \mathrm{yr}^{-1}$ by 2016 and $\sim 24 \mathrm{Gg} \mathrm{yr}^{-1}$ by 2035 (Miller and Kuijpers, 2011). Emissions for 2016, derived from atmospheric observations, are $12.3 \mathrm{Gg} \mathrm{yr}^{-1}$, well below the worstcase scenario, but above the best-practice scenario of $\sim 11 \mathrm{Gg} \mathrm{yr}^{-1}$. With implementation of the provisions of the Kigali Amendment, future HFC-23 emissions are expected to be limited significantly.

Recently, developments in chemical synthesis may have opened up the use of HFC-23 as feedstock for the production of a wide range of $-\mathrm{CF}_{3}$ containing fluorochemicals (Grushin, 2014), which may affect future HFC-23 emissions.

\subsubsection{HFC Alternatives}

\subsubsection{Alternatives: HFOs, Hydrocarbons, $\mathrm{CO}_{2}, \mathrm{NH}_{3}$, Not-In-Kind Alternatives}

Commercially-available alternatives with low- to medium-GWPs are available for high-GWP HFCs for many refrigeration and $\mathrm{AC}$ sector applications; however, more supporting work (e.g., standards development and code adoption) is needed for use of some of the lowest GWP options and fastest growing sectors, such as certain air conditioning sectors. Efforts to optimize cooling capacity and energy efficiency performance of refrigeration and air conditioning equipment containing low-GWP and zero-ODP refrigerants continue to make progress, as do standards development in all sectors.

In recent years, there has been a focus on natural refrigerants $\left(\mathrm{CO}_{2}\right.$, hydrocarbons, and ammonia), lowGWP HFCs, and HFOs alone or in blends with saturated HFCs to replace fluids with high-GWP. The use of hydrocarbons (e.g., iso-butane [R-600a] and propane [R-290]), ammonia (R-717), and carbon dioxide (R-744) continues.

European domestic refrigerator and freezer manufacturers have been required to use refrigerants with a GWP less than 150 since 2015 (EU, 2014). In the USA, domestic appliance manufacturers have created a voluntary commitment to convert away from HFC-134a use as a refrigerant (AHAM, 2016). A charge size of up to $57 \mathrm{~g}$ of iso-butane (R-600a) has been allowed in refrigeration and has been in commercial use for some time in self-contained refrigerated food cases and smaller domestic refrigerators (US EPA, 2011). Other options to replace HFC-134a include HFC-1234yf, HFC-152a, and non-flammable blends of HFOs and HFCs. European commercial refrigeration GWP limits are phased in gradually; limits are initially placed on HFCs with GWPs greater than 2,500, and in 2020, on HFCs with GWPs larger than 150 in applications where alternatives are available and affordable. In addition, there is a service ban on HFCs having GWPs greater than 2,500 starting in 2020 (EU, 2014). In the USA, the HFC-blend R-404A is not allowed in new equipment as of 1 January 2017 for supermarkets, as of 1 January 2018 for condensing units, and as of 1 January 2019 for self-contained systems (2020 for larger systems). High-GWP blends such as R-404A 
are not allowed in new refrigerated food processing and dispensing equipment from 1 January 2021 and in new warehouse applications from 1 January 2023 (US EPA, 2015a). Canada has published draft recommendations that limit the use of fluids having GWPs above 650 starting in 2020 for stand-alone, medium temperature commercial refrigeration systems and they limit the use of fluids having GWPs above 1,500 in stand-alone low temperature commercial refrigeration (Environment and Climate Change Canada, 2017).

Low-GWP refrigerant blends of $\mathrm{HFC} / \mathrm{HFO} /$ hydrochlorofluoroolefins (such as R-448A, R-449A, R-449B, R-450A, and R-513A; Table 2-4) have GWPs that are $50-70 \%$ lower than refrigerants they typically replace, and they are in commercial use in refrigeration equipment. The use of R-407A and R-407F (at approximately half the GWP of R-404A) continues to grow in many parts of the world. Non-halocarbon refrigerants such as $\mathrm{CO}_{2}$ (R-744) and propane (R-290) are increasingly being used in supermarkets.

\subsubsection{SAfETy IsSUES}

Some alternatives to high-GWP HFCs (e.g., water and inert gases) pose no safety risk to handle but others do entail some risk. According to safety ratings, hydrocarbons have higher flammability than most HFCs, while ammonia and some HFOs have lower flammability, and $\mathrm{CO}_{2}$ is non-flammable. Safety ratings also indicate higher toxicity for ammonia than for most HFCs and lower toxicity for hydrocarbons, HFC-1234yf, and $\mathrm{CO}_{2}$ (ASHRAE, 2016). Safety issues can be resolved by changes in design of equipment, limiting the refrigerant charge sizes, and limiting potential emissions (UNEP, 2011).

\subsubsection{Energy EfFiciency VIS-À-VIS GWP}

The overall life-cycle climate impact of refrigeration and air conditioning applications that use halocarbons as refrigerants depends on many factors including, but not limited to

- the GWP of the refrigerant used,

- the loss (or recovery) of the refrigerant at the end of life of the equipment,

- the leakage rate of the refrigerant and recharge rates during service,
- the energy required to operate the coolant device,

- the number of hours that the equipment is used, and

- the carbon intensity of the electricity used to power the equipment.

Of these, for most applications, emissions due to the energy use of the equipment tend to dominate the life-cycle emissions (unless the grid is exceptionally free of carbon-emitting energy sources or the hours of use are very low). For example, Goetzler et al. (2016) estimated $73-76 \%$ of global $\mathrm{CO}_{2}$-eq emissions from AC systems in 2010 to be indirect emissions from the energy use. Hence the energy efficiency resulting from the use of specific refrigerants is a very important consideration.

In the context of the Montreal Protocol, energy efficiency ${ }^{4}$ has had a range of commonly accepted meanings, which include, but are not limited to the following:

1. The performance of a refrigerant relative to an HFC, HCFC, or CFC refrigerant being replaced such that it consumes less energy to perform the same service in the same (or similar) refrigeration or air-conditioning equipment, henceforth referred to as "refrigerant energy efficiency".

2. The performance of refrigeration or air-conditioning equipment by replacing one or more components other than the refrigerant such that it consumes less energy to perform the same service, henceforth referred to as "equipment energy efficiency".

There are other methods to reduce energy consumption in refrigeration, air conditioning, or other applications in which halocarbons are used, which fall under a broader consideration of "energy efficiency", such as using building insulation or maintenance to ensure optimal operation. Such methods (sometimes called "not-in-kind") are less germane to a discussion of energy efficiency in the context of the Montreal

\footnotetext{
4 Sometimes "energy efficiency" is also used to denote a metric or quantitative measure designed to measure the amount of energy used to perform a particular service, e.g., reduce the temperature of one ton of chilled water by 1 degree $C$. The less energy used to perform the same service, the more energy efficient the technology being used.
} 
Protocol, since the influence of these approaches is generally independent of the chemical chosen as coolant.

Many studies have been conducted to evaluate both types of energy efficiency improvement mentioned above (e.g., Schultz, 2016; Abdelaziz et al., 2015). For example, in a study of refrigerant energy efficiency in air conditioners, Schultz (2016) found that some alternate low-GWP refrigerants, e.g., HFC-32 and R-452B (blend of 67\% HFC-32, 7\% HFC-125, and 26\% HFC1234yf, also referred to as DR-55), perform as well as or better than the HFC refrigerant R-410A (blend of 50\% HFC-32 and 50\% HFC-125). Meanwhile, Abdelaziz et al. (2015) found that the low-GWP refrigerant R-290 (propane) achieved a slightly higher efficiency than HCFC-22, but with a slightly lower cooling capacity under test conditions.

Equipment energy efficiency has been evaluated mainly under the aegis of market transformation programs for energy efficiency such as those run by the EU Ecodesign program (EuP, 2008) and the U.S. Department of Energy (DOE, 2017). Shah et al. (2013) found that a $\sim 30 \%$ efficiency improvement, relative to current technologies, for air conditioners was cost-effective in many economies.

The conversion from using HFC refrigerants with high GWPs to refrigerants with lower GWPs, which will most likely result from the Kigali Amendment, provides an opportunity to consider other technological improvements that offer additional climate benefits through improvements in equipment energy efficiency.

Shah et al. (2015) found that if, in 2030, the world mini-split AC stock (i.e., the total number of installed and operational mini-split $\mathrm{ACs}^{5}$ ) transitioned from high-GWP, low-efficiency equipment to low-GWP refrigerants such as HFC-32 or propane (R-290), coupled with improved equipment that was $30 \%$ more efficient, the climate benefit over the $\sim 10$ year lifetime of the ACs would be over $25 \mathrm{GtCO}_{2}$-eq emissions. This would roughly double the $\mathrm{CO}_{2}$-eq emission reductions in comparison with either policy (refrigerant transition or equipment energy efficiency improvement) implemented in isolation. The combined direct and indirect emissions abatement from both policies implemented together for mini-split ACs would be roughly $98 \mathrm{GtCO}_{2}$-eq emissions by 2050 , as a result of the large projected growth in ACs in developing countries (Figure 2-22). Regions with higher hours of use or more carbon-intensive electricity grids would benefit more from energy efficiency improvement.

Based on the various alternate refrigerant testing programs listed above and the various energy efficiency market transformation studies, similar results (in \% terms) may also be found for other air-conditioning and refrigeration equipment. Results are dependent on hours of use, emissions during operation or at end of life, grid carbon intensity, growth rates, and other relevant factors.

In conclusion, improvements in energy efficiency in refrigeration and air conditioning equipment during the transition to low-GWP alternative refrigerants can potentially double the climate benefits of the HFC phasedown of the Kigali Amendment. The potential magnitude of these combined benefits would contribute to achieving the targets of the UNFCCC 2015 Paris Agreement, which aims to keep global temperature rise this century well below $2{ }^{\circ} \mathrm{C}$ above pre-industrial levels.

\footnotetext{
5 Mini-split ACs are the most widely used type of AC system,
} representing roughly $\sim 70 \%$ of sales by unit worldwide. 


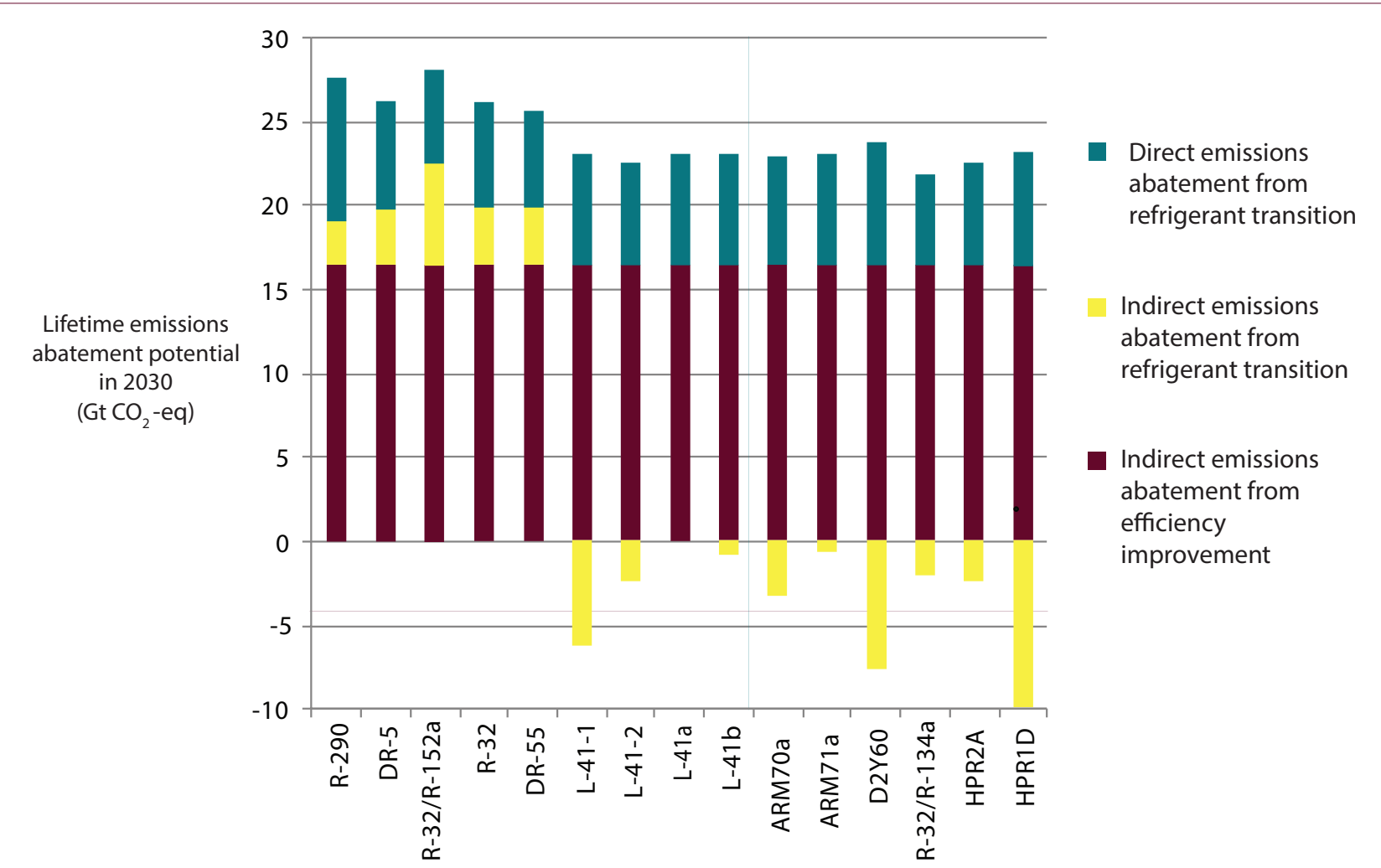

Figure 2-22. Estimated emissions abatement potential of air conditioning (AC) Stock in 2030 over 10-year AC lifetime. Positive numbers indicate $\mathrm{CO}_{2}$ emission reductions while negative numbers indicate increases in $\mathrm{CO}_{2}$ emissions ${ }^{1}$. Source: Shah et al. (2015). The purple bar indicates the "indirect" emissions abatement from the $\sim 30 \%$ equipment efficiency improvement (compared with current technologies) while the yellow bar indicates the "indirect" emissions abatement refrigerant energy efficiency improvement (or reduction), and the blue bar indicates the direct emissions abatement due to the lower GWP of the refrigerant compared to the commonly used AC refrigerant R-410A ${ }^{2}$. See Table 2-4 for the acronyms of the different refrigerants. R32/ R152a is a blend of 95\% HFC-32 and 5\% HFC-152a. R32/R134a is a blend of 95\% HFC-32 and 5\% HFC-134a.

1 Shah et al. (2015) estimated the world AC stock (\# of installed units) will grow from 900 million units in 2015 to roughly 1.6 billion units in 2030.

2 Indirect emissions are emissions from the electricity grid due to the energy consumption of the equipment, while direct emissions are emissions of the refrigerant from the equipment due to leakage or at the end of life. 


\section{REFERENCES}

Abdelaziz, O., S.S. Shrestha, J.D. Munk, R.L. Linkous, W. Goetzler, M. Guernsey, and T. Kassuga, Alternative Refrigerant Evaluation for High-AmbientTemperature Environments: $R-22$ and $R-410 A$ Alternatives for Mini-Split Air Conditioners, No. ORNL/TM-2015/536, Oak Ridge National Laboratory, Oak Ridge, Tennessee, USA, https:// energy.gov/sites/prod/files/2015/10/f27/bto_ pub59157_101515.pdf, 2015.

AHAM (Association of Home Appliance Manufacturers), Home Appliance Industry Sets Goal to Eliminate Use of HFC Refrigerants, http://www. aham.org/AHAM/News/Latest_News/Home_ Appliance_Industry_Sets_Goals_to_Eliminate_ Use_of_HFC_Refrigerants.aspx, 2016.

Ammann, M., R.A. Cox, J.N. Crowley, H. Herrmann, M.E. Jenkin, V.F. McNeil, A. Mellouki, M.J. Rossi, J. Troe, and T.J. Wallington, IUPAC Task Group on Atmospheric Chemical Kinetic Data Evaluation, http://iupac.pole-ether.fr, 2017.

Andersen, S.O., M.L. Halberstadt, and N. BorgfordParnell, Stratospheric ozone, global warming, and the principle of unintended consequences-An ongoing science and policy success story, J. Air Waste Manag. Assoc., 63 (6), 607-647, doi:10. 1080/10962247.2013.791349, 2013.

Arnold, T., D.J. Ivy, C.M. Harth, M.K. Vollmer, J. Mühle, P.K. Salameh, L.P. Steele, P.B. Krummel, R.H.J. Wang, D. Young, C.R. Lunder, O. Hermansen, T.S. Rhee, J. Kim, S. Reimann, S. O'Doherty, P.J. Fraser, P.G. Simmonds, R.G. Prinn, and R.F. Weiss, HFC-43-10mee atmospheric abundances and global emission estimates, Geophys. Res. Lett., 41 (6), 2228-2235, doi:10.1002/2013GL059143, 2014.

ASHRAE (American Society of Heating, and Refrigerating and Air-Conditioning Engineers), Refrigerant Designations, ANSI/ASHRAE 34-2016m, http://www.ashrae.org/technical-resources/ standards-and-guidelines/ashrae-refrigerant-designations, 2016.

Baasandorj, M., and J.B. Burkholder, Rate coefficient for the gas-phase $\mathrm{OH}+\mathrm{CHF}=\mathrm{CF}_{2}$ reaction between 212 and $375 \mathrm{~K}$, Int. J. Chem. Kinet., 48 (11), 714-723, doi:10.1002/kin.21027, 2016.

Baasandorj, M., P. Marshall, R.L. Waterland, A.R. Ravishankara, and J.B. Burkholder, Rate coeffi- cient measurements and theoretical analysis of the $\mathrm{OH}+(E)-\mathrm{CF}_{3} \mathrm{CH}=\mathrm{CHCF}_{3}$ reaction, J. Phys. Chem. A, 122(19), 4635-4646, doi:10.1021/acs. jpca.8b02771, 2018.

Barletta, B., P. Nissenson, S. Meinardi, D. Dabdub, F. Sherwood Rowland, R.A. VanCuren, J. Pederson, G.S. Diskin, and D.R. Blake, HFC-152a and HFC134a emission estimates and characterization of CFCs, CFC replacements, and other halogenated solvents measured during the 2008 ARCTAS campaign (CARB phase) over the South Coast Air Basin of California, Atmos. Chem. Phys., 11 (6), 2655-2669, doi:10.5194/acp-11-2655-2011, 2011.

Brunner, D., T. Arnold, S. Henne, A. Manning, R.L. Thompson, M. Maione, S. O'Doherty, and S. Reimann, Comparison of four inverse modelling systems applied to the estimation of HFC-125, HFC134a, and $\mathrm{SF}_{6}$ emissions over Europe, Atmos. Chem. Phys., 17 (17), 10651-10674, doi:10.5194/ acp-17-10651-2017, 2017.

Burkholder, J.B., R.A. Cox, and A.R. Ravishankara, Atmospheric degradation of ozone depleting substances, their substitutes, and related species, Chem. Rev., 115 (10), 3704-3759, doi:10.1021/ cr5006759, 2015a.

Burkholder, J.B., S.P. Sander, J. Abbatt, J.R. Barker, R.E. Huie, C.E. Kolb, M.J. Kurylo, V.L. Orkin, D.M. Wilmouth, and P.H. Wine, Chemical Kinetics and Photochemical Data for Use in Atmospheric Studies, Evaluation No. 18, JPL Publication 1510, Jet Propulsion Laboratory, Pasadena, Calif., http://jpldataeval.jpl.nasa.gov/, 2015b.

Carpenter, L.J., S. Reimann (Lead Authors), J.B. Burkholder, C. Clerbaux, B.D. Hall, R. Hossaini, J.C. Laube, S.A. Yvon-Lewis, Update on Ozone-Depleting Substances (ODSs) and Other Gases of Interest to the Montreal Protocol, Chapter 1 in Scientific Assessment of Ozone Depletion: 2014, Global Ozone Research and Monitoring ProjectReport No. 55, World Meteorological Organization, Geneva, Switzerland, 2014.

CDIAC (Carbon Dioxide Information Analysis Center), The ALE / GAGE / AGAGE Network (DB1001), Investigators: R.G. Prinn, R.F. Weiss, P.B. Krummel, S. O’Doherty, P.J. Fraser, J. Mühle, S. Reimann, M.K. Vollmer, P.G. Simmonds, M. Maione, J. Arduini, C.R. Lunder, N. Schmidbauer, D. Young, H.J. Wang, J. Huang, M. Rigby, C.M. Harth, P.K. Salameh, T.G. Spain, L.P. Steele, T. Ar- 
nold, J. Kim, O. Hermansen, N. Derek, B. Mitrevski, and R. Langenfelds, Oak Ridge National Laboratory, doi:10.3334/CDIAC/atg.db1001, 2016.

Chen, L., T. Uchimaru, S. Kutsuna, K. Tokuhashi, A. Sekiya, and H. Okamoto, Kinetics and mechanism of gas-phase reaction of $\mathrm{CF}_{3} \mathrm{CF}_{2} \mathrm{CF}_{2} \mathrm{CF}_{2}$ $\mathrm{CF}_{2} \mathrm{CF}_{2} \mathrm{CF}_{2} \mathrm{CF}_{2} \mathrm{H}$ with $\mathrm{OH}$ radicals in an environmental reaction chamber at $253-328 \mathrm{~K}$, Chem. Phys. Lett., 501 (4), 263-266, doi:10.1016/j. cplett.2010.12.009, 2011.

Collins, M., R. Knutti, (Lead Authors), J. Arblaster, J.L. Dufresne, T. Fichefet, P. Friedlingstein, X. Gao, W.J. Gutowski, T. Johns, G. Krinner, M. Shongwe, C. Tebaldi, A.J. Weaver, M. Wehner, Long-term Climate Change: Projections, Commitments and Irreversibility, Chapter 12 in Climate Change 2013: The Physical Science Basis: Contribution of Working Group I to the Fifth Assessment Report of the Intergovernmental Panel on Climate Change, edited by T.F. Stocker, D. Qin, G.-K. Plattner, M. Tignor, S.K. Allen, J. Boschung, A. Nauels, Y. Xia, V. Bex, and P.M. Midgley, Cambridge University Press, Cambridge, United Kingdom, 2013.

Cunnold, D.M., R.G. Prinn, R.A. Rasmussen, P.G. Simmonds, F.N. Alyea, C.A. Cardelino, A.J. Crawford, P.J. Fraser, and R.D. Rosen, The Atmospheric Lifetime Experiment: 3. Lifetime methodology and application to three years of $\mathrm{CFCl}_{3}$ data, $J$. Geophys. Res., 88 (C13), 8379-8400, doi:10.1029/ JC088iC13p08379, 1983.

DeMore, W.B., Experimental and estimated rate constants for the reactions of hydroxyl radicals with several halocarbons, J. Phys. Chem., 100 (14), 5813-5820, doi:10.1021/jp953216+, 1996.

DOE (U.S. Department of Energy), Technical Support Document: Energy Efficiency Program for Consumer Products: Residential Central Air Conditioners and Heat Pumps, Washington, D.C., http:// www.regulations.gov/contentStreamer?documentId=EERE-2014-BT-STD-0048-0098\&attachmentNumber $=1 \&$ contentType $=$ pdf, 2017.

EDGAR, European Commission, Joint Research Centre / Netherlands Environmental Assessment Agency, Emission Database for Global Atmospheric Research (EDGAR), release version 4.2 FT2010, http://edgar.jrc.ec.europa.eu/overview. php?v=42FT2010, 2013.

Environment and Climate Change Canada, Canada Environmental Protection Act, 1999, Regulations
Amending the Ozone-Depleting Substances and Halocarbon Alternatives Regulations, Part II Vol. 151, http://www.puntofocal.gov.ar/notific_otros_ miembros/can507a1_t.pdf, 2017.

EU (European Union), Directive 2006/40/EC of the European Parliament and of the Council of 17 May 2006 relating to emissions from air-conditioning systems in motor vehicles, OJEU, L161, 14.6.2006, 12-18, 2006.

EU (European Union), Regulation (EU) No 517/2014 of the European Parliament and of the Council of 16 April 2014 on fluorinated greenhouse gases and repealing Regulation (EC) No 842/2006, OJEU, L150, 195-230, http://eur-lex.europa. eu/legal-content/EN/TXT/PDF/?uri=CELEX:32014R0517\&from=EN, 2014.

EuP, Preparatory study on the environmental performance of residential room conditioning appliances (airco and ventilation), Final Report of Task 6, http://www.eup-network.de/fileadmin/user_upload/Produktgruppen/Aircon_Final_report_of_ Task_6.pdf, European Commission Ecodesign Directive, 2008.

Fang, X., A. Stohl, Y. Yokouchi, J. Kim, S. Li, T. Saito, S. Park, and J. Hu, Multiannual top-down estimate of HFC-23 emissions in East Asia, Environ. Sci. Technol., 49 (7), 4345-4353, doi:10.1021/ es505669j, 2015.

Fang, X., G.J.M. Velders, A.R. Ravishankara, M.J. Molina, J. Hu, and R.G. Prinn, Hydrofluorocarbons (HFCs) emissions in China: An inventory for 2005-2013 and projections to 2050, Environ. Sci. Technol., 50 (4), 2027-2034, doi:10.1021/acs. est.5b04376, 2016.

Fortems-Cheiney, A., M. Saunois, I. Pison, F. Chevallier, P. Bousquet, C. Cressot, S.A. Montzka, P.J. Fraser, M.K. Vollmer, P.G. Simmonds, D. Young, S. O’Doherty, R.F. Weiss, F. Artuso, B. Barletta, D.R. Blake, S. Li, C. Lunder, B.R. Miller, S. Park, R. Prinn, T. Saito, L.P. Steele, and Y.C.J. Yokouchi, Increase in HFC-134a emissions in response to the success of the Montreal Protocol, J. Geophys. Res., 120 (22), 11,728-11,742, doi: 10.1002/2015JD023741, 2015.

Goetzler, W., M. Guernsey, J. Young, J. Fuhrman, and O. Abdelaziz., The Future of Air Conditioning for Buildings-Executive Summary (DOE/EE-1394), Oak Ridge National Laboratory, Oak Ridge, Tennessee, USA, https://energy.gov/sites/prod/ 
files/2016/07/f33/The\%20Future\%20 of\%20 AC\%20Report\%20-\%20Executive\%20Summary_0.pdf, 2016.

Graziosi, F., J. Arduini, F. Furlani, U. Giostra, P. Cristofanelli, X. Fang, O. Hermanssen, C. Lunder, G. Maenhout, S. O'Doherty, S. Reimann, N. Schmidbauer, M.K. Vollmer, D. Young, and M. Maione, European emissions of the powerful greenhouse gases hydrofluorocarbons inferred from atmospheric measurements and their comparison with annual national reports to UNFCCC, Atmos. Environ., 158, 85-97, doi:10.1016/j.atmosenv.2017.03.029, 2017.

Grushin, V.V., Fluoroform as a feedstock for highvalue fluorochemicals: Novel trends and recent developments, Chimi. Oggi-Chem. Today, 32 (3), 81-88, 2014.

Gschrey, B., W. Schwarz, C. Elsner, and R. Engelhardt, High increase of global F-gas emissions until 2050, Greenhouse Gas Meas. and Mgmt., 1 (2), 8592, doi:10.1080/20430779.2011.579352, 2011.

Harris, N.R.P., D.J. Wuebbles (Lead Authors), J.S. Daniel, J. Hu, L.J.M. Kuijpers, K.S. Law, M.J. Prather, and R. Schofield, Scenarios and information for policymakers, Chapter 5 in Scientific Assessment of Ozone Depletion: 2014, Global Ozone Research and Monitoring Project-Report No. 55, World Meteorological Organization, Geneva, Switzerland, 2014.

Harrison, J.J., C.D. Boone, A.T. Brown, N.D.C. Allen, G.C. Toon, and P.F. Bernath, First remote sensing observations of trifluoromethane (HFC23 ) in the upper troposphere and lower stratosphere, J. Geophys. Res., 117 (D5), D05308, doi: 10.1029/2011JD016423, 2012.

Harrison, J.J., Infrared absorption cross sections for trifluoromethane, J. Quant. Spect. Rad. Trans., 130, 359-364, doi: 10.1016/j.jqsrt.2013.05.026, 2013.

Harrison, J.J., Infrared absorption cross sections for 1,1,1,2-tetrafluoroethane, J. Quant. Spect. Rad. Trans., 151, 210-216, doi:10.1016/j.jqsrt.2014.09.023, 2015.

Hartmann, D.L., A.M.G.K. Tank, M. Rusticucci (Coordinating Lead Authors), L.V. Alexander, S. Brönnimann, Y.A.-R. Charabi, F.J. Dentener, E.J. Dlugokencky, D.R. Esaterling, A. Kaplan, B.J. Soden, P.W. Thorne, M. Wild, P, Zhai, Observations: Atmosphere and Surface, Chapter 2 in Climate Change 2013: The Physical Science Basis:
Contribution of Working Group I to the Fifth Assessment Report of the Intergovernmental Panel on Climate Change, edited by T.F. Stocker, D. Qin, G.-K. Plattner, M. Tignor, S.K. Allen, J. Boschung, A. Nauels, Y. Xia, V. Bex, and P.M. Midgley, Cambridge University Press, Cambridge, United Kingdom, 2013.

Hodnebrog, Ø., M. Etminan, J.S. Fuglestvedt, G. Marston, G. Myhre, C.J. Nielsen, K.P. Shine, and T.J. Wallington, Global warming potentials and radiative efficiencies of halocarbons and related compounds: A comprehensive review, Rev. Geophys., 51 (2), 300-378, doi:10.1002/rog.20013, 2013.

Höglund-Isaksson, L., P. Purohit, M. Amann, I. Bertok, P. Rafaj, W. Schöpp, and J. Borken-Kleefeld, Cost estimates of the Kigali Amendment to phasedown hydrofluorocarbons, Environ. Sci. Policy, 75, 138-147, doi:10.1016/j.envsci.2017.05.006, 2017.

Hu, A., Y. Xu, C. Tebaldi, W.M. Washington, and V. Ramanathan, Mitigation of short-lived climate pollutants slows sea-level rise, Nature Clim. Change, 3, 730-734, doi:10.1038/nclimate1869, 2013.

Hu, L., S.A. Montzka, S.J. Lehman, D.S. Godwin, B.R. Miller, A.E. Andrews, K. Thoning, J.B. Miller, C. Sweeney, C. Siso, J.W. Elkins, B.D. Hall, D.J. Mondeel, D. Nance, T. Nehrkorn, M. Mountain, M.L. Fischer, S.C. Biraud, H. Chen, and P.P. Tans, Considerable contribution of the Montreal Protocol to declining greenhouse gas emissions from the United States, Geophys. Res. Lett., 44 (15), 8075-8083, doi:10.1002/2017GL074388, 2017.

Hurwitz, M.M., E.L. Flemming, P.A. Newman, F. Li, E. Mlawer, K. Cady-Pereira, and R. Bailey, Ozone depletion by hydrofluorocarbons, Geophys. Res. Lett., 42, 8686-8692, doi:10.1002/2015GL065856, 2015.

Javadi, M.S., R. Søndergaard, O.J. Nielsen, M.D. Hurley, and T.J. Wallington, Atmospheric chemistry of trans $-\mathrm{CF}_{3} \mathrm{CH}=\mathrm{CHF}$ : Products and mechanisms of hydroxyl radical and chlorine atom initiated oxidation, Atmos. Chem. Phys., 8 (12), 3141-3147, doi:10.5194/acp-8-3141-2008, 2008.

Jia, X., L. Chen, J. Mizukado, S. Kutsuna, and K. Tokuhashi, Rate constants for the gas-phase reactions of cyclo- $\mathrm{CX}=\mathrm{CXCF}_{2} \mathrm{CF}_{2}-(\mathrm{X}=\mathrm{H}, \mathrm{F})$ with $\mathrm{OH}$ radicals at a temperature range of $253-328 \mathrm{~K}$, Chem. Phys. Lett., 572, 21-25, doi:10.1016/j. cplett.2013.04.020, 2013.

Keller, C.A., D. Brunner, S. Henne, M.K. Vollmer, S. O'Doherty, and S. Reimann, Evidence for under- 
reported western European emissions of the potent greenhouse gas HFC-23, Geophys. Res. Lett., 38 (15), L15808, doi:10.1029/2011GL047976, 2011.

Keller, C.A., M. Hill, M.K. Vollmer, S. Henne, D. Brunner, S. Reimann, S. O’Doherty, J. Arduini, M. Maione, Z. Ferenczi, L. Haszpra, A.J. Manning, and T. Peter, European emissions of halogenated greenhouse gases inferred from atmospheric measurements, Environ. Sci. Technol., 46 (1), $217-$ 225, doi:10.1021/es202453j, 2012.

Kim, J., S. Li, K.-R. Kim, A. Stohl, J. Mühle, S.-K. Kim, M.-K. Park, D.-J. Kang, G. Lee, C.M. Harth, P.K. Salameh, and R.F. Weiss, Regional atmospheric emissions determined from measurements at Jeju Island, Korea: Halogenated compounds from China, Geophys. Res. Lett., 37 (12), L12801, doi: 10.1029/2010GL043263, 2010.

Laube, J.C., P. Martinerie, E. Witrant, T. Blunier, J. Schwander, C.A.M. Brenninkmeijer, T.J. Schuck, M. Bolder, T. Röckmann, C. van der Veen, $H$. Bönisch, A. Engel, G.P. Mills, M.J. Newland, D.E. Oram, C.E. Reeves, and W.T. Sturges, Accelerating growth of HFC-227ea (1,1,1,2,3,3,3-heptafluoropropane) in the atmosphere, Atmos. Chem. Phys., 10 (13), 5903-5910, doi:10.5194/acp-105903-2010, 2010.

Le Bris, K., J. DeZeeuw, P.J. Godin, and K. Strong, Infrared absorption cross-sections, radiative efficiency and global warming potential of HFC43-10mee, J. Mol. Spectrosc., 348, 64-67, doi: 10.1016/j.jms.2017.06.004, 2017.

Leedham Elvidge, E., H. Bönisch, C.A.M. Brenninkmeijer, A. Engel, P.J. Fraser, E. Gallacher, R. Langenfelds, J. Mühle, D.E. Oram, E.A. Ray, A.R. Ridley, T. Röckmann, W.T. Sturges, R.F. Weiss, and J.C. Laube, Evaluation of stratospheric age of air from $\mathrm{CF}_{4}, \mathrm{C}_{2} \mathrm{~F}_{6}, \mathrm{C}_{3} \mathrm{~F}_{8}, \mathrm{CHF}_{3}$, HFC-125, HFC227ea and $\mathrm{SF}_{6}$; implications for the calculations of halocarbon lifetimes, fractional release factors and ozone depletion potentials, Atmos. Chem. Phys., 18 (5), 3369-3385, doi:10.5194/acp-183369-2018, 2018.

Li, S., J. Kim, K.-R. Kim, J. Mühle, S.-K. Kim, M.-K. Park, A. Stohl, D.-J. Kang, T. Arnold, C.M. Harth, P.K. Salameh, and R.F. Weiss, Emissions of halogenated compounds in east Asia determined from measurements at Jeju Island, Korea, Environ. Sci. Technol. (13), 5668-5675, doi:10.1021/es104124k,
2011.

Luecken, D.J., R.L. Waterland, S. Papasavva, K.N. Taddonio, W.T. Hutzell, J.P. Rugh, and S.O. Andersen, Ozone and TFA impacts in North America from degradation of 2,3,3,3-tetrafluoropropene (HFO$1234 \mathrm{yf})$, a potential greenhouse gas replacement, Environ. Sci. Technol., 44 (1), 343-348, doi: 10.1021/es902481f, 2010.

Lunt, M.F., M. Rigby, A.L. Ganesan, A.J. Manning, R.G. Prinn, S. O’Doherty, J. Mühle, C.M. Harth, P.K. Salameh, T. Arnold, R.F. Weiss, T. Saito, Y. Yokouchi, P.B. Krummel, L.P. Steele, P.J. Fraser, S. Li, S. Park, S. Reimann, M.K. Vollmer, C. Lunder, O. Hermansen, N. Schmidbauer, M. Maione, J. Arduini, D. Young, and P.G. Simmonds, $\mathrm{W} \Sigma \mathrm{W} \sum$ Reconciling reported and unreported HFC emissions with atmospheric observations, Proc. Natl. Acad. Sci., 112 (19), 5927-5931, doi:10.1073/pnas.1420247112, 2015.

Meinshausen, M., S. Smith, K. Calvin, J. Daniel, M. Kainuma, J.F. Lamarque, K. Matsumoto, S. Montzka, S. Raper, K. Riahi, A. Thomson, G. Velders, and D.P. van Vuuren, The RCP greenhouse gas concentrations and their extensions from 1765 to 2300, Clim. Change., 109 (1), 213241, doi:10.1007/s10584-011-0156-z, 2011.

METI, Act on the rational use and proper management of fluorocarbons (Act No. 64 of 2001), Ministry of Economy, Trade and Industry, Japan, http://conf. montreal-protocol.org/meeting/workshops/hfc_ management/presentations/Statements by Heads of Delegations/M. Ohki Session 4, 2014.

Miller, B.R., R.F. Weiss, P.K. Salameh, T. Tanhua, B.R. Greally, J. Muhle, and P.G. Simmonds, Medusa: A sample preconcentration and GC/MS detector system for in situ measurements of atmospheric trace halocarbons, hydrocarbons, and sulfur compounds, Anal. Chem., 80 (5), 1536-1545, doi: 10.1021/ac702084k, 2008.

Miller, B.R., M. Rigby, L.J.M. Kuijpers, P.B. Krummel, L.P. Steele, M. Leist, P.J. Fraser, A. McCulloch, C. Harth, P. Salameh, J. Mühle, R.F. Weiss, R.G. Prinn, R.H.J. Wang, S. O’Doherty, B.R. Greally, and P.G. Simmonds, HFC-23 $\left(\mathrm{CHF}_{3}\right)$ emission trend response to $\mathrm{HCFC}-22\left(\mathrm{CHClF}_{2}\right)$ production and recent HFC-23 emission abatement measures, Atmos. Chem. Phys., 10 (16), 78757890, doi:10.5194/acp-10-7875-2010, 2010.

Miller, B.R., and L.J.M. Kuijpers, Projecting future 
HFC-23 emissions, Atmos. Chem. Phys., 11 (24), 13259-13267, doi:10.5194/acp-11-13259-2011, 2011.

Miller, J.B., S.J. Lehman, S.A. Montzka, C. Sweeney, B.R. Miller, A. Karion, C. Wolak, E.J. Dlugokencky, J. Southon, J.C. Turnbull, and P.P. Tans, Linking emissions of fossil fuel $\mathrm{CO}_{2}$ and other anthropogenic trace gases using atmospheric ${ }^{14} \mathrm{CO}_{2}$, J. Geophys. Res., 117 (D8), D08302, doi: 10.1029/2011JD017048, 2012.

Montzka, S.A., R.C. Myers, J.H. Butler, J.W. Elkins, L.T. Lock, A.D. Clarke, and A.H. Goldstein, Observations of HFC-134a in the remote troposphere, Geophys. Res. Lett., 23 (2), 169-172, doi: 10.1029/95gl03590, 1996.

Montzka, S.A., L. Kuijpers, M.O. Battle, M. Aydin, K.R. Verhulst, E.S. Saltzman, D.W. Fahey, Recent increases in global HFC-23 emissions, Geophys. Res. Lett., 37,L02808, doi:10.1029/2009GL041195, 2010.

Montzka, S.A., E.J. Dlugokencky, J.H. Butler, Non$\mathrm{CO}_{2}$ greenhouse gases and climate change, $\mathrm{Na}$ ture, 476, 43-50, doi:10.1038/nature10322, 2011.

Montzka, S.A., M. McFarland, S.O. Andersen, B.R. Miller, D.W. Fahey, B.D. Hall, L. Hu, C. Siso, and J.W. Elkins, Recent trends in global emissions of hydrochlorofluorocarbons and hydrofluorocarbons: Reflecting on the 2007 adjustments to the Montreal Protocol, J. Phys. Chem. A, 119 (19), 4439-4449, doi:10.1021/jp5097376, 2015.

Myhre, G., D. Shindell (Coordinating Lead Authors), F.-M. Bréon, W. Collins, J. Fuglestvedt, J. Huang, D. Koch, J.-F. Lamarque, D. Lee, B. Mendoza, T. Nakajima, A. Robock, G. Stephens, T. Takemura, and H. Zhang, Anthropogenic and Natural Radiative Forcing, Chapter 8 in Climate Change 2013: The Physical Science Basis: Contribution of Working Group I to the Fifth Assessment Report of the Intergovernmental Panel on Climate Change, edited by T.F. Stocker, D. Qin, G.-K. Plattner, M. Tignor, S.K. Allen, J. Boschung, A. Nauels, Y. Xia, V. Bex, and P.M. Midgley, Cambridge University Press, Cambridge, United Kingdom, 2013.

Nassar, R., P.F. Bernath, C.D. Boone, S.D. McLeod, R. Skelton, K.A. Walker, C.P. Rinsland, and P. Duchatelet, A global inventory of stratospheric fluorine in 2004 based on Atmospheric Chemistry Experiment Fourier transform spectrometer (ACE-FTS) measurements, J. Geophys. Res.,
111 (D22), D22313, doi:10.1029/2006JD007395, 2006.

O’Doherty, S., D.M. Cunnold, B.R. Miller, J. Mühle, A. McCulloch, P.G. Simmonds, A.J. Manning, S. Reimann, M.K. Vollmer, B.R. Greally, R.G. Prinn, P.J. Fraser, L.P. Steele, P.B. Krummel, B.L. Dunse, L.W. Porter, C.R. Lunder, N. Schmidbauer, O. Hermansen, P.K. Salameh, C.M. Harth, R.H.J. Wang, and R.F. Weiss, Global and regional emissions of HFC-125 $\left(\mathrm{CHF}_{2} \mathrm{CF}_{3}\right)$ from in situ and air archive atmospheric observations at AGAGE and SOGE observatories, J. Geophys. Res., 114, D23304, doi: 10.1029/2009JD012184, 2009.

O’Doherty, S., M. Rigby, J. Mühle, D.J. Ivy, B.R. Miller, D. Young, P.G. Simmonds, S. Reimann, M.K. Vollmer, P.B. Krummel, P.J. Fraser, L.P. Steele, B. Dunse, P.K. Salameh, C.M. Harth, T. Arnold, R.F. Weiss, J. Kim, S. Park, S. Li, C. Lunder, O. Hermansen, N. Schmidbauer, L.X. Zhou, B. Yao, R.H.J. Wang, A.J. Manning, and R.G. Prinn, Global emissions of HFC-143a $\left(\mathrm{CH}_{3} \mathrm{CF}_{3}\right)$ and HFC-32 $\left(\mathrm{CH}_{2} \mathrm{~F}_{2}\right)$ from in situ and air archive atmospheric observations, Atmos. Chem. Phys., 14 (17), 92499258, doi:10.5194/acp-14-9249-2014, 2014.

O’Neill, B.C., T.R. Carter, K.L. Ebi, J. Edmonds, S. Hallegatte, E. Kemp-Benedict, E. Kriegler, L. Mearns, R. Moss, K. Riahi, B. van Ruijven, and D. van Vuuren, Meeting Report of the Workshop on The Nature and Use of New Socioeconomic Pathways for Climate Change Research, 110 pp., Boulder, Colorado, November 2-4, 2011, available at http://www.isp.ucar.edu/socioeconomicpathways, 2012.

Oram, D.E., C.E. Reeves, W.T. Sturges, S.A. Penkett, P.J. Fraser, and R.L. Langenfelds, Recent tropospheric growth rate and distribution of HFC-134a $\left(\mathrm{CF}_{3} \mathrm{CH}_{2} \mathrm{~F}\right)$, Geophys. Res. Lett., 23 (15), 19491952, doi:10.1029/96GL01862, 1996.

Oram, D.E., W.T. Sturges, S.A. Penkett, A. McCulloch, and P.J. Fraser, Growth of fluoroform $\left(\mathrm{CHF}_{3}, \mathrm{HFC}-23\right)$ in the background atmosphere, Geophys. Res. Lett., 25 (1), 35-38, doi: 10.1029/97GL03483, 1998.

Papadimitriou, V.C., and J.B. Burkholder, $\mathrm{OH}$ radical reaction rate coefficients, infrared spectrum, and global warming potential of $\left(\mathrm{CF}_{3}\right)_{2} \mathrm{CFCH}=\mathrm{CHF}$ (HFO-1438ezy(E)), J. Phys. Chem. A, 120 (33), 6618-6628, doi:10.1021/acs.jpca.6b06096, 2016.

Papasavva, S., D.J. Luecken, R.L. Waterland, K.N. 
Taddonio, and S.O. Andersen, Estimated 2017 refrigerant emissions of 2,3,3,3-tetrafluoropropene (HFC-1234yf) in the United States resulting from automobile air conditioning, Environ. Sci. Technol., 43 (24), 9252-9259, doi:10.1021/es902124u, 2009.

Papasavva, S., W.R. Hill, and S.O. Andersen, GREENMAC-LCCP: A tool for Assessing the life cycle climate performance of MAC Systems, Environ. Sci. Technol., 44 (19), 7666-7672, doi:10.1021/ es100849g, 2010.

Purohit, P., and L. Höglund-Isaksson, Global emissions of fluorinated greenhouse gases 2005-2050 with abatement potentials and costs, Atmos. Chem. Phys., 17 (4), 2795-2816, doi:10.5194/acp17-2795-2017, 2017.

Rigby, M., R.G. Prinn, S. O’Doherty, S.A. Montzka, A. McCulloch, C.M. Harth, J. Mühle, P.K. Salameh, R.F. Weiss, D. Young, P.G. Simmonds, B.D. Hall, G.S. Dutton, D. Nance, D.J. Mondeel, J.W. Elkins, P.B. Krummel, L.P. Steele, and P.J. Fraser, Re-evaluation of the lifetimes of the major CFCs and $\mathrm{CH}_{3} \mathrm{CCl}_{3}$ using atmospheric trends, Atmos. Chem. Phys., 13 (5), 2691-2702, doi:10.5194/acp13-2691-2013, 2013.

Rigby, M., R.G. Prinn, S. O'Doherty, B.R. Miller, D. Ivy, J. Mühle, C.M. Harth, P.K. Salameh, T. Arnold, R.F. Weiss, P.B. Krummel, L.P. Steele, P.J. Fraser, D. Young, and P.G. Simmonds, Recent and future trends in synthetic greenhouse gas radiative forcing, Geophys. Res. Lett., 41 (7), 26232630, doi:10.1002/2013GL059099, 2014.

Saito, T., X. Fang, A. Stohl, Y. Yokouchi, J. Zeng, Y. Fukuyama, and H. Mukai, Extraordinary halocarbon emissions initiated by the 2011 Tohoku earthquake, Geophys. Res. Lett., 42 (7), 2500-2507, doi:10.1002/2014GL062814, 2015.

Say, D., A.J. Manning, S. O'Doherty, M. Rigby, D. Young, and A. Grant, Re-evaluation of the UK's HFC-134a emissions inventory based on atmospheric observations, Environ. Sci. Technol., 50 (20), 1112911136, doi:10.1021/acs.est.6b03630, 2016.

Schultz, K., Summary of High Ambient Temperature (HAT) Tests Conducted under AREP II, AHRI Low-GWP Alternate Refrigerant Evaluation Program Conference, Orlando, Florida, available at http://www.ahrinet.org/App_Content/ahri/files/ RESEARCH/AREP_II/REF-3_HAT_Summary_ Ingersol_Rand.pdf, 2016.

Shah, N., P. Waide, and A. Phadke, Cooling the Plan- et: Opportunities for Deployment of Superefficient Room Air Conditioners, Report No. LBNL6164E, Lawrence Berkeley National Laboratory, https://eta.lbl.gov/sites/default/files/publications/ lbnl-6164e.pdf, 2013.

Shah, N., M. Wei, V.E. Letschert, and A.A. Phadke, Benefits of Leapfrogging to Superefficiency and Low Global Warming Potential Refrigerants in Room Air Conditioning, Report No. LBNL-1003671, Energy Technology Areas, Lawrence Berkeley National Laboratory, https://eta.lbl.gov/sites/default/files/publications/lbnl-1003671.pdf, 2015.

Simmonds, P.G., R.G. Derwent, A.J. Manning, A. McCulloch, and S. O'Doherty, USA emissions estimates of $\mathrm{CH}_{3} \mathrm{CHF}_{2}, \mathrm{CH}_{2} \mathrm{FCF}_{3}, \mathrm{CH}_{3} \mathrm{CF}_{3}$ and $\mathrm{CH}_{2} \mathrm{~F}_{2}$ based on in situ observations at Mace Head, Atmos. Environ., 104, 27-38, doi:10.1016/j. atmosenv.2015.01.010, 2015.

Simmonds, P.G., M. Rigby, A.J. Manning, M.F. Lunt, S. O'Doherty, A. McCulloch, P.J. Fraser, S. Henne, M.K. Vollmer, J. Mühle, R.F. Weiss, P.K. Salameh, D. Young, S. Reimann, A. Wenger, T. Arnold, C.M. Harth, P.B. Krummel, L.P. Steele, B.L. Dunse, B.R. Miller, C.R. Lunder, O. Hermansen, N. Schmidbauer, T. Saito, Y. Yokouchi, S. Park, S. Li, B. Yao, L.X. Zhou, J. Arduini, M. Maione, R.H.J. Wang, D. Ivy, and R.G. Prinn, Global and regional emissions estimates of 1,1-difluoroethane (HFC-152a, $\mathrm{CH}_{3} \mathrm{CHF}_{2}$ ) from in situ and air archive observations, Atmos. Chem. Phys., 16 (1), 365-382, doi: 10.5194/acp-16-365-2016, 2016.

Simmonds, P.G., M. Rigby, A. McCulloch, S. O’Doherty, D. Young, J. Mühle, P.B. Krummel, P. Steele, P.J. Fraser, A.J. Manning, R.F. Weiss, P.K. Salameh, C.M. Harth, R.H.J. Wang, and R.G. Prinn, Changing trends and emissions of hydrochlorofluorocarbons (HCFCs) and their hydrofluorocarbon (HFCs) replacements, Atmos. Chem. Phys., 17 (7), 4641-4655, doi:10.5194/acp17-4641-2017, 2017.

Simmonds, P.G., M. Rigby, A. McCulloch, M.K. Vollmer, S. Henne, J. Mühle, B.R. Miller, S. O’Doherty, A.J. Manning, P.B. Krummel, P.J. Fraser, D. Young, R.F. Weiss, P.K. Salameh, C.M. Harth, S. Reimann, C.M. Trudinger, L.P. Steele, R.H.J. Wang, D. Ivy, R.G. Prinn, B. Mitrevski and D.M. Etheridge, Recent increases in the growth rate and emissions of HFC-23 $\left(\mathrm{CHF}_{3}\right)$ and the link to HCFC-22 $(\mathrm{CH}-$ $\mathrm{ClF}_{2}$ ) production, Atmos. Chem. Phys., 18, 4153- 
4169, doi:10.5194/acp-18-4153-2018, 2018.

Simpson, I.J., O.S. Aburizaiza, A. Siddique, B. Barletta, N.J. Blake, A. Gartner, H. Khwaja, S. Meinardi, J. Zeb, and D.R. Blake, Air quality in Mecca and surrounding holy places in Saudi Arabia during Hajj: Initial survey, Environ. Sci. Technol., 48 (15), 8529-8537, doi:10.1021/es5017476, 2014.

Solomon, K.R., G.J.M. Velders, S.R. Wilson, S. Madronich, J. Longstreth, P.J. Aucamp, and J.F. Bornman, Sources, fates, toxicity, and risks of trifluoroacetic acid and its salts: Relevance to substances regulated under the Montreal and Kyoto Protocols, J. Toxicol. Environ. Health Part A, 19 (7), 1-16, doi: 10.1080/10937404.2016.1175981, 2016.

SPARC (Stratosphere-troposphere Processes And their Role in Climate), SPARC Report on the Lifetimes of Stratospheric Ozone-Depleting Substances, Their Replacements, and Related Species, edited by M. Ko, P. Newman, S. Reimann, and S. Strahan, SPARC Report No. 6, WCRP-15/2013, 2013.

Spivakovsky, C.M., J.A. Logan, S.A. Montzka, Y.J. Balkanski, M. Foreman-Fowler, D.B.A. Jones, L.W. Horowitz, A.C. Fusco, C.A.M. Brenninkmeijer, M.J. Prather, S.C. Wofsy, and M.B. McElroy, Three-dimensional climatological distribution of tropospheric OH: Update and evaluation, J. Geophys. Res., 105 (D7), 8931-8980, doi:10.1029/ 1999JD901006, 2000.

Stemmler, K., D. Folini, S. Ubl, M.K. Vollmer, S. Reimann, S. O'Doherty, B.R. Greally, P.G. Simmonds, and A.J. Manning, European emissions of HFC$365 \mathrm{mfc}$, a chlorine-free substitute for the foam blowing agents HCFC-141b and CFC-11, Environ. Sci. Technol., 41 (4), 1145-1151, doi:10.1021/ es061298h, 2007.

Stohl, A., P. Seibert, J. Arduini, S. Eckhardt, P. Fraser, B.R. Greally, C. Lunder, M. Maione, J. Mühle, S. O’Doherty, R.G. Prinn, S. Reimann, T. Saito, N. Schmidbauer, P.G. Simmonds, M.K. Vollmer, R.F. Weiss, and Y. Yokouchi, An analytical inversion method for determining regional and global emissions of greenhouse gases: Sensitivity studies and application to halocarbons, Atmos. Chem. Phys., 9 (5), 1597-1620, doi:10.5194/acp-9-15972009, 2009.

Stohl, A., J. Kim, S. Li, S. O’Doherty, J. Mühle, P.K. Salameh, T. Saito, M.K. Vollmer, D. Wan, R.F. Weiss, B. Yao, Y. Yokouchi, and L.X. Zhou, Hydrochlorofluorocarbon and hydrofluorocarbon emissions in East Asia determined by inverse modeling, Atmos. Chem. Phys., 10 (8), 3545-3560, doi:10.5194/acp-10-3545-2010, 2010.

Su, S., X. Fang, L. Li, J. Wu, J. Zhang, W. Xu, and J. Hu, HFC-134a emissions from mobile air conditioning in China from 1995 to 2030, Atmos. Environ., 102, 122-129, doi:10.1016/j. atmosenv.2014.11.057, 2015.

Sulbaek Andersen, M.P., O.J. Nielsen, A. Toft, T. Nakayama, Y. Matsumi, R.L. Waterland, R.C. Buck, M.D. Hurley, and T.J. Wallington, Atmospheric chemistry of $\mathrm{C}_{x} \mathrm{~F}_{2 x+1} \mathrm{CHCH}_{2}(x=1,2,4,6$, and 8): Kinetics of gas-phase reactions with $\mathrm{Cl}$ atoms, $\mathrm{OH}$ radicals, and $\mathrm{O}_{3}$, J. Photochem. Photobio., 176 (1), 124-128, doi:10.1016/j.jphotochem.2005.06.015, 2005.

UNEP (United Nations Environment Programme), Report of the Nineteenth Meeting of the Parties to the Montreal Protocol on Substances that Deplete the Ozone Layer, UNEP/OzL.Pro.19/7, Montreal, Canada, http://ozone.unep.org/Meeting_Documents/mop/19mop/MOP-19-7E.pdf, 2007.

UNEP (United Nations Environment Programme), Technology and Economic Assessment Panel: Assessment of HCFCs and Environmentally Sound Alternatives, Scoping Study on Alternatives to HCFC Refrigerants Under High Ambient Temperature Conditions, in TEAP 2010 Progress Report, Volume 1, 178 pp., coordinated by S.O. Andersen, L. Kuijpers, and J. Pons-Pons, Nairobi, Kenya, 2010.

UNEP (United Nations Environment Programme), HFCs: A Critical Link in Protecting Climate and the Ozone Layer, 40 pp., Nairobi, Kenya, http://wedocs. unep.org/bitstream/handle/20.500.11822/8014/HFCs_\%20A\%20Critical\%20Link\%20in\%20 Protecting\%20\%20Climate\%20and\%20the $\% 20$ Ozone\%20Layer-20111072.pdf, 2011.

UNEP (United Nations Environment Programme), Environmental Effects Assessment Panel, Environmental Effects of Ozone Depletion and its Interactions with Climate Change: 2014 Assessment, Nairobi, Kenya, http://ozone.unep.org/ Assessment_Panels/EEAP/eeap_report_2014. pdf, 2014a.

UNEP (United Nations Environment Programme), Halons Technical Options Committee: 2014 Assessment Report, Volume 1, 46 pp., Nairobi, Kenya, http://ozone.unep.org/en/Assessment_Panels/ 
TEAP/Reports/HTOC/HTOC\%202014\%20Assessment\%20Report.pdf, 2014b.

UNEP (United Nations Environment Programme), Technology and Economic Assessment Panel: October 2014 Decision XXV/5 task force report additional information to alternatives on ODSs, Nairobi, Kenya, http://ozone.unep.org/Assessment_Panels/TEAP/Reports/TEAP_Reports/ TEAP_Task\%20Force\%20XXV5-October2014. pdf, 2014c.

UNEP (United Nations Environment Programme), Production and consumption of ozone depleting substances under the Montreal Protocol, Nairobi, Kenya, http://ozone.unep.org/en/data-reporting/ data-centre, 2015.

UNEP (United Nations Environment Programme), Report of the Twenty-Eighth Meeting of the Parties to the Montreal Protocol on Substances that Deplete the Ozone Layer, UNEP/OzL.Pro.28/12, Kigali, Rwanda, http://conf.montreal-protocol. org/meeting/mop/mop-28/final-report/SitePages/Home.aspx, 2016a.

UNEP (United Nations Environment Programme), Technology and Economic Assessment Panel: September 2016 Decision XXVII/4 Task Force Update Report Further Information On Alternatives To Ozone-Depleting Substances, Volume 1, 179 pp., Nairobi, Kenya, http://conf.montreal-protocol. org/meeting/mop/mop-28/presession/Background\%20Documents\%20are\%20available\%20 in\%20English\%20only/TEAP_TFXXVII-4_Report_September2016.pdf, 2016b.

UNEP (United Nations Environment Programme), 2017 Progress Report of the Technology and Economic Assessment Panel, 105 pp., coordinated by B. Maranion, M. Pizano, and A. Woodcock, Volume 1, Nairobi, Kenya, http://conf.montreal-protocol.org/meeting/oewg/oewg-39/presession/ Background-Documents/TEAP-Progress-Report-May2017.pdf, 2017a.

UNEP (United Nations Environment Programme), Report to the Executive Committee of the Multilateral Fund for the Implementation of the Montreal Protocol, Key Aspects Related to HFC-23 By-Product Control Technologies (Decision 78/5), UNEP/OzL.Pro/ExCom/79/48, Bangkok, Thailand, 2017b.

UNFCCC (United Nations Framework Convention on Climate Change), National Inventory Submis- sions 2014, last access: November 2014, Climate Change Secretariat, Bonn, Germany, http:// unfccc.int/national_reports/annex_i_ghg_inventories/national_inventories_submissions/ items/8108.php, 2014.

UNFCCC (United Nations Framework Convention on Climate Change), National Inventory Submissions 2017, last access: June 2017, http://unfccc. int/national_reports/annex_i_ghg_inventories/ national_inventories_submissions/items/10116. php, 2017.

US EPA (U.S. Environmental Protection Agency), Protection of the Stratospheric Ozone: Change of Listing Status for Certain Substitutes Under the Significant New Alternatives Policy Program; Final Rule, Federal Register, 76 (244), Part II 2040 Part CFR 2082, https://www.gpo.gov/fdsys/pkg/FR2011-12-20/pdf/2011-32175.pdf, 2011.

US EPA (U.S. Environmental Protection Agency), 2017 and Later Model Year Light-Duty Vehicle Greenhouse Gas Emissions and Corporate Average Fuel Economy Standards, Federal Register, 77 (199), https://www.gpo.gov/fdsys/pkg/FR-201210-15/pdf/2012-21972.pdf, 2012.

US EPA (U.S. Environmental Protection Agency), Protection of Stratospheric Ozone: Change of listing status for certain substitutes under the significant new alternatives policy program, EPA-HQOAR-2014-0198, https://www.federalregister. gov/documents/2014/09/19/2014-22382/protection-of-stratospheric-ozone-change-of-listingstatus-for-certain-substitutes-under-the, 2015a.

US EPA (U.S. Environmental Protection Agency), Protection of Stratospheric Ozone: Determination 30 for Significant New Alternatives Policy Program, Federal Register, 80, (136), https://www.gpo.gov/ fdsys/pkg/FR-2015-07-16/pdf/2015-17469.pdf, 2015b.

US EPA (U.S. Environmental Protection Agency), Protection of Stratospheric Ozone: Determination 32 for Significant New Alternatives Policy Program, Federal Register, 81, (196), 40 CFR Part 82, https://www.gpo.gov/fdsys/pkg/FR-2016-10-11/ pdf/2016-24381.pdf, 2016.

US EPA (U.S. Environmental Protection Agency), Inventory of U.S. Greenhouse Gas Emissions and Sinks: 1990 - 2015, EPA 430-P-17-001, https:// www.epa.gov/sites/production/files/2017-02/ documents/2017_complete_report.pdf, 2017. 
US EPA (U.S. Environmental Protection Agency), Advance version of Notice of Guidance and a Stakeholder Meeting Concerning the Significant New Alternatives Policy Program, EPA-HQ-OAR-2003-0118, https://www.epa.gov/snap/advance-version-notice-guidance-and-stakeholder-meeting-concerning-significant-new-alternatives, 2018.

Velders, G.J.M., D.W. Fahey, J.S. Daniel, M. McFarland, and S.O. Andersen, The large contribution of projected HFC emissions to future climate forcing, Proc. Natl. Acad. Sci., 106 (27), 1094910954, doi:10.1073/pnas.0902817106, 2009.

Velders, G.J.M., S. Solomon, and J.S. Daniel, Growth of climate change commitments from HFC banks and emissions, Atmos. Chem. Phys., 14 (9), 4563 4572, doi:10.5194/acp-14-4563-2014, 2014.

Velders, G.J.M., D.W. Fahey, J.S. Daniel, S.O. Andersen, and M. McFarland, Future atmospheric abundances and climate forcings from scenarios of global and regional hydrofluorocarbon (HFC) emissions, Atmos. Environ., 123, 200-209, doi: 10.1016/j.atmosenv.2015.10.071, 2015.

Vollmer, M.K., S. Reimann, D. Folini, L.W. Porter, and L.P. Steele, First appearance and rapid growth of anthropogenic HFC-245 $\mathrm{fa}\left(\mathrm{CHF}_{2} \mathrm{CH}_{2} \mathrm{CF}_{3}\right)$ in the atmosphere, Geophys. Res. Lett., 33 (20), L20806, doi:10.1029/2006GL026763, 2006.

Vollmer, M.K., B.R. Miller, M. Rigby, S. Reimann, J. Mühle, P.B. Krummel, S. O’Doherty, J. Kim, T.S. Rhee, R.F. Weiss, P.J. Fraser, P.G. Simmonds, P.K. Salameh, C.M. Harth, R.H.J. Wang, L.P. Steele, D. Young, C.R. Lunder, O. Hermansen, D. Ivy, T. Arnold, N. Schmidbauer, K.-R. Kim, B.R. Greally, M. Hill, M. Leist, A. Wenger, and R.G. Prinn, Atmospheric histories and global emissions of the anthropogenic hydrofluorocarbons HFC365mfc, HFC-245fa, HFC-227ea, and HFC236fa, J. Geophys. Res., 116 (D8), D08304, doi: 10.1029/2010JD015309, 2011.

Vollmer, M.K., S. Reimann, M. Hill, and D. Brunner, First observations of the fourth generation synthetic halocarbons HFC-1234yf, HFC-1234ze(E), and HCFC-1233zd(E) in the atmosphere, Environ. Sci. Technol., 49 (5), 2703-2708, doi:10.1021/ es505123x, 2015.

Wallington, T.J., M.P.S. Andersen, and O.J. Nielsen, Atmospheric chemistry of short-chain haloolefins: Photochemical ozone creation potentials (POCPs), global warming potentials
(GWPs), and ozone depletion potentials (ODPs), Chemosphere, 129, 135-141, doi:10.1016/j. chemosphere.2014.06.092, 2015.

Xiang, B., P.K. Patra, S.A. Montzka, S.M. Miller, J.W. Elkins, F.L. Moore, E.L. Atlas, B.R. Miller, R.F. Weiss, R.G. Prinn, and S.C. Wofsy, Global emissions of refrigerants HCFC-22 and HFC-134a: Unforeseen seasonal contributions, Proc. Natl. Acad. Sci., 111 (49), 17379-17384, doi:10.1073/ pnas.1417372111, 2014.

Xu, Y., D. Zaelke, G.J.M. Velders, and V. Ramanathan, The role of HFCs in mitigating 21st century climate change, Atmos. Chem. Phys., 13 (12), 60836089, doi:10.5194/acp-13-6083-2013, 2013.

Yao, B., M.K. Vollmer, L.X. Zhou, S. Henne, S. Reimann, P.C. Li, A. Wenger, and M. Hill, In-situ measurements of atmospheric hydrofluorocarbons (HFCs) and perfluorocarbons (PFCs) at the Shangdianzi regional background station, China, Atmos. Chem. Phys., 12 (21), 10181-10193, doi: 10.5194/acp-12-10181-2012, 2012.

Yokouchi, Y., S. Taguchi, T. Saito, Y. Tohjima, H. Tanimoto, and H. Mukai, High frequency measurements of HFCs at a remote site in east Asia and their implications for Chinese emissions, 3. Res. Lett., 33(21), L21814, doi:10.1029/2006GL026403, 2006.

Young, C.J., M.D. Hurley, T.J. Wallington, and S.A. Mabury, Atmospheric chemistry of $\mathrm{CF}_{3} \mathrm{CF}_{2} \mathrm{H}$ and $\mathrm{CF}_{3} \mathrm{CF}_{2} \mathrm{CF}_{2} \mathrm{CF}_{2} \mathrm{H}$ : Kinetics and products of gasphase reactions with $\mathrm{Cl}$ atoms and $\mathrm{OH}$ radicals, infrared spectra, and formation of perfluorocarboxylic acids, Chem. Phys. Lett., 473 (4), 251-256, doi:10.1016/j.cplett.2009.04.001, 2009a.

Young, C.J., M.D. Hurley, T.J. Wallington, and S.A. Mabury, Atmospheric chemistry of perfluorobutenes $\left(\mathrm{CF}_{3} \mathrm{CF}=\mathrm{CFCF}_{3}\right.$ and $\left.\mathrm{CF}_{3} \mathrm{CF}_{2} \mathrm{CF}=\mathrm{CF}_{2}\right)$ : Kinetics and mechanisms of reactions with $\mathrm{OH}$ radicals and chlorine atoms, IR spectra, global warming potentials, and oxidation to perfluorocarboxylic acids, Atmos. Environ., 43 (24), 37173724, doi:10.1016/j.atmosenv.2009.04.025, 2009 b.

Zhang, J., and C. Wang, China's hydrofluorocarbon challenge, Nature Clim. Change, 4 (11), 943-945, doi:10.1038/nclimate2377, 2014.

Zhang, N., L. Chen, J. Mizukado, H. Quan, and H. Suda, Rate constants for the gas-phase reactions of $(Z)-\mathrm{CF}_{3} \mathrm{CHCHF}$ and $(E)-\mathrm{CF}_{3} \mathrm{CHCHF}$ with $\mathrm{OH}$ radicals at $253-328 \mathrm{~K}$, Chem. Phys. Lett., 621, 78- 
84, doi:10.1016/j.cplett.2014.12.044, 2015.

Zhang, N., T. Uchimaru, Q. Guo, F. Qing, L. Chen, and J. Mizukado, Atmospheric chemistry of perfluorocyclopentene (cyc- $\mathrm{CF}_{2} \mathrm{CF}_{2} \mathrm{CF}_{2} \mathrm{CF}=\mathrm{CF}-$ ): Kinetics, products and mechanism of gas-phase reactions with $\mathrm{OH}$ radicals, and atmospheric implications, Atmos. Environ., 160, 46-54, doi: 10.1016/j.atmosenv.2017.04.012, 2017.
Zickfeld, K., S. Solomon, and D.M. Gilford, Centuries of thermal sea-level rise due to anthropogenic emissions of short-lived greenhouse gases, Proc. Natl. Acad. Sci., 114 (4), 657-662, doi:10.1073/ pnas.1612066114, 2017. 